\title{
Gradhiva
}

GRADHIV

Revue d'anthropologie et d'histoire des arts

25 | 2017

Gottfried Semper, habiter la couleur

\section{Choix de textes originaux de Gottfried Semper, extraits de Der Stil}

Traduits par Isabelle Kalinowski avec la collaboration d'Estelle Thibaut

\section{Gottfried Semper}

Traducteur : Isabelle Kalinowski

\section{(2) OpenEdition}

1 Journals

Édition électronique

URL : http://journals.openedition.org/gradhiva/3337

DOI : 10.4000/gradhiva.3337

ISSN : $1760-849 X$

Éditeur

Musée du quai Branly Jacques Chirac

Édition imprimée

Date de publication : 31 mai 2017

Pagination : 178-255

ISBN : 978-2-35744-095-1

ISSN : 0764-8928

Référence électronique

Gottfried Semper, «Choix de textes originaux de Gottfried Semper, extraits de Der Stil », Gradhiva [En ligne], 25 | 2017, mis en ligne le 31 mai 2019, consulté le 03 janvier 2020. URL : http://

journals.openedition.org/gradhiva/3337 ; DOI : 10.4000/gradhiva.3337

(c) musée du quai Branly 


\title{
DER S TIL
}

in den

technischen und tektonischen Künsten,

oder

\section{PRAKTISCHE AESTHETIK.}

Ein Handbuch für Techniker, Künstler und Kunstfreunde

von

\section{Gottfried Semper,}

Professor der Baukunst an dem allg. eidg. Polytechnikum zu Zarich.

\author{
Rrster Band. \\ Textile Kunst.
}

FRANKFURT a. M.

Verlag für Kunst und Wissenschaft. 1860 .

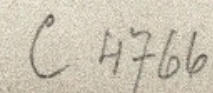




\section{Choix de textes originaux de Gottfried Semper, extraits de Der Stil Traduits par Isabelle Kalinowski avec la collaboration d'Estelle Thibaut}

Voici les bonnes feuilles de la première traduction française intégrale de Der Stil par Isabelle Kalinowski avec la collaboration d'Estelle Thibault à paraître aux Éditions d'en bas (Lausanne) en 2018.

Le premier tome du Style parut en 1860, le second en 1863; le troisième ne vit jamais le jour mais une deuxième édition du premier tome enrichie de différents ajouts parut en 1878, juste avant la mort de Semper (1879).

Le plan général de l'ouvrage obéit à une classification par techniques d'élaboration d'un matériau: le tome I traite de l'art textile et le tome II de la céramique, de la tectonique (menuiserie), de la stéréotomie (constructions en pierre) et du travail du métal. Semper se conforme ainsi au modèle de la classification par matériau mais le revisite entièrement en centrant son propos, plutôt que sur les matériaux eux-mêmes, sur les techniques associées à ces derniers: la différence est de taille, elle induit la possibilité d'appliquer à d'autres supports les techniques initialement conçues pour l'un d'entre eux. Ainsi, tout le tome I vise à montrer que des techniques d'abord élaborées dans le domaine de l'art textile ont joué un rôle fondamental dans l'architecture et le travail du bois, de la pierre et du métal.

Cette sélection de textes tirés du premier volume de Der Stil (dans l'édition de 1860) offre un éventail représentatif de cette œuvre multiforme, dans sa variété et sa singularité. Le premier texte, consacré aux ornements en rangées et bandeaux, relève d'une grammaire ornementale (voir aussi l'article de Rémi Labrusse) et illustre les liens de Semper avec la pensée morphologique (évoquée par Muriel van Vliet); la fin du texte, un développement sur le drapeau américain, atteste que Semper ne perdait pas de vue I'horizon d'application directe de son livre, sous-titré «Un manuel pour les techniciens, artistes et amateurs d'art ». Les deuxième et troisième textes, qui traitent des peaux et fourrures animales puis du caoutchouc, apportent eux aussi la preuve que Semper s'intéressait aussi bien aux industries de son temps qu'aux arts de l'Antiquité classique: la question du «style» répondait pour lui directement à des enjeux contemporains. On verra avec le quatrième texte, sur les teintures d'origine végétale ou à base de pourpre marine, avec quelle évidence Semper incluait dans son champ d'étude les artisanats populaires (et féminins) d'autres civilisations, et traçait des ponts entre les époques et les temporalités. Les cinquième et sixième textes, plus théoriques, offrent une synthèse percutante de l'anthropologie sempérienne, articulée autour du principe de revêtement en architecture et du besoin de «masquer» (analysé par Caroline van Eck). Enfin, le dernier texte révèle l'importance de l'architecture chinoise comme source d'inspiration des thèses de Der Stil.

Les gravures en noir et blanc dessinées ou adaptées par Semper sont tirées de l'édition originale de l'ouvrage; le choix des images en couleurs nous revient.

ci-contre

fig. 1

Page de titre de Der Stil, t. I, 1860 
Le style dans les arts techniques et tectoniques ou esthétique pratique. Un manuel pour les techniciens, artistes et amateurs d'art.

La traduction du sommaire des deux tomes fait apparaître en couleur la place des sept extraits qu'on pourra lire ici.

\section{Tome I. Art textile}

Prolégomènes

I. Introduction

II. Classification des arts techniques

III. L'art textile. Considérations formelles générales

Premières finalités de cette technique

$$
\begin{aligned}
& \text { La rangée (extrait 1, p. 182) } \\
& \text { Le bandeau (extrait 1, p. 184) } \\
& \text { La couverture } \\
& \text { La couture }
\end{aligned}
$$

\section{L'art textile. Considérations techniques et historiques}

Du style en tant qu'il est conditionné par les matériaux bruts

Les peaux animales (cuirs) (extrait 2, p. 191)

Le caoutchouc (extrait 3, p. 210)

La laque

Le lin

Le coton

La laine

La soie

Du style en tant qu'il est conditionné par le traitement des matériaux Rubans et fils

Nœuds

Mailles

Le tressage

Le tissu

La broderie

La teinture (extrait 4, p. 219)

Les vêtements

Le principe du revêtement en architecture (extraits 5, p. 230, et 6, p. 242) (Nouvelle-Zélande et Polynésie; Chine (extrait 7, p. 248); Inde;

Mésopotamie; Phénicie et Judée; Égypte. Ancien et Nouvel Empire; Asie Mineure; Grèce; Rome; Époque chrétienne en Occident, en Orient; Renaissance)

Remarques conclusives

\section{Tome II. Céramique, tectonique, stéréotomie, techniques métalliques}

V. La céramique (poterie). Considérations esthétiques et formelles VI. La céramique. Données techniques et historiques

VII. La tectonique (menuiserie). Considérations esthétiques et formelles VIII. La tectonique. Données techniques et historiques

IX. La stéréotomie (constructions en pierre).

Considérations fonctionnelles et formelles

$X$. La stéréotomie. Données techniques et historiques

XI. Les techniques métalliques (travail du métal) 
Inhalt des ersten Bandes.

\section{Prolegomena .}

Erstes Hauptstüok. Einleitung

Zweites Tauptstick. Klasgifkation der technischen Kainsto

Drittes Hauptstïck. Textile Kunst. Allgemein Formelles

Erste Zweeke dieser Technik

Die Reihung
Das Band

Die Decke

Die Naht

Viertes Hauptstück. Textile Kunst. Technisch-Historisches

Von dem Stil als bedungen durch die Rohstoffe .

Thierfolle (I

Kautschnk

Lacke

Flachs

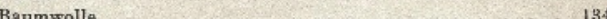

Wolle. . . . . . . . . . . . . . . . 137

Seide . . . . . . . . 14

Von dem Stil als bedungen durch die Art der Bearbeitung der Stoffor

Bänder und Fiden ............ 177

Knoten . . . . . . . . 180

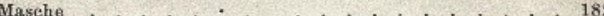

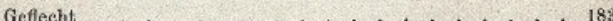

Gewebe ..................... 190

Stickerei . . . . . . . . . . . . . . 193

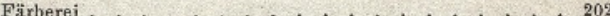

Kleiderwesen . . . . . . . . . . . . 209

Prinzip der Bekleidung in der Bankunst . . . . . . . . 217

Neuseeland and Polynesien .............. 238

China . . . . . . . . . . . . . . , 241
Indien - Selte

Mesopotamien .................. . . . 267

Phönikien und Judä̊ . . . . . . . . . . . . . . . . . 396

Aegypten. Altes und nenes Reich . . . ... . . . . . 405

Kleinssien ........ 428

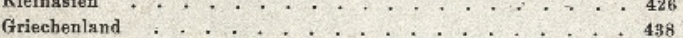

Griechenland . . . . . . . . . . . . 438

Christliches Zeitalter (Westen) . . . . . . . 505

" " (Osten) . . . . . . . . . . . . 512

Renaissance ............. 513

Schlussbemerkungen ................ 514

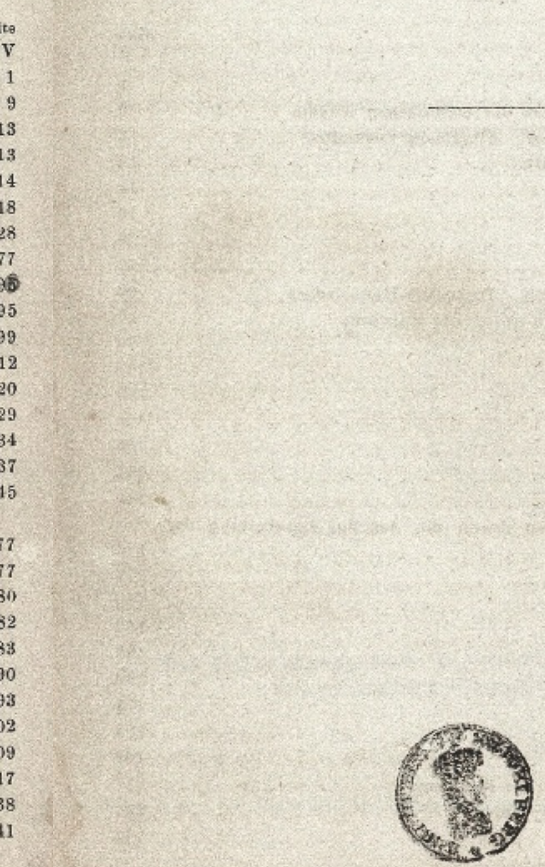


extrait 1

Troisième chapitre. L'art textile. Considérations formelles générales. Sections 4 à 7 .

Notes page 190

\section{A. Généralités formelles}

\section{§4. Pourquoi les arts textiles viennent en premier}

II est difficile de déterminer - et, pour être exact, il importe peu de savoir - laquelle, parmi les branches de la technique énumérées dans le chapitre précédent ${ }^{\mathbf{1}}$, a été la première à être pratiquée dans le cours naturel de l'évolution de l'homme. Dans tous les cas, il ne fait aucun doute que les deux premières citées, à savoir l'art textile et la céramique, sont aussi les premières dans lesquelles, à côté de la finalité poursuivie, l'aspiration à l'embellissement s'est exprimée par le choix des formes et par les ornementations. Entre ces deux arts, cependant, la primauté absolue revient à l'art textile: celui-ci se donne à connaître comme l'art originel, pour ainsi dire, par le fait que tous les autres, la céramique non exceptée, ont emprunté leurs types et leurs symboles à l'art textile, alors que lui-même apparaît tout à fait autonome sous ce rapport, forge ses types tout seul ou les emprunte directement à la nature.

II ne fait pas de doute que les premiers principes du style se sont fixés dans cette technique artistique qui est la plus originelle.

\section{§5. Premières finalités de cette technique}

L'idée est venue à l'homme d'articuler un système d'unités matérielles dont les propriétés caractéristiques sont la malléabilité, la souplesse et la résistance, pour les raisons suivantes:

Premièrement pour former des rangées et attacher ensemble;

Deuxièmement pour couvrir, protéger et clôturer.

Toutes les formes qui découlent de ces finalités se rapprochent soit de la forme fondamentale linéaire, soit de la forme fondamentale planimétrique. Les premières se prêtent davantage à former de fait une rangée et un bandeau ou à figurer ces notions de façon imagée; les secondes en revanche sont nécessaires lorsqu'on veut couvrir, protéger et clôturer, et elles sont en même temps devenues les symboles des notions de protection, de couverture et de clôture dans l'art, qui s'expliquent d'eux-mêmes. Pour désigner ces notions, la langue elle-même a emprunté ses expressions aux arts textiles ${ }^{2}$, qui sont donc, selon toute apparence, antérieurs à l'apparition de nos formes linguistiques actuelles. II en va de même des plus anciens symboles religieux.

\section{§ 6. La rangée}

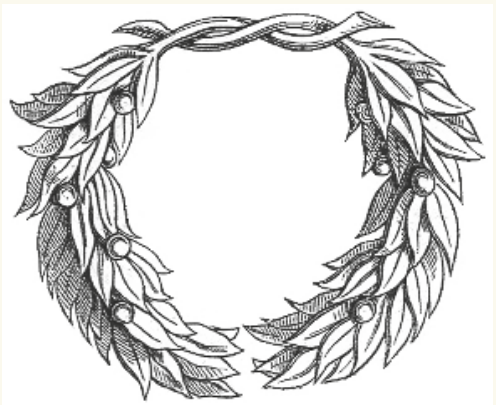

La rangée consiste dans l'enchaînement en bande d'une forme simple et par suite jusque-là encore esthétiquement indifférente; c'est certainement le plus originel des produits de l'art, la première manifestation effective du sens de la beauté, qui aspire à produire l'expression de l'unité à travers une multiplicité d'éléments reliés pour constituer une forme eurythmique et, en même temps, s'oppose en tant que multiplicité à l'unité visée par la rangée, ce qui permet de souligner davantage et de renforcer l'autorité et l'unicité du sujet. 
La couronne de feuilles est peut-être la plus ancienne des rangées; en tant que couronne, elle a conservé dans les arts de tous les temps son ancien primat, comme symbole de couronnement, de limitation vis-à-vis d'en haut ou, à l'inverse, de symbole de limitation vis-à-vis d'en bas, un usage dans lequel les pointes des feuilles qui composent la couronne sont dirigées vers le bas ${ }^{3}$.

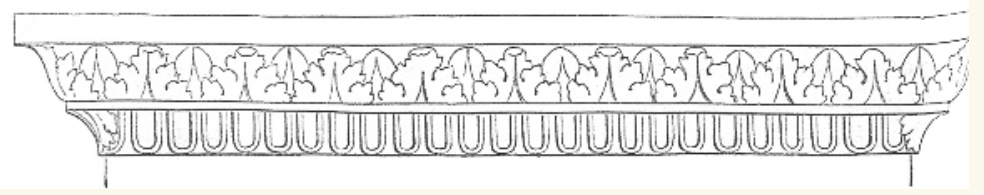

Les rangées de plumes qui, à l'instar des couronnes de feuilles, entourent certes, mais sans lier ni attacher, possèdent la même ancienneté et la même signification.
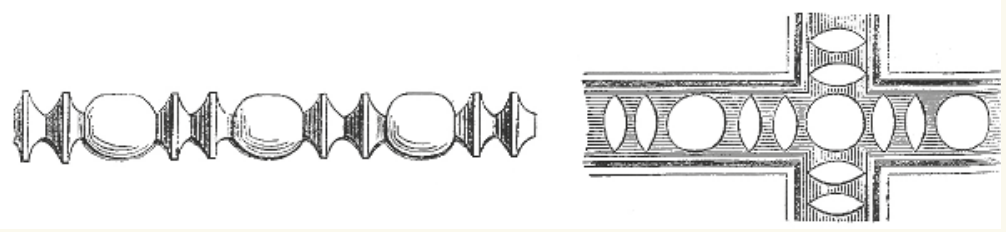

Un symbole apparenté mais qui exprime une autre nuance de cette notion fondamentale est la rangée de corps solides (perles ou osselets, desmoi astragalotoi) ordonnés de manière régulière et selon les lois de l'eurythmie sur un lacet. Cette rangée ne renvoie ni vers le haut ni vers le bas, elle est donc neutre sous ce rapport; l'attache n'est active que pour tenir ensemble les unités qui composent la rangée; elle n'est pas mise en relation avec ce qui l'entoure et les unités ne sont donc pas toujours caractérisées comme attachées lorsque ce symbole est utilisé: c'est plutôt leur autonomie qui est davantage encore soulignée. La signification du symbole en question va déjà dans ce sens quand on a affaire à la parure de perles ornant le cou d'une belle. Pourtant, ce symbole renvoie également souvent à la désignation d'une attache légère.

La couronne de feuilles ou de fleurs éveille une semblable association d'idées lorsqu'elle est composée d'éléments alternativement orientés vers le haut et vers le bas; elle n'est pas neutre comme la rangée de perles sur un fil, qui ne connaît aucune notion de haut ou de bas; elle renvoie bien plutôt expressément à l'un et à l'autre et joue donc le rôle d'intermédiaire entre les deux. Souvent, elle possède une signification fonctionnelle: en d'autres termes, on l'utilise comme symbole pour exprimer la simultanéité ou l'alternance de fonctions allant dans un sens opposé ou l'action de forces contraires.

Exemples: le col d'un récipient verseur qui verse et reçoit à la fois. Le trochile de la base des colonnes ioniques, dans lequel s'exprime le conflit entre la charge de la colonne et la résistance du sol fixe.

Le même symbole revêt souvent la forme d'une simple ligne de vagues ou celle d'une rangée d'unités inorganiques ou tout à fait conventionnelles alternativement dirigées vers le haut et vers le bas.
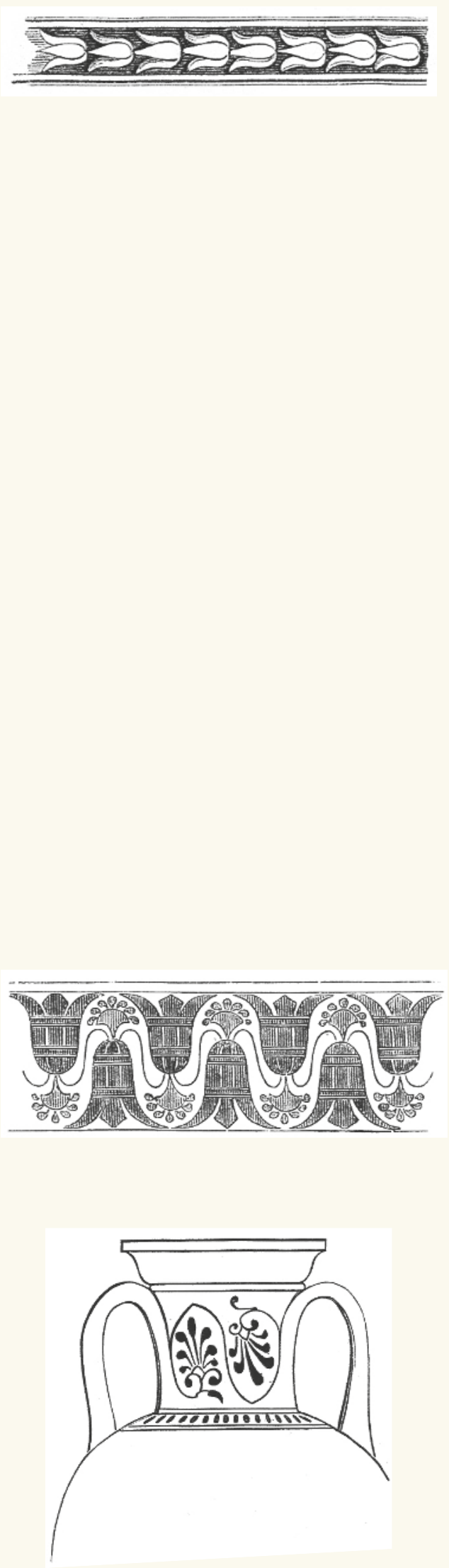


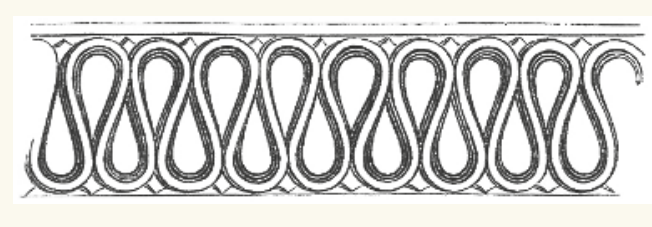

La rangée d'unités conventionnelles dont la forme renvoie à un haut ou un bas est aussi fréquemment employée pour les mêmes usages que la couronne de feuilles dirigée vers le haut ou vers le bas. C'est le cas de ce qu'on appelle la rangée d'oves.
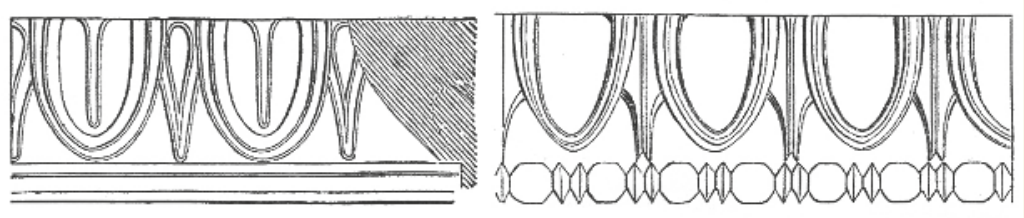

L'ove ne se distingue de la rangée de perles que par le fait que la seconde est absolument indifférente aux notions de haut et de bas tandis que la première actualise au contraire une de ces deux notions. II n'est pas systématiquement nécessaire de penser, comme le fait Bötticher, que ces unités conventionnelles étaient des feuilles retombant l'une sur l'autre et se recouvrant elles-mêmes à demi; elles remplissent en tout cas parfaitement la finalité voulue (à savoir la symbolisation d'un haut ou d'un bas) sans même qu'on ait à formuler une telle hypothèse. Sur ce point, voir la suite dans la section sur l'art grec.

\section{§6. Le bandeau}

\section{Ornement en bande rigide}

La rangée n'exprime la notion de liaison qu'au sens où elle permet de rattacher entre elles des unités et de les associer avec un agent intermédiaire de leur relation; le bandeau, en revanche, rattache entre elles des parties qui ne lui appartiennent pas, ou fait le lien entre elles en les encadrant.

Le bandeau doit se manifester en tant que tel, c'est-à-dire qu'il doit présenter extérieurement un certain degré de rigidité absolue, associée à la flexibilité.

Le degré de solidité se manifeste d'une part dans la relation, rapportée aux proportions spatiales, entre ce qui lie et ce qui est lié, deuxièmement dans la texture et la résistance ostensible du matériau liant. Les deux manières d'exprimer le degré de solidité du bandeau sont en un certain sens opposées: un bandeau qui se signale dans certaines circonstances comme exerçant une action en force n'a pas besoin d'être conforté par une mise en valeur formelle de la résistance de la texture, et, inversement, dans les cas où le rapport du liant au lié est faible, la notion de liaison doit être soulignée le plus fortement possible par la résistance ostensible du bandeau.

Un bandeau très léger doit sembler jouer en fonction des circonstances et de la résistance ostensible. Exemples: la file de perles (astragale), la guirlande de feuilles (stephanos).
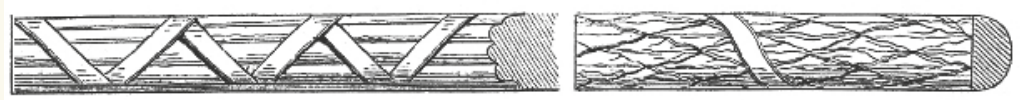


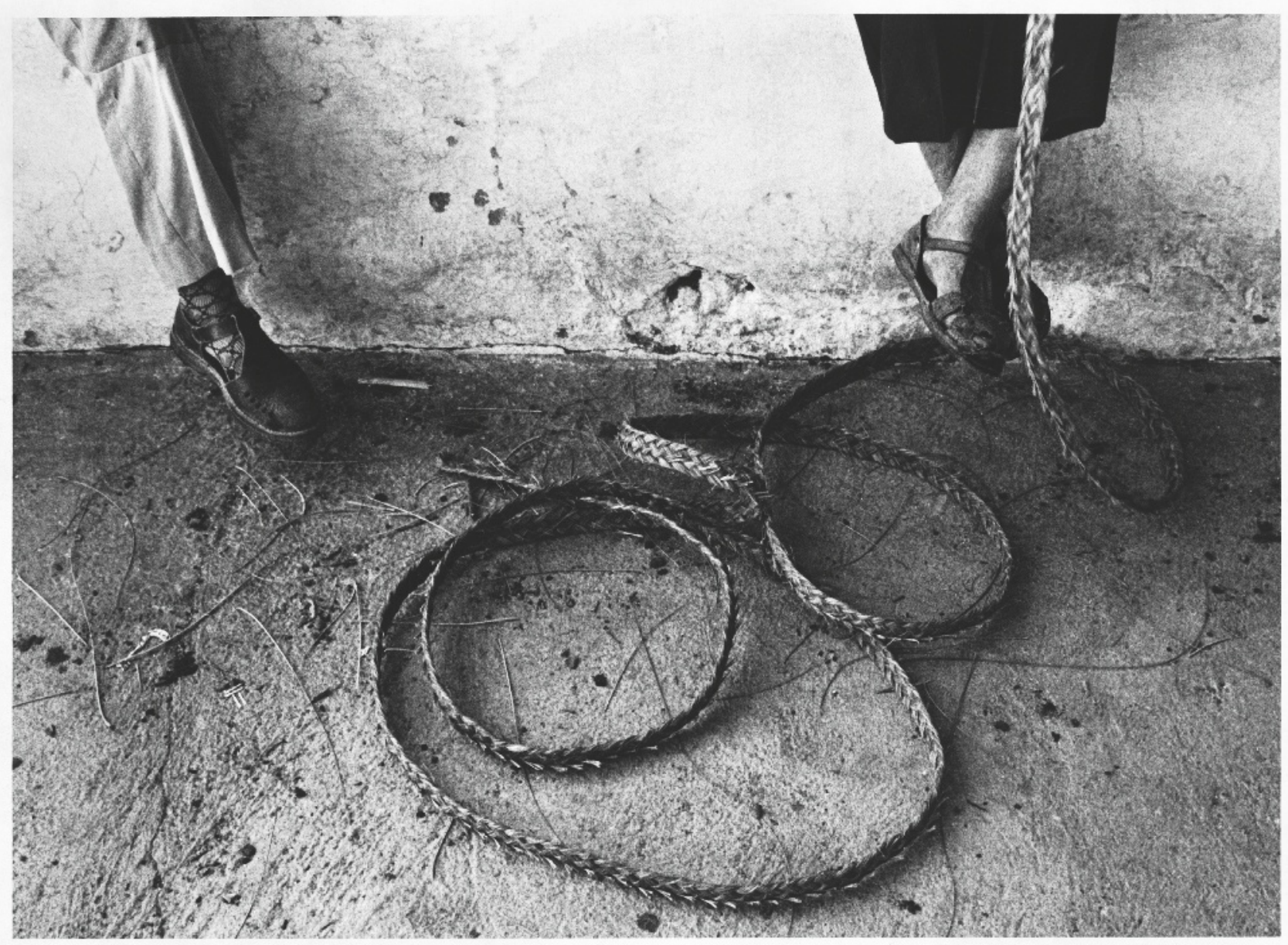

fig. 3

Michel Dieuzaide, Tissage

d'une tresse en paille.

Huebro (Almería, Espagne),

1987. Akg-images / Michel

Dieuzaide. 
Chaque bandeau se donne à connaître comme un produit textile, comme un produit dans lequel a été utilisé un matériau brut qui se distingue par sa ténacité et sa solidité absolue, dont on peut exiger, en d'autres termes, une résistance à la déchirure.

Le bandeau le plus simple est la ligne, le fil de section plate ou circulaire. La bande renforcée comprend plusieurs lignes ou fils du même type alignés les uns à côté des autres en ordre parallèle ou torsadés les uns autour des autres selon un mouvement de rotation.
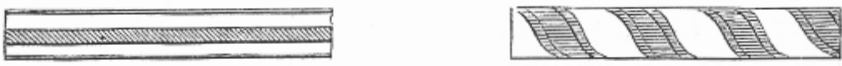

Une expression encore plus forte de la notion fondamentale de liaison est atteinte avec l'entrelacs, qui revêt soit la forme plate du tænia soit la forme semi-circulaire du tore ou de l'échine. La notion de liaison est particulièrement soulignée et fortement mise en avant avec les listels, dont l'épaisseur est rendue visible.
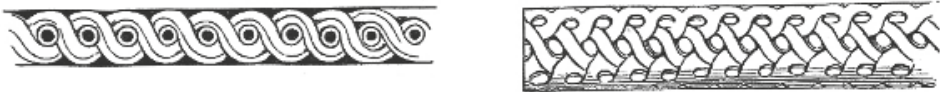

Le bandeau plat (la ceinture, la zone) se donne souvent à voir en tant que tissage sous une forme plus discrète. Il est le plus souvent utilisé comme bandeau frontal (epikranon), bordure (limbus) et encadrement (crepido, margo).

Dans certains cas, les ceintures larges se présentent comme des bandeaux suspendus dans le vide, tendus entre deux points fixes qu'ils rattachent l'un à l'autre tout en étant destinés à l'accrochage de couvertures entre les deux. Dans ce cas, la ceinture remplit une double fonction, en tant qu'elle relie horizontalement et en tant que couture (voir infra); en d'autres termes, elle s'étire en longueur et en même temps en largeur ou en biais. À quoi s'ajoute la charge qui ne peut que renforcer la tension en fonction de la longueur. Cette riche combinaison trouve son application, du point de vue de la symbolique du style, dans le système de couverture entièrement articulé des temples grecs; je renvoie sur ce point aux sections de ce chapitre consacrées à la tectonique et au chapitre sur l'art grec.

À la notion de lier se rattache celle de relier. Le relié se présente comme quelque chose qui était à l'origine séparé. Les bandeaux trouvent place là où on relie et articule. Ils servent à mettre en avant le caractère unifié des parties et, en même temps, leurs relations avec le tout et à marquer l'articulation.

La bordure et la couture sont des bandeaux qui ne sont pas tendus et tenus en longueur, mais en biais. Ils seront examinés ainsi que les exigences générales de leur style sous la rubrique suivante consacrée au vêtement et à la couverture.

\section{§ 7. L'ornement de bandeaux flottants}

L'ornement de bandeaux flottants, les houppes et autres tentures textiles représentent l'antithèse des types évoqués précédemment. Ce sont 
des symboles d'absence de liaison et ils sont utilisés en tant que tels dans l'art de la toilette. Ce sont en même temps des accessoires inépuisables pour accentuer convenablement ${ }^{4}$ la direction et le mouvement d'une figure. Selon le degré plus ou moins grand de légèreté des matériaux choisis à cet effet et leur degré de souplesse, le mouvement de vague des bandeaux ornementaux peut être plus ou moins indépendant du mouvement de leur support; ainsi, à la différence de lourdes tentures, ils ne reproduisent pas la moindre courbe dans sa contingence; ils ne traduisent et ne soulignent, dans leur flottement, que la direction et le degré de rapidité avec lequel cette direction est suivie, ainsi que les grandes courbes obligatoires de la tige enrubannée. Ce point est décisif pour le style à donner à ces ornements en fonction de leur destination.

Il faut d'abord choisir les ornementations et les broderies du bandeau ornemental conformément à ce caractère général de mobilité, qui le fait s'enrouler avec le mouvement. Mentionnons à titre d'exemple les drapeaux et fanions. Ils sont souvent choisis de telle sorte que leurs rayures de couleur ne sont pas parallèles à leur mouvement, mais le coupent en travers, ce qui est contraire à tout style. Un drapeau de ce type manque presque toujours de clarté: on dissimule ainsi à la vue une partie intégrante du système de couleurs, sans laquelle ce dernier perd sa signification d'un point de vue héraldique ou esthétique (le plus souvent les deux). (Cf. ce qui est dit plus loin sur les vêtements plissés très colorés.)

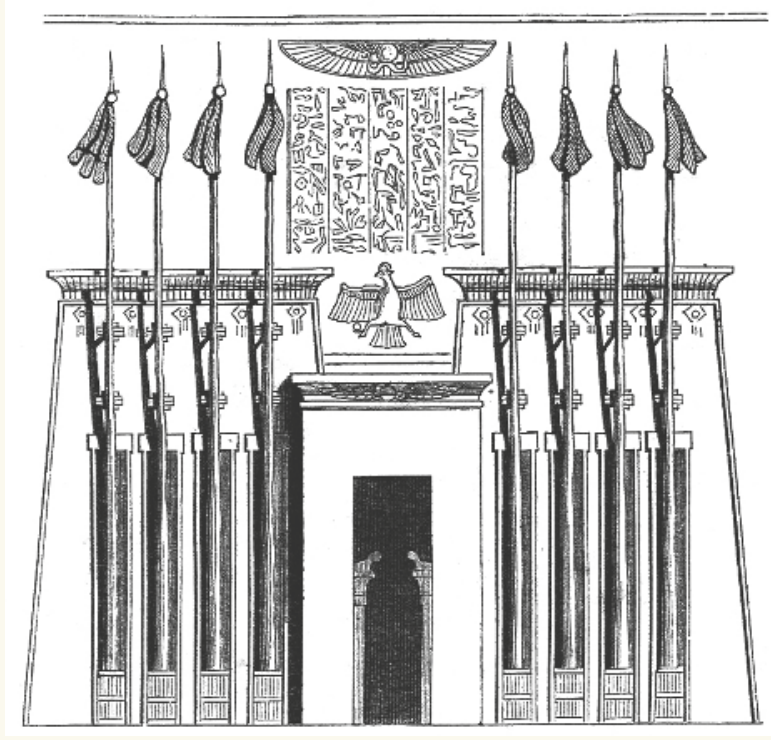

L'un des plus beaux drapeaux est le drapeau américain, qui se déplie simplement et dans lequel le rapport entre les rayures et l'ensemble est bien choisi. Les couleurs sont également harmonieuses, joyeuses et non criardes. À quoi s'ajoute le fait que la partie significative, le champ étoilé, a été très adroitement placée tout près de la tige du drapeau, en sorte que son image ne peut jamais se «brouiller ». Son antithèse et un modèle de mauvais goût est le drapeau tricolore napoléonien, vulgaire dans ses couleurs, mal proportionné dans la disposition de ses parties, et pour finir doté de rayures verticales, donc toujours indistinct. fig. 4

Étendards, ornement des pylônes égyptiens; d'après une peinture murale du temple de Khon à Thèbes.

\section{double page suivante}

fig. 5

Jasper Johns, Flag,

1954, encaustique,

huile et collage sur tissu monté sur contreplaqué, 107,3 x 153,8 cm, détail. New York, MoMA, gift of Philip Johnson in honor of Alfred H. Barr, Jr., inv. 106.1973 (C) 2017 Jasper Johns / ADAGP, Paris (C) 2017. Digital image, The Museum of Modern Art, New York/Scala. 


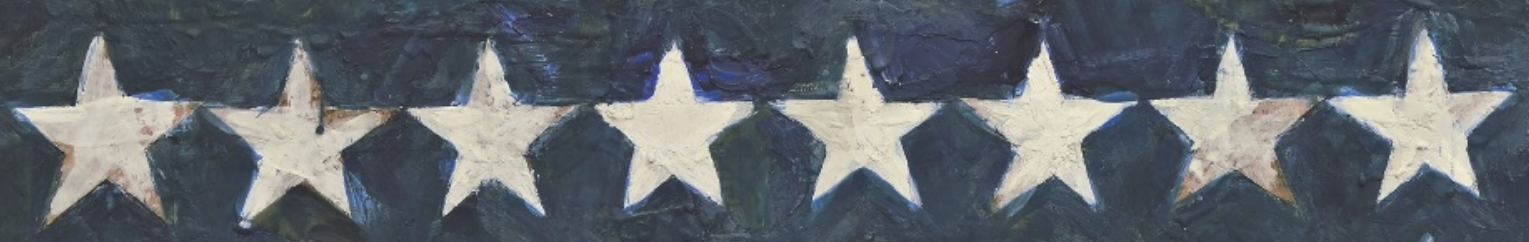

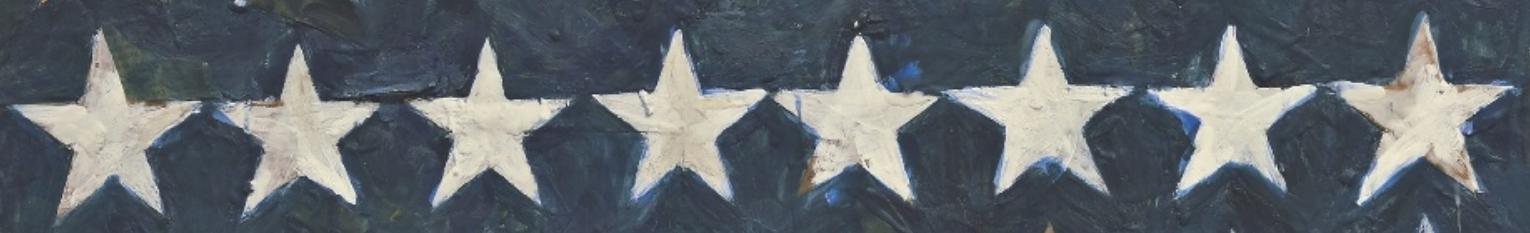

औरी

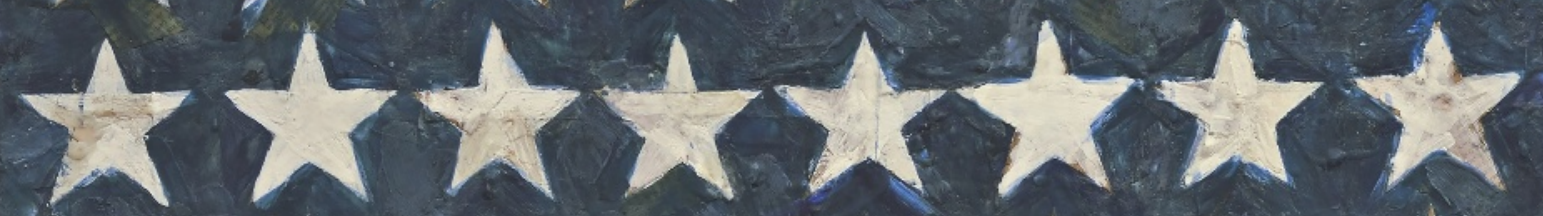

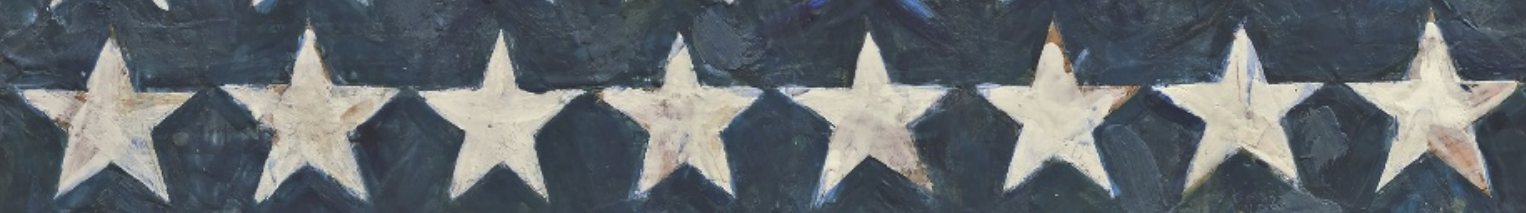

a.

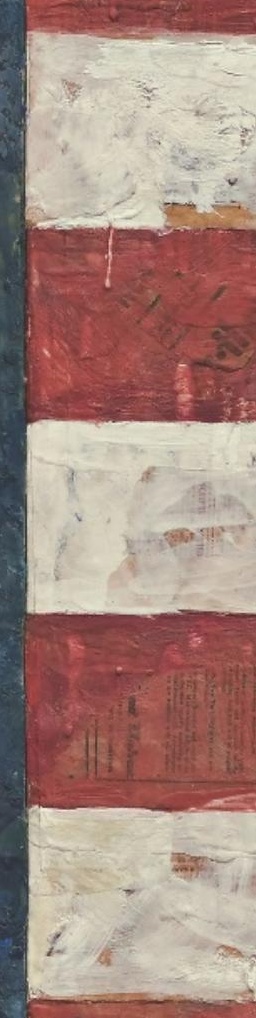


-

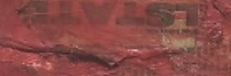
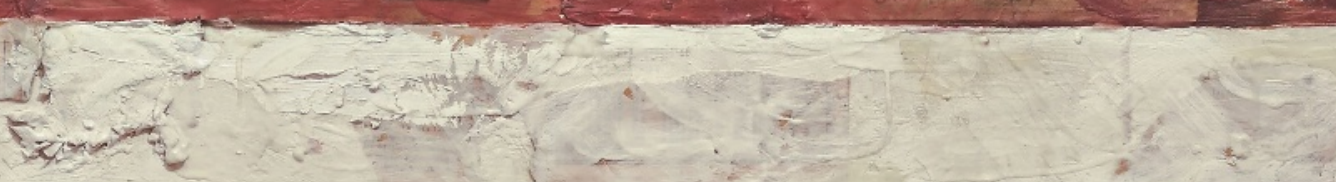

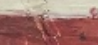

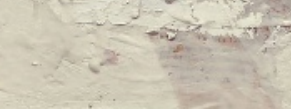

$1+2$

is 5

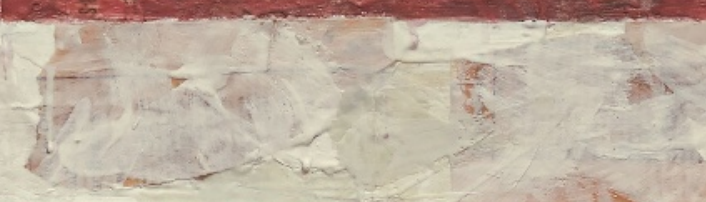

13

15 
1. Semper avait distingué quatre grands domaines techniques associés à un type de propriétés des matériaux:

1. Le textile (matériau souple et indéchirable); 2. La céramique (matériau plastique, mou et susceptible de durcir) ;

3. La tectonique et menuiserie (matériau relativement solide); 4. La stéréotomie et maçonnerie (matériau solide et dense résistant à la pression).

Voir Gottfried Semper, Der Stil, t. I, Francfortsur-le-Main, Verlag für Kunst und Wissenschaft, 1860 : 8. [NdT]

2. Semper fait ici allusion à la parenté étymologique qu'il établissait entre les termes de Wand (le mur, la cloison) et de Gewand (le vêtement), un rapprochement sur lequel il revient à de multiples reprises dans différents textes. [NdT]
3. On peut lire chez Athénée (Les Déipnosophistes XV, 16) que le couronnement désigne un certain accomplissement (to dè stephein plèrosin tina sémainei). II ressort de tout le passage de l'auteur qui vient d'être cité que, chez les Grecs, les couronnes faisaient l'objet d'une exécution artistique aussi aboutie que toutes leurs autres activités artistiques plus sérieuses et plus importantes. Athénée énumère toute une série de couronnes qui se distinguent en fonction de leur caractère et de leur signification et il justifie sa classification des couronnes avec des citations d'auteurs anciens. II revient plusieurs fois sur cette question. Il existait des couronnes de tête (stéphanoi) et des couronnes portées autour du cou (upothumiadai), qui étaient torsadées soit en lotus, comme chez les Égyptiens, soit avec d'autres herbes parfumées et rafraîchissantes, et avec des fleurs.

"Plektas d'hupothumiadas Peri stèphési lotinas ethento."

(Ils leur suspendaient autour du cou

Des couronnes tressées de lotus.)

En moyenne, l'industrie moderne manifeste très peu d'intelligence et de goût dans les modèles de rubans et de nœuds destinés aux toilettes féminines. De façon générale, on peut supposer que les modèles les plus répandus sur les métiers à tisser sont aussi ceux qui se déroulent et se déplient de la plus belle façon - cependant, à notre époque, tout est répandu dans les métiers à tisser et cette épreuve de style n'est donc plus surmontée avec succès chez nous. Nous touchons là à l'un des écueils les plus dangereux de l'industrie moderne de l'art et des arts dans leur ensemble. Ce n'est qu'en s'en tenant par principe aux lois éternellement valables de l'art, en étudiant assidûment les œuvres proches de l'origine de l'art et qui manifestent encore la loi du style dans sa pleine naïveté et en observant ce qui est issu de ces motifs dans les périodes où le développement de l'art a atteint ses sommets, que l'on peut reconnaître les limites de la loi et du beau en dépit de cette surabondance de moyens. À y regarder précisément, le mauvais goût qui est associé à cette richesse montre que nous avons su l'obtenir mais que nous n'avons pas encore appris à l'utiliser. Nous ne sommes pas encore devenus intellectuellement maîtres du matériau et, de ce point de vue, nous avons à rougir face aux Hindous et aux Iroquois ${ }^{5}$.

Les Grecs suivirent dans ce domaine encore le modèle des Égyptiens, comme on peut le voir sur les nombreuses représentations qui figurent sur les murs des tombes égyptiennes, où les hôtes sont accueillis par des femmes et des jeunes gens qui leur tendent des bouquets de fleurs. D'autres parent leur cou de couronnes de lotus. Sur ces peintures murales égyptiennes, comme dans les sculptures et peintures grecques, on reconnaît le caractère proprement architectonique, c'està-dire rythmiquement réglé des couronnes antiques; le romantisme naturaliste plus moderne des bouquets et des couronnes n'était en usage dans l'Antiquité que là où il était significatif (dans les cortèges bacchiques par exemple). La plupart des combinaisons antiques de fleurs, de fruits et de feuilles consistaient plutôt en rangées simples ou alternées: des feuilles étaient simplement alignées avec le bout de leur tige les unes à côté des autres sur une tige ou un fil, ou bien on enfilait les fleurs comme des perles, comme on le voit sur la figure ci-dessous. D'autres couronnes se présentaient sous la forme de tressages et de bourrelets torsadés.
Il existait des couronnes doubles et triples, mais aussi à rangs multiples; chaque espèce de couronne possédait une signification symbolique déterminée.

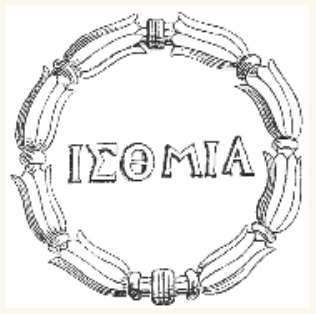

"kisso te narkisso te triélikas kuklo stephanon elikton. "

Les couronnes torsadées d'une triple rangée de lierre et de narcisses refermées en cercle.

Chérémon d'Athènes cité par Athénée, l c.

Pour la compréhension de beaucoup de types d'architecture antiques, il serait important de connaître le caractère prédominant de leurs couronnes et le sens qu'ils attribuaient à certaines modifications de ces dernières. Le chapitre d'Athénée qui a été cité et le chapitre IV du livre XVI de Pline l'Ancien sont les principaux textes qui traitent de cette question. [Note de Semper]
4. Voir la préface.

[Note de Semper]

5. Voir infra et mon texte Wissenschaft, Industrie und Kunst, Braunschweig, Vieweg, 1852 [Science, industrie et art, trad. de l'allemand par Émile Reiber, Estelle Thibault (éd.), Gollion (Suisse), Infolio, 2012]. 


\section{Généralités}

\section{§ 24. Le produit doit se présenter de manière visible comme une conséquence du matériau}

Le besoin de renforcer et de couvrir a très tôt conduit les hommes à faire usage de fils naturels, de bandeaux et de surfaces couvrantes, à commencer il est vrai par celles qui sortaient pour ainsi dire des ateliers de la nature, toutes prêtes à être utilisées. Avec les progrès de l'industrie, on a appris à donner à ces produits naturels certaines propriétés et certaines coupes ou à les combiner de telle façon qu'ils soient mieux adaptés à la finalité pour laquelle on voulait les utiliser. À quoi s'est associée très tôt la tendance naturelle à la parure dont on ne sait pas, de façon générale, si elle n'a pas été le premier mobile des inventions qui ont vu le jour dans le domaine dont il est question ici.

La caractéristique de ces premiers produits de l'industrie est la stricte préservation des spécificités des matériaux bruts dans la forme et la couleur, une propriété qui, il est vrai, va entièrement de soi, mais n'en est pas moins pour nous de la plus grande importance et fort instructive, dans la mesure où cette évidence qui a été déterminante pour les premiers inventeurs a soulevé ensuite de plus en plus de difficultés et a été toujours davantage ébranlée quand l'industrie en progrès a inventé des moyens de plus en plus artificiels pour répondre aux besoins complexes d'une époque hautement civilisée. De cette propriété qui fait du produit, pour ainsi dire, une conséquence naturelle logiquement dérivée du matériau brut, et le fait apparaître comme tel, découle la justesse stylistique et la première justesse stylistique technique d'une œuvre.

Celle-ci dépend donc en premier lieu des propriétés naturelles du matériau brut à traiter, qui doivent être précisément connues de celui qui soit veut produire lui-même une œuvre technique, soit a vocation à préparer un mode d'emploi, des prescriptions et un modèle pour les producteurs. À l'époque moderne, la main du producteur ne possède que rarement ou jamais suffisamment de compétence et de loisir pour être elle-même celle qui invente, dès que cette invention sort du domaine du savoir expérimental et du calcul et se rapproche, ne serait-ce qu'en partie, d'une «conception » au sens artistico-formel. Du reste, alors que, de nos jours justement, la bureaucratie et la quête de profits des patrons de l'industrie, le machinisme et l'esclavage des prolétaires ont entièrement écarté l'ouvrier de ces questions d'art, on peut déplorer que même ceux qui auraient l'occasion de les remplacer dans ce domaine ne répondent pas toujours aux attentes et n'exercent pas l'influence favorable qu'on aurait pu attendre d'eux pour élever le niveau y compris artistique de l'industrie et la rendre florissante, pour cette raison surtout que la connaissance la plus précise des matériaux bruts et des procédures techniques utilisées dans les différentes branches de l'industrie pour façonner ceux-ci n'est pas suffisamment répandue chez eux, qu'ils ne sont certainement pas non plus toujours convaincus de la nécessité de se laisser guider, dans leurs compositions «pleines d'esprit», par les propriétés des matériaux bruts et l'influence des procédures en question; il n'est pas rare, enfin, qu'ils ne connaissent absolument pas les lois stylistiques auxquelles doit nécessairement conduire la juste évaluation des composantes mentionnées dans la production industrielle ${ }^{1}$. Pour chaque extrait 2

Quatrième chapitre.
L'art textile.
Considérations
techniques et
historiques.
Sections 24 à 29.
Notes page 209 


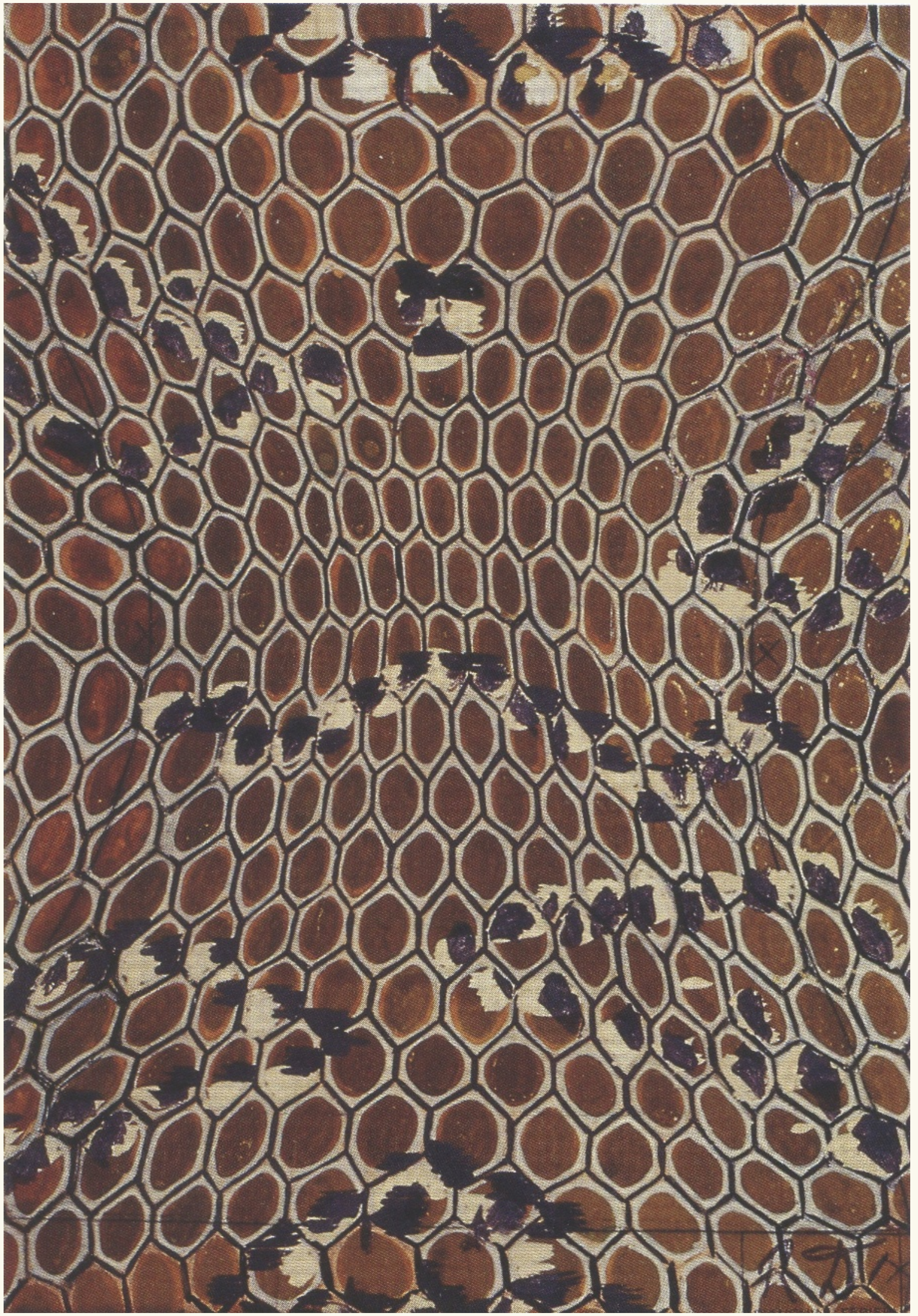


branche de l'activité industrielle appartenant ne serait-ce qu'en partie au domaine de l'art ou apparentée, il serait vraiment nécessaire de posséder une théorie des formes vraiment pratique, qui entrerait pleinement dans les spécificités de cette branche, tout en étant rédigée par un auteur ayant reçu une formation artistique!

Nous l'avons déjà expliqué plus haut, il n'est pas dans le projet de ce livre d'entrer de manière allusive dans la spécificité de chaque art, et c'est bien plutôt la référence proche ou lointaine à l'architecture qui restera ici le critère déterminant dans le traitement de la riche matière qui nous occupe, dont il serait sinon presque impossible de faire le tour.

\section{Produits naturels simples employés à l'état entièrement naturel ou seulement après une élaboration technique préalable ne faisant pas subir de modification essentielle aux propriétés constructives et formelles des matériaux}

\section{§25. La peau humaine, la plus naturelle des couvertures}

Le premier produit naturel dont il va être question ici est à n'en pas douter notre propre cuir ou la peau humaine; la peinture et le tatouage de la peau, ce phénomène si singulier de l'histoire culturelle, sont également du plus grand intérêt du point de vue de l'histoire du style. Nous ne savons pas vraiment si les traits et entrelacs peints ou tatoués dont les peuples qui vont entièrement ou partiellement nus ont coutume d'orner presque entièrement leur peau sont la pratique la plus ancienne dans l'art de l'ornement ou si, comme c'est bien souvent le cas lorsque quelque chose est tenu pour originel, on a affaire ici à la réminiscence d'une culture supérieure plus ancienne.

En gardant cette interrogation à l'esprit, il faudrait consacrer un chapitre au tatouage dans la rubrique d'histoire culturelle de cette grande section, comme une sous-rubrique du vêtement; par suite, nous nous contenterons d'indiquer ici que la plupart des peuples dits sauvages savent trouver pour ces peintures de peau les couleurs qui correspondent le mieux à la couleur de la leur. Beaucoup de peuples révèlent même une connaissance juste de l'emplacement et des fonctions des muscles recouverts par la peau dans la façon dont ils reproduisent ces muscles et leur fonctionnement à la surface de la peau, à la façon d'une image pour ainsi dire, ou les représentent plutôt graphiquement par le biais de lignes, un phénomène très singulier qui prouve que l'ornement, chez ces peuples, était déjà conçu dans son sens constructivo-symbolique et compris de manière très juste. Ceci nous autorise-t-il à en conclure que cette conception de l'ornement est la plus originelle ou bien doit-elle être plutôt considérée comme le signe que les peuples chez qui elle se manifeste ont atteint un niveau de culture secondaire ${ }^{2}$ ?

Les ornements qui figurent sur la peau de ces peuples sont faits de fils peints ou tatoués qui se croisent dans de nombreux entrelacs et spires et alternent avec des lignes droites.

Ces lignes nous ramènent ainsi, dans le même temps, au fil comme élément linéaire de la surface textile. ci-contre

fig. 6

Raoul Dufy, Peau de serpent, s.d., $42,5 \times 29 \mathrm{~cm}$, coll. part. (C) ADAGP, Paris 2017, photo DR. 
24

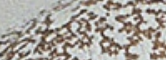

s.t.

mon

4. $\rightarrow$ (3) $\rightarrow$

7 .

6 . 3 . (t)

C.5.

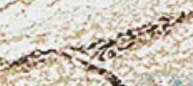

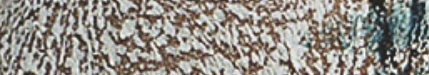

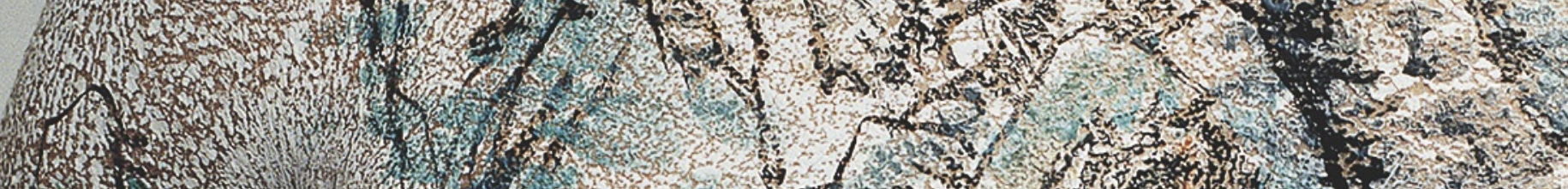

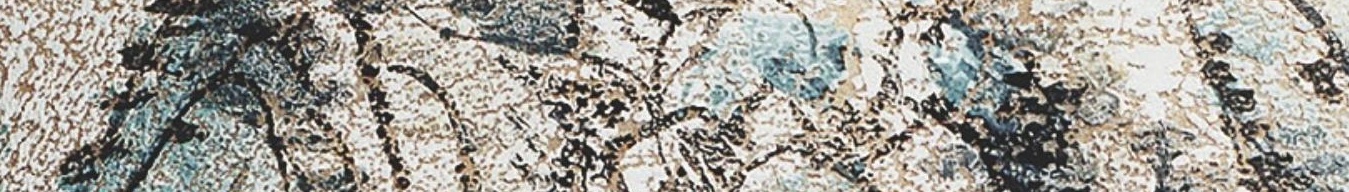
(1)

m, s r on

10.

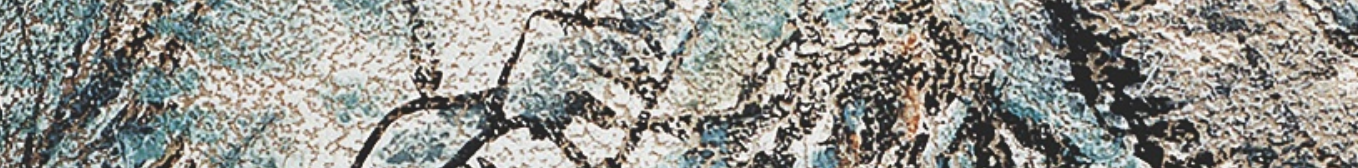

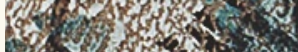

of

40

to 10

$4 y^{2}=$

of is.

(2) Stros

(1)

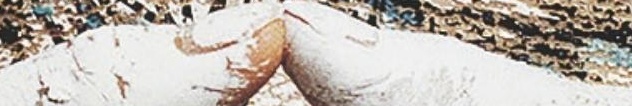

म4.
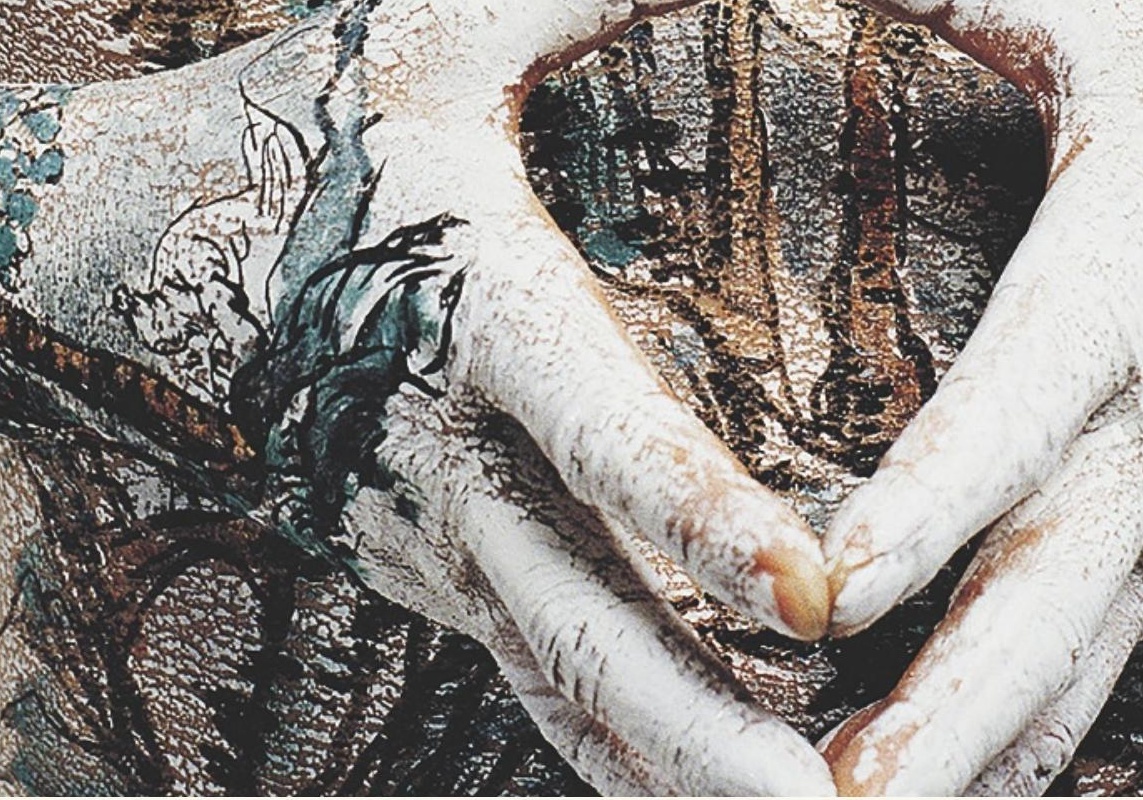


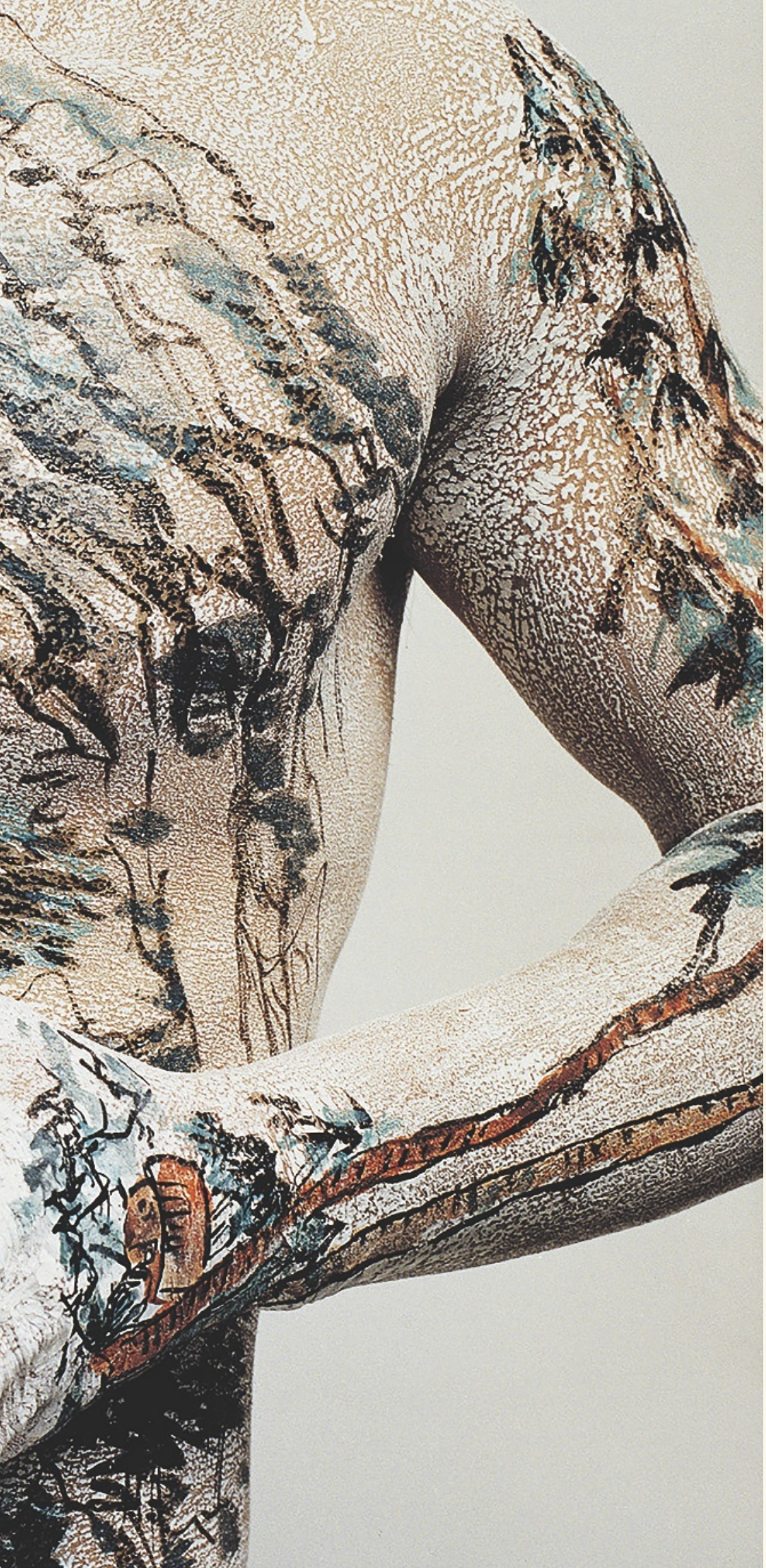




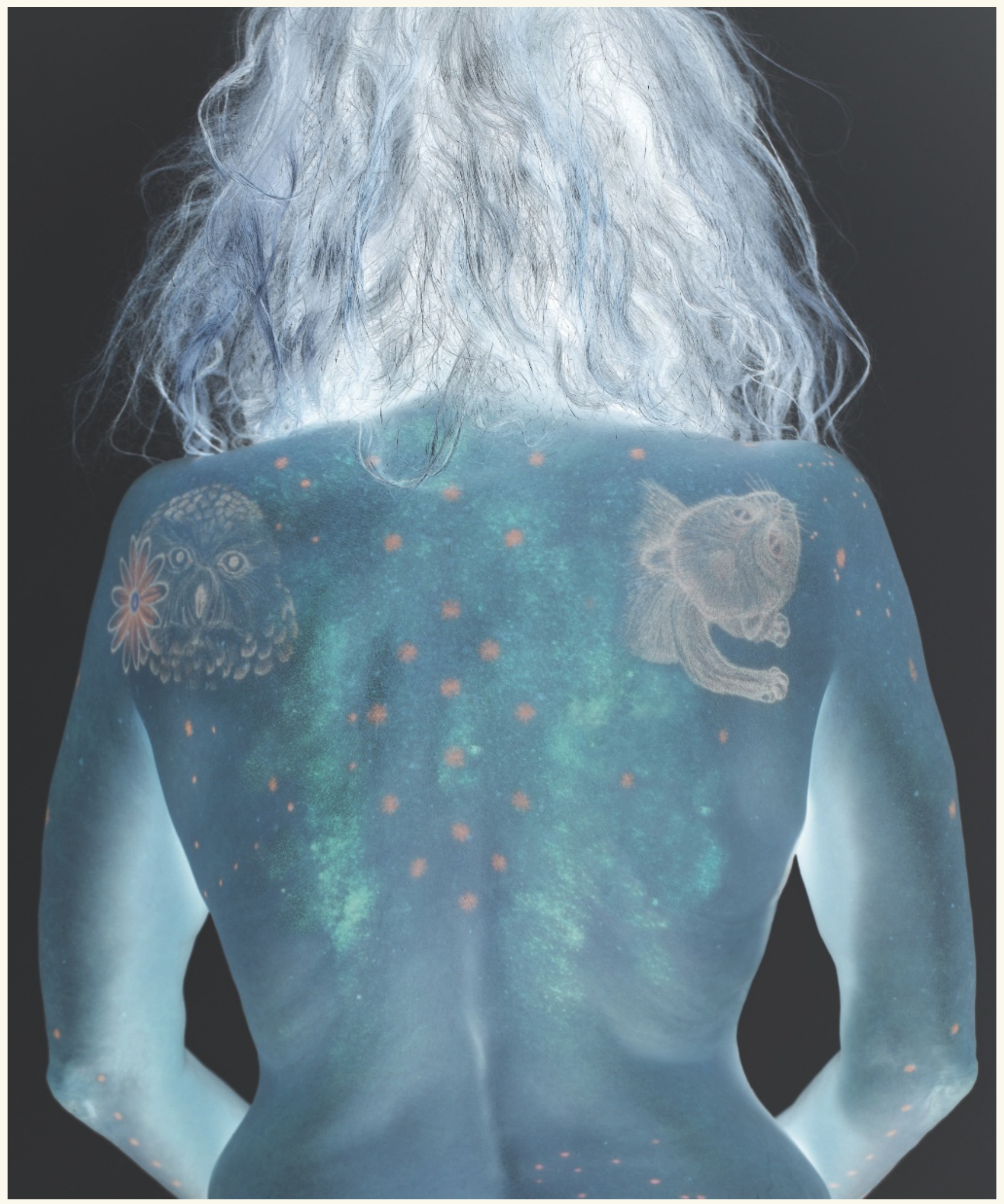




\section{§ 26. Les liens sur les outils et les armes}

Le besoin de lier et de renforcer est certainement l'un des plus anciens chez l'animal qui est doté de mains mais ne possède pas d'armes naturelles: l'homme. Les matériaux les plus naturels qui s'offrent pour satisfaire ce besoin sont issus du règne végétal et du règne animal. L'écorce des arbres et les tiges des variétés de graminées les plus solides sont des liens naturels dont l'utilisation a présupposé d'emblée le recours à certaines procédures et donné naissance à une sorte de style. Une grande habileté, un instinct mécanique juste et une aspiration manifeste à satisfaire le sentiment de la beauté tout en assurant la solidité sont visibles dans les entrelacs d'écorces et d'herbes qui accompagnent les armes et les outils des sauvages.

Ils rappellent par bien des points les outils et armes de l'Égypte ancienne, dont quelques-uns ont été conservés dans les grottes-tombeaux de la vallée du Nil.

Il en va de même des armes, ustensiles et outils des Assyriens, des Grecs, des Étrusques et des Romains. Là comme ailleurs, on peut être convaincu que la haute culture de l'Antiquité était pour ainsi dire directement greffée ${ }^{3}$ sur la nature.

Le goût qui distingue ces outils simples est particulièrement remarquable dans l'alternance et le choix heureux de liens de couleurs différentes pour faire la jointure entre les parties; le recours aux couleurs naturelles des matériaux bruts qui sont utilisés, dont il a déjà été question plus haut, est partout visible.

L'usage de fibres et de tendons animaux, de poils, d'intestins et de bandeaux ou lanières de cuir en guise de liens fait déjà appel à des procédures plus complexes et présuppose une sorte de transformation des propriétés des matériaux; dans les modes d'utilisation de ces derniers, on ne peut là encore qu'admirer l'habileté et le goût des peuples de cette période ancienne de la civilisation.

\section{§27. La pelleterie, une technique négligée par rapport au passé.} Les fourrures animales.

La corporation des fourreurs peut faire valoir le primat de son ancienneté par rapport à la plupart des corporations associées. L'art d'utiliser et d'apprêter le tissu naturel ou plutôt les fibres naturelles des peaux animales et des pelages était parvenu à un développement raffiné et à un prestige important alors que les autres arts étaient encore balbutiants; une grande partie de ces derniers n'ont été cultivés que sous l'impulsion de la pelleterie qui les employait pour remplir ses propres fins. Nous voyons ainsi toutes les tribus partiellement civilisées exceller dans la pelleterie; c'est en tout cas vrai de celles qui vivent sous un climat rude. Dans ce domaine, elles ont été nos professeurs et nos maîtres de façon beaucoup plus incontestable encore que ce n'est le cas pour d'autres branches de l'industrie - une vérité qui n'est peut-être pas agréable à entendre pour Messieurs les fourreurs patentés de la cour, accrédités par les médailles de leurs petites et grandes expositions. Là encore, il faudrait un connaisseur de cette branche à la fois

\section{ci-contre}

fig. 8

Valerie Hammond, Apports, 2012 (C) Valerie Hammond. Avec l'aimable autorisation de l'artiste. 
intelligent et doté d'une formation esthétique pour remettre à l'honneur ce magnifique matériau naturel que nous ne savons plus à présent manier que de la façon la plus grossière et sur un mode purement utilitariste (nous montrant sur ce point infiniment plus barbares que les Lapons, les Toungouses et les Iroquois), et publier une monographie relative à la pelleterie, assortie d'illustrations comme il se doit, dans une perspective qui touche à la fois à la technique et au style et, en même temps, aux sciences de la culture. Il faudrait que cette discipline des arts techniques soit abordée par quelqu'un qui, d'un point de vue pratique, en ait une connaissance intime, et qui ne l'appréhende pas sous son aspect purement technique mais prenne spécifiquement en compte les questions artistico-formelles et celles qui touchent au style: ce serait là le seul moyen d'œuvrer en faveur d'une meilleure orientation du goût dans les domaines inférieurs de la production artistique; c'est sur une telle base populaire que pourrait ensuite prendre appui un projet plus ambitieux de théorie pratique de la beauté qui s'étendrait aux arts supérieurs.

L'homme a tôt appris à préparer les peaux de bêtes de telle sorte qu'elles résistent à la putréfaction et acquièrent le degré de souplesse leur permettant d'être portées et de servir à l'habillement.

En préparant les peaux, en particulier lorsqu'elles avaient été prélevées sur des bêtes tuées à la chasse d'une espèce noble et de grande taille, on cherchait autant que possible à conserver le caractère de ces animaux; très tôt, on aima porter sur les épaules les exuvies des bêtes et s'en couvrir la tête pour faire allusion à sa propre force, son adresse et son ardeur combattante. Les mythes des peuples antiques qui vivaient sur le pourtour de la Méditerranée revêtaient leurs héros et héroïnes de peaux de lion et de panthère, d'ours et de loup, voire d'écailles de poisson et de lézard. Les prêtres égyptiens et assyriens en portaient en costume, signe certain d'une tradition extrêmement ancienne et historiquement fondée, car ce clergé a toujours su préserver celle-ci et l'entourer de l'aura de dignité des origines immémoriales. Nous voyons la même chose chez les anciens Germains et les peuples scythes, qui étaient non seulement capables de préparer les fourrures et le cuir avec habileté et de leur donner une nouvelle forme, au demeurant très raffinée, mais savaient aussi préserver au mieux, dans leurs tenues de guerre et sans doute aussi leurs ornements liturgiques, la forme et le caractère de l'animal dont la fourrure était utilisée, en les rendant même plus effrayants encore et en accentuant leur côté terrifiant. Parmi les symboles favoris de ces peuples nordiques, on peut citer la peau d'auroch, dont les cornes longues d'un coude étaient portées comme une parure de tête guerrière et brandies en l'air, ou encore la peau d'élan et la peau d'ours, ainsi que l'exuvie de l'aigle royal, dont les ailes formaient une parure de casque d'une terrifiante beauté. D'après Plutarque (Vie de Marius $27^{4}$ ), les Cimbres portaient des casques évoquant la gueule d'animaux terribles et possédant d'autres formes étranges; ils étaient surmontés de grands panaches de plumes en formes d'ailes qui les faisaient paraître nettement plus grands.

Aujourd'hui encore, dans leurs danses guerrières sauvages, les Indiens de la prairie dissimulent leur visage derrière des masques animaux effrayants, inspirés du bison ou de l'ours. On rencontre des masques d'apparat semblables chez les sauvages des îles des mers du Sud. Ces masques animaux 
terrifiants se retrouvent chez les prêtres égyptiens sous une forme plus raffinée, dans les parures de tête sacrées du prêtre qui représente le dieu. Le masque animal devint, dans les temps anciens, le symbole de ce qui était caché, mystérieux et effrayant. Souvent, il n'en resta que le signe particulièrement caractéristique de l'animal; par exemple les cornes de taureau comme parure de Mithra chez les souverains assyriens, les cornes de bélier comme ornement de tête chez les rois égyptiens, repris et porté par Alexandre comme souverain d'Égypte et fils d'Ammon. L'effrayant gorgeion de Pallas Athéné qui brandit l'égide est un masque. Ce fut un symbole important dans la vie et les arts bien avant que l'art dramatique ne s'en empare; là encore, nous voyons à nouveau comment les composantes semble-t-il les plus raffinées de l'art antique étaient directement greffées sur la nature la plus originelle.

\section{§28. La peau des arbres}

Entre les peaux des arbres, à savoir l'écorce et le liber, et les peaux animales, on peut voir un singulier rapport remarquable à un double titre pour la question qui nous occupe. L'écorce, comme la peau animale, a sans doute dû éveiller naturellement très tôt l'idée de peler cette couverture naturelle de l'arbre et de l'utiliser à des fins proches de sa destination originelle. Sans évoquer ici le fameux "full dress of an Indian Lady» qu'on a exhibé dans les deux grandes expositions de Londres et de Paris et qui se compose d'un unique morceau d'écorce triangulaire que les dames de Guyane utilisent comme cache-sexe, l'écorce joue le rôle d'un important matériau d'habillement, à côté des peaux de bêtes, pour bon nombre de peuples qui ont déjà connu des avancées culturelles significatives. Dans ce domaine, ce sont cependant les indigènes d'Amérique du Nord qui sont peut-être allés le plus loin: dans leurs canoës confectionnés à base d'écorce et de cuir, ils ont développé un style artistique particulier, extrêmement original aussi bien dans sa forme que dans sa couleur. On peut parler d'un style de tanneurs. La couleur brun-rouge des écorces, apparentée par nature à celle du cuir et identifiée en outre à cette dernière par le processus du tannage, fournit le ton fondamental de la polychromie, sur lequel se détachent quatre couleurs, le bleu, le rouge, le noir et le blanc (le jaune est exclu), utilisées pour les charmants bandeaux de jointure et les coutures. On retrouve des tendances analogues dans les fameuses productions à base d'écorce de poirier qui constituent une branche majeure de l'industrie agricole norvégienne.

Une industrie déjà plus raffinée ou plutôt une industrie de transition fait usage des fibres de bois pour des vêtements de toute nature: elles sont pressées dans un moule à l'aide d'une lessive alcaline et on s'en sert pour fabriquer des vêtements et des couvertures. Les tribus des mers du Sud, tout comme les peuples américains, ont su développer avec style et avec un goût impeccable cette branche de l'industrie qui marque la transition avec le tressage de fibres 5 .

En Inde également, l'écorce des arbres et le liber sont travaillés depuis les temps les plus reculés pour produire des étoffes vestimentaires. Hérodote (III 98) les appelle esthès phloïnè; Ktésias (Indic. 22) parle d'imatia xulina. C'étaient les vêtements des nécessiteux et des renonçants. Shakuntala portait un manteau de ce type avant que les dévanis ne lui offrent en cadeau 


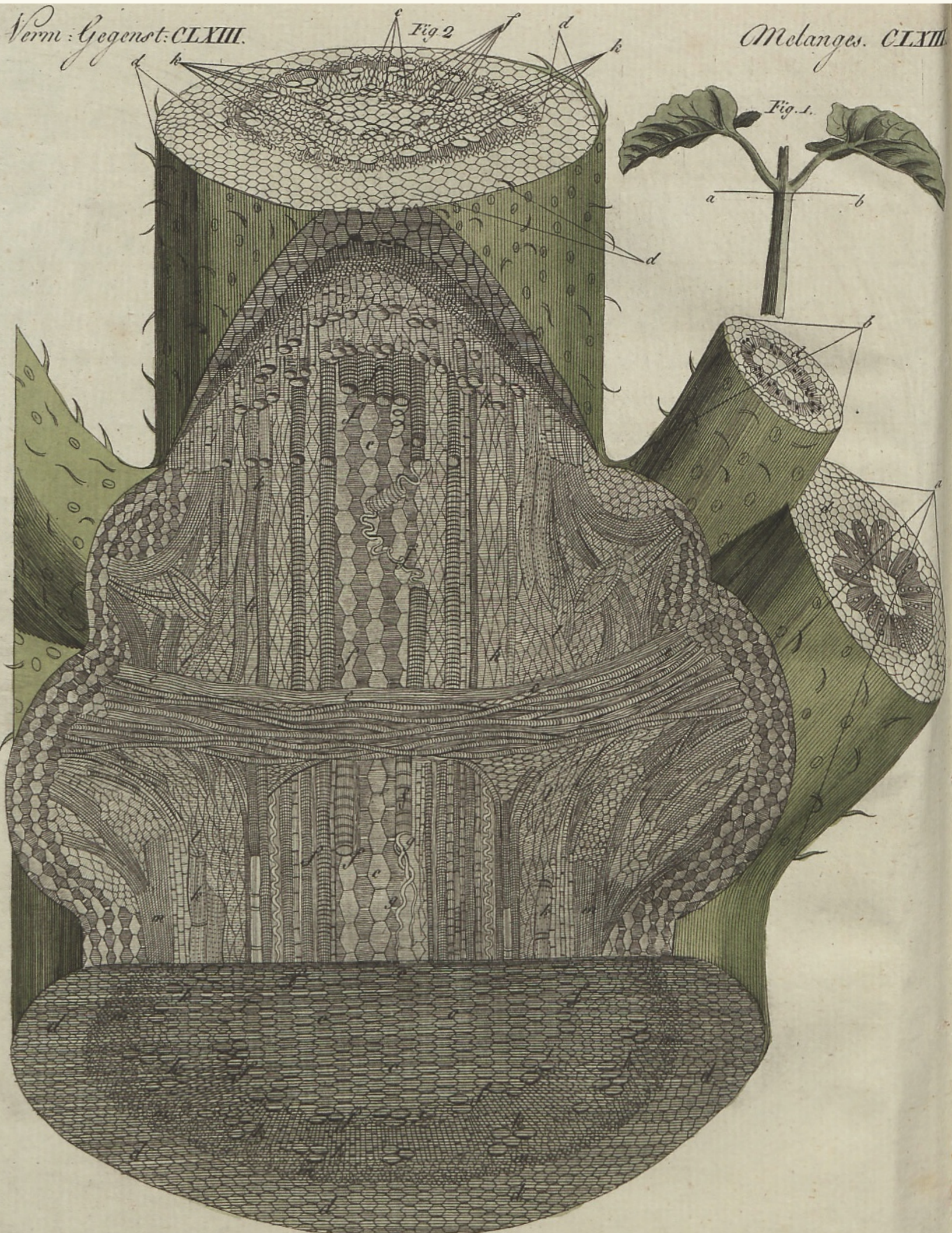


ses précieux vêtements. Dushmanta endossa un tel habit en devenant renonçant ${ }^{6}$. On ne sait s'il était tissé comme les guingans ou composé d'un assemblage de pièces naturelles. Lorsqu'on confectionnait ces vêtements, on les faisait sécher au soleil.

Il existe cependant une autre affinité élective entre l'écorce et la peau animale: comme la seconde, la première offre matière à affinage ou tannage. Les Chinois étaient déjà passés maîtres dans l'art du tannage au moins 2500 ans avant notre ère. Chez les Égyptiens, les tanneurs et les ouvriers des manufactures de cuir représentaient une branche importante de la troisième classe, la classe industrieuse, et ce, depuis les temps les plus reculés. On trouve sur les momies des bandeaux de cuir très joliment ornés, avec beaucoup de goût, d'impressions de figures et de hiéroglyphes. Ces objets datent pour une part d'une époque antérieure à la sortie des Juifs d'Égypte. Certaines représentations que l'on peut voir sur les parois des tombes se rapportent à la fabrication du cuir et à l'utilisation de ce matériau pour des chaussures, des housses de meubles, des voitures et des instruments de musique. Les peaux de bouc servaient aussi à fabriquer des outres de vin qui étaient apparemment décorées avec un certain art. Les peaux tannées étaient aussi utilisées comme tapisseries et toits de protection, comme il ressort déjà de la fameuse description du Tabernacle, tendu d'un double tapis de poil de chèvre sur lequel on avait posé une couverture de poil de bouc teinté en rouge, surmontée elle-même d'une couverture de poil de blaireau (Ex. 25, 5 et 26, 14). Les ouvriers juifs qui exécutaient ces ouvrages dans le désert avaient sans doute appris leur art en Égypte ${ }^{\mathbf{7}}$; la coloration des peaux (dont témoignent au demeurant déjà les vestiges qui ont réellement été trouvés et les représentations de fauteuils recouverts de cuir de couleur) était donc connue des Égyptiens dès cette époque ancienne. Pour la coloration, on employait vraisemblablement (comme c'est encore le cas aujourd'hui en Égypte) la plante Periploca secamone. Sur les murs des tombes de Beni Hassan, on voit des tailleurs de courroies qui se servent du couteau de forme semi-circulaire encore utilisé de nos jours par les selliers et qui avait donc déjà été inventé il y a quatre mille ans, comme d'autres outils encore courants aujourd'hui.

Les vestiges de cuir pressé dont il a été question plus haut et les cuirs de couleur recouvrant certains meubles qui sont représentés sur les parois des tombeaux de Thèbes et qui figuraient certainement des cuirs de couleur pressés ne sont pas moins importants, pour l'histoire du style de cette intéressante industrie qui a trouvé récemment de nouveaux débouchés, que les exemples plus brillants et mieux conservés de cette technique qui datent des siècles du Moyen Âge et de la Renaissance. Avec les moyens aujourd'hui à notre disposition, on peut exécuter en cuir et dans un matériau apparenté au cuir ou imité du cuir n'importe quel relief et n'importe quel caprice ornemental: mais il n'en demeure pas moins souhaitable d'observer une grande prudence dans l'emploi des libertés qui nous sont données et, de façon générale, de ne pas dépasser les limites imposées autrefois par l'utilisation des moyens les plus simples et les plus originels, afin de satisfaire à une condition essentielle, celle qui veut que la surface de cuir demeure toujours une surface. Une autre raison est que ce qui sort directement de la main de l'homme possède le charme des origines et de la liberté artistique,

\section{ci-contre}

fig. 9

Friedrich Justin Bertuch, Carl Bertuch, Structure intérieure d'un pied de fève, pl. CLXIII, vol. VII, n 64, in Bilderbuch für Kinder: enthaltend eine angenehme Sammlung von Thieren, Pflanzen, Früchten, Mineralien... alle nach den besten Originalen gewählt, gestochen und mit einer... den Verstandes-Kräften eines Kindes angemessenen Erklärung begleitet (Band 7): Monographie - Weimar, 1810. Photo (C)

Universitätsbibliothek Heidelberg. 
mais que ce charme est perdu quand la machine dévoile ses artifices et prétend réaliser ce que la main de l'homme n'est pas en mesure de représenter. La machine ne produira un effet bénéfique sur les arts que lorsqu'elle aura appris à se soumettre au matériau et à ses propriétés naturelles.

\section{§29. Les cuirs pressés égyptiens et le style} de la sculpture égyptienne en général

Les raisons ne manquent pas d'insérer ici une note sur la sculpture égyptienne en général, à l'occasion de ce passage sur les cuirs égyptiens pressés à la façon des bas-reliefs. Le style singulier de la plastique égyptienne, dont nous traiterons plus en détail le moment venu, s'explique pour une part du moins par les exigences techniques du matériau dur auquel il faisait appel et des moyens simples qui étaient employés pour le contraindre. Les colosses de granit, avec leurs extrémités et accessoires très ajustés, avec leurs contours fortement accentués, raffinés tout en étant massifs, sont pour ainsi dire un compromis entre le matériau dur et résistant et la main délicate de l'homme avec ses outils simples, le marteau, le ciseau, la lime et la meule. Ils sont en même temps le résultat de l'intention de créer un ouvrage fait pour durer longtemps et qui ne soit pas facile à détruire. Leur immobilité grandiose et leur massivité, la finesse un peu anguleuse et plate de leurs linéaments, la modération qu'ils révèlent dans le traitement d'un matériau difficile, tout leur habitus sont des beautés stylistiques qui, aujourd'hui, ont en partie perdu leur raison d'être, à l'heure où les machines nous permettent de tailler les pierres les plus dures comme du fromage et du pain - mais nous aurions tout intérêt à n'employer ces pierres dures que lorsque la dureté et la durabilité de la matière deviennent nécessaires et de ne faire dériver que de ces deux propriétés la loi stylistique à laquelle la machine doit se soumettre et se conformer dans son travail. Il en va de même - bien que les prémisses soient différentes (puisque les conditions du matériau sont dans ce cas la souplesse, la planéité et la durabilité) - des lois stylistiques qui doivent tempérer la toute-puissance de la machine dans les fabrications de cuir.

\section{$\S 29$ bis. Autres remarques sur les cuirs et fourrures}

On peut se demander si l'art du tannage n'était pas parvenu à un degré élevé de perfection en Asie plus tôt encore qu'en Égypte. On l'a dit, nous savons que dès le $\|^{\mathrm{e}}$ millénaire avant Jésus-Christ, les Chinois n'étaient plus des débutants dans cette technique comme dans presque toutes les autres. Dès les temps anciens, ils collectionnaient les antiquités, et les plus anciens documents écrits de ce peuple font allusion à l'adresse de leurs ancêtres et à l'excellence des œuvres de ces époques immémoriales.

La population de la vallée de l'Euphrate, elle aussi extrêmement ancienne, connaissait cet art depuis une époque qui était au moins aussi éloignée des débuts de l'histoire que nous le sommes aujourd'hui, en sens inverse. Ils ne fabriquaient pas seulement des cuirs courants, mais aussi des vêtements raffinés, pressés et colorés, dont les coutures étaient brodées, et les outils de cuir étaient parmi ces peuples des articles de luxe très appréciés. Les cuirs de Babylone et de Perse, sans doute analogues aux cuirs de Saffian et de Cordoue, héritiers arabes ultérieurs de la civilisation extrêmement ancienne de l'Asie occidentale, étaient célèbres depuis des temps immémoriaux. 
Les produits de fourrure et de cuir étaient également mentionnés dans les plus anciens documents écrits de l'Inde. Dans le Ramayana ${ }^{8}$, le roi de Videha offre aussi à sa fille Sita, entre autres étoffes magnifiques de soie et de laine, des fourrures. D'après le Periplous ${ }^{9}$, la fourrure semble cependant avoir été introduite en Inde depuis la Séricie (Chine). Il est certain que les boucliers de beau cuir pressé et les autres armes défensives en cuir tanné, notamment en peau de rhinocéros, que nous admirons dans les collections indiennes, sont assurément une invention extrêmement ancienne.

Les «peaux d'ours» de sinistre réputation, les Germains, passaient pour être des fourreurs et tanneurs très habiles, dépassant dans ces arts leurs voisins hautement cultivés du Sud de l'Europe ${ }^{10}$. Leurs fourrures étaient très différentes de celles des pâtres romains qui, d'après la légende, étaient aussi portées par les sénateurs à Rome avant l'introduction du textile, dans les temps les plus anciens, et dont la forme s'est conservée jusqu'à nos jours dans le costume des bergers de la campagne romaine. La Junon de Lanuvium porte la peau de mouton latine, à l'état brut: c'est le signe que cette divinité est native du pays. Les tabliers de fourrure des Germains, en revanche, étaient travaillés avec art, bien tannés, taillés sur mesure et pourvus de coutures joliment brodées. Le côté poilu était tourné vers l'intérieur et ils n'étaient garnis de parties fourrées plus précieuses que sur les bordures. On les appelait des renones (des peaux de renne) et ils étaient sans doute très semblables aux peaux canadiennes; à l'époque du déclin de Rome, c'était un article commercial recherché.

Le fait de porter les fourrures à l'envers a fait accéder l'art de la pelleterie à un stade nouveau; il s'oppose ainsi déjà à la nature, ne disparaît pas en elle comme c'était le cas auparavant et doit désormais suivre naturellement un style tout à fait nouveau, dans lequel les ourlets (bordures) et les coutures (qui se composent de broderies colorées et de bandeaux de fourrure intercalés), ainsi que les autres accessoires tels que les houppes, glands et autres, animent le fond chaud du cuir brun-rouge.

Ce style a eu pour conséquence qu'on a prêté attention aux petits animaux à fourrure dont les peaux n'avaient jusque-là guère éveillé d'intérêt. Comme ces animaux ne possèdent de bonnes fourrures que dans les pays froids, c'est sans doute leur présence abondante dans ces contrées qui a conduit pour la première fois au style du tablier de fourrure qui, de là, fut transmis sous sa forme achevée aux peuples cultivés du bassin méditerranéen et conserva toujours quelque chose d'étranger et de barbare. Les petites fourrures précieuses étaient employées pour les bordures des peaux; et, de la même façon, les peaux cessèrent par la suite d'être montrées à nu et furent recouvertes, à l'extérieur, d'étoffes précieuses (drap et soieries).

Dans l'Antiquité classique, ce luxe des fourrures les plus raffinées était déjà connu depuis des époques très anciennes. Certains chercheurs affirment même que l'expédition des Argonautes était une spéculation sur des fourrures ${ }^{11}$, tout comme les voyages des Normands vers les côtes de l'Amérique du Nord. Pline mentionne les fourrures chinoises ${ }^{12}$; plus tard, on les faisait venir du pays des Parthes; c'est la raison pour laquelle les marchands de peaux étaient appelés Parthiarii dans le droit romain. 


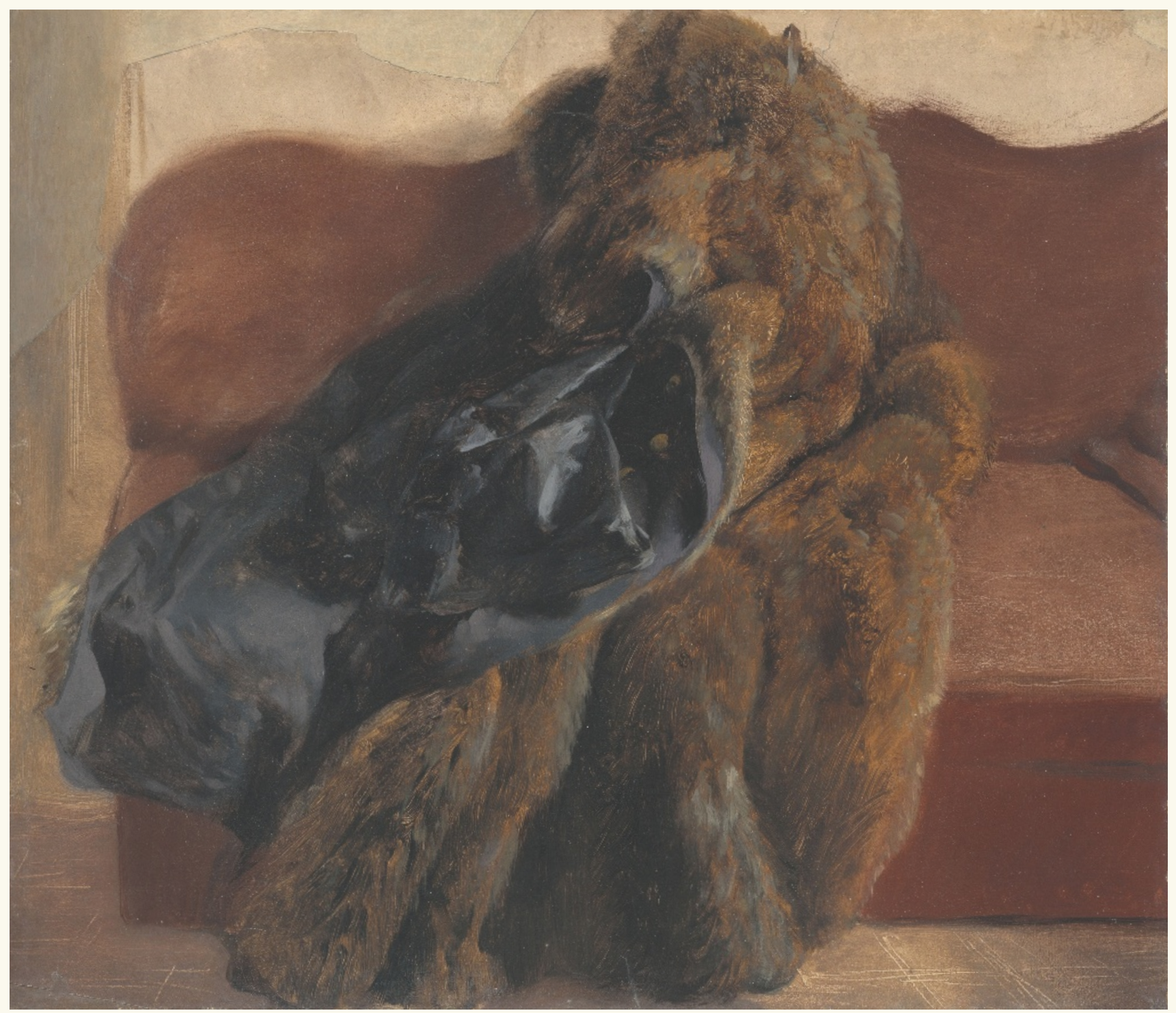


Le commerce se faisait par voie de terre puis s'étendit au-delà de la mer Noire. Sénèque loue la finesse et l'épaisseur des fourrures scythes, de renard et de zibeline (murium). Ces peaux étaient cousues ensemble et étaient alors appelées caftans (kanautanès). Tacite et Justin mentionnent eux aussi les terga murina. Les peaux de chevrotin étaient aussi très recherchées, en raison de leur parfum de musc ${ }^{13}$.

À l'époque de Charlemagne, des vêtements fourrés, bordés de fourrures d'oiseaux et richement brodés de plumes étaient portés par les femmes comme par les hommes; c'était une vieille coutume franque privilégiée par l'empereur. Un gilet (thorax) de fourrure de loutre protégeait les épaules et la poitrine. À la cour de Charlemagne, les princesses portaient des cols de manteaux en hermine ornés de pierres précieuses. Les Scythes et les Huns portaient eux aussi des habits en peau de souris et de chat ${ }^{\mathbf{1 4}}$.

Ce commerce continua d'être florissant jusqu'à la fin du Moyen Âge, qui développa un grand luxe de peaux - mais la chasse aux animaux à fourrure noble fut poussée toujours davantage vers le Nord où ils ne tardèrent pas à être exterminés. Le Canada et la Nouvelle-Écosse approvisionnèrent alors le marché en fourrures non moins abondantes avec lesquelles nos pelletiers confectionnaient des boas, des manchons, des bottes fourrées et de lourds surtouts de fourrure.

Là encore, tout art a disparu de ce secteur de l'industrie vestimentaire et, dans ce domaine, l'absence de goût n'est nulle part aussi criante qu'en Angleterre, bien que ce pays soit le seul où la fourrure distingue encore de nos jours la dignité de la noblesse, des juges et des autorités communales et où cet ornement héraldique s'est perpétué depuis le Moyen Âge dans toute sa signification; les petites queues d'hermine sur les couronnes et les cols des duchesses, des marquises et des baronnes ne sont plus, de nos jours, qu'un symbole assez indigent et raccourci de la magnificence antique.

Depuis des temps immémoriaux, les Asiatiques ont été les plus habiles préparateurs du cuir, et ils le sont restés. Parmi les produits asiatiques qui, au demeurant, ont aussi été fabriqués en Espagne, en Sicile et partout où les Maures et les Sarrasins ont implanté leur industrie, les plus célèbres sont les cuirs de Cordoue, de Saffian, le chagrin et le cuir de Russie.

Le cordovan tire son nom de la ville mauresque de Cordoue en Espagne. C'est à cause de lui que les cordonniers sont ainsi appelés en français: au Moyen Âge, en particulier aux $\mathrm{xl}^{\mathrm{e}}$ et $\mathrm{xIl}^{\mathrm{e}}$ siècles, ce cuir était le matériau à partir duquel on fabriquait presque exclusivement les chaussures les plus fines. Le saffiano, également appelé cuir marocain, est une variété meilleure et un peu différente. Ce cuir brillant et de belle teinte, dont le grain rappelle le chagrin, est toujours produit d'excellente façon dans le Levant; nos industries de machines raffinées ne peuvent rivaliser avec lui. Ce n'est qu'en Russie, en Pologne, en Hongrie, en Espagne, en un mot dans les pays où la technologie n'est pas encore enseignée dans les universités, qu'on sait fabriquer ces variétés de cuir nobles et aussi les utiliser dans le respect du style. Parmi les Allemands, seuls les Tyroliens sont encore capables de remplir cette deuxième condition: ils savent orner avec beaucoup d'adresse fig: 10

Adolf Friedrich Erdmann von Menzel, Manteau de fourrure sur un canapé (La Pelisse de l'artiste), vers 1840/50. Allemagne, Munich, Bayerische Staatsgemäldesammlungen, Neue Pinakothek. Photo (C) BPK, Berlin. Dist. RMN-Grand Palais / image BStGS. 


\section{ci-contre}

fig. 11

Raoul Dufy/Joseph Llorens Artigas, Carreau à la naïade, vers 1925 , céramique $13,7 \times 13,7 \mathrm{~cm}$. Paris, MNAM AM 1164 OA, en dépôt aux Arts décoratifs (c) ADAGP, Paris, 2017

(C) Photo Les Arts Décoratifs, Paris/Jean Tholance. et de goût leurs ceintures et leurs bretelles de broderies et de bordures en plumes de paon et de coq de bruyère.

Un produit intéressant est le chagrin, sagre en persan, solide et rigide, qui, du côté fleur, semble être couvert de petits grains arrondis. Les meilleurs lieux de fabrication sont aujourd'hui la Perse, Constantinople, Alger et Tripoli. Pallas nous explique la procédure de granulation du chagrin; elle consiste à étendre les peaux sur le sol et à les parsemer de petits grains de Chenopodium album, à les enfoncer dans la partie tendre des peaux puis à les extraire à nouveau, à racler le cuir du côté bosselé et à le faire tremper dans l'eau pendant quelques jours. Les points imprimés en relief par les petits grains ressortent ensuite en gonflant, et ils reproduisent la forme arrondie du grain: plus les petits points ont été pressés, plus ils gonflent au milieu. Un processus tout à fait analogue pourrait certainement être appliqué de façon très pratique à la fabrication des tapisseries de cuir en relief: il faudrait alors utiliser non pas des formes creuses mais des formes en relief pour le pressage préalable, puis racler et assouplir. L'avantage serait une plus grande souplesse des contours, assortie d'une plus grande finesse du modelé et, en même temps, un certain naturel des formes dont la production ne serait pas trop mécanique. Le processus peut également être étendu à des surfaces d'une autre matière, par exemple le bois, l'ivoire, le papier mâché, etc., comme c'est de fait l'usage dans les pays du Levant.

Un produit étonnant est le cuir de Russie, avec son parfum pénétrant qui, dans les variétés les plus fines, est très agréable et rafraîchissant. Cette odeur résulte de l'usage des huiles de bouleau qui permettent d'assouplir le cuir. Cette invention aussi provient d'Asie. Les meilleurs cuirs de ce type sont fabriqués dans différentes provinces de Russie et en Lituanie. C'est également dans ces pays qu'a été développé un véritable style de bottes; les bottes russes (les bottes d'apparat en l'occurrence) forment de véritables mosaïques de cuir, composées d'un grand nombre de bandes de cuir vert, rouge et jaune qui sont cousues ensemble solidement et avec beaucoup de goût. II s'agit manifestement là d'une tradition bulgaro-byzantine.

Notre cuir laqué européen, aux monotones surfaces frottées, ne peut guère être mentionné parmi les cuirs artistiques. II est sans style parce qu'on applique dans sa fabrication un principe de décoration en surface qui n'est utilisable et applicable, c'est-à-dire qui ne peut être exécuté avec quelque garantie de tenue et de fonctionnalité, que sur des surfaces plates, mais qu'on emploie cependant pour des surfaces souples et sans cesse soumises à des plis et à des mouvements. La conséquence inévitable qui en résulte est que même les laques les plus souples se fissurent immédiatement dans les endroits où ces pliures sont constantes. Les pays du Levant connaissent beaucoup mieux le sens de leur tâche lorsqu'ils recouvrent d'emblée la surface brillante du cuir souple avec un réseau de fines rayures réalisées artificiellement ou lui donnent un grain et lui impriment de fines différences de niveau, ce qui évite de faire ressortir les déchirures naturelles provoquées par la pliure des surfaces et permet en même temps d'obtenir que l'éclat se concentre dans beaucoup de petits points lumineux de ces surfaces et paraisse ainsi plus riche et produise plus d'effet, d'un côté, tout en étant d'un autre côté adouci et tempéré. Nous connaissons un autre exemple 


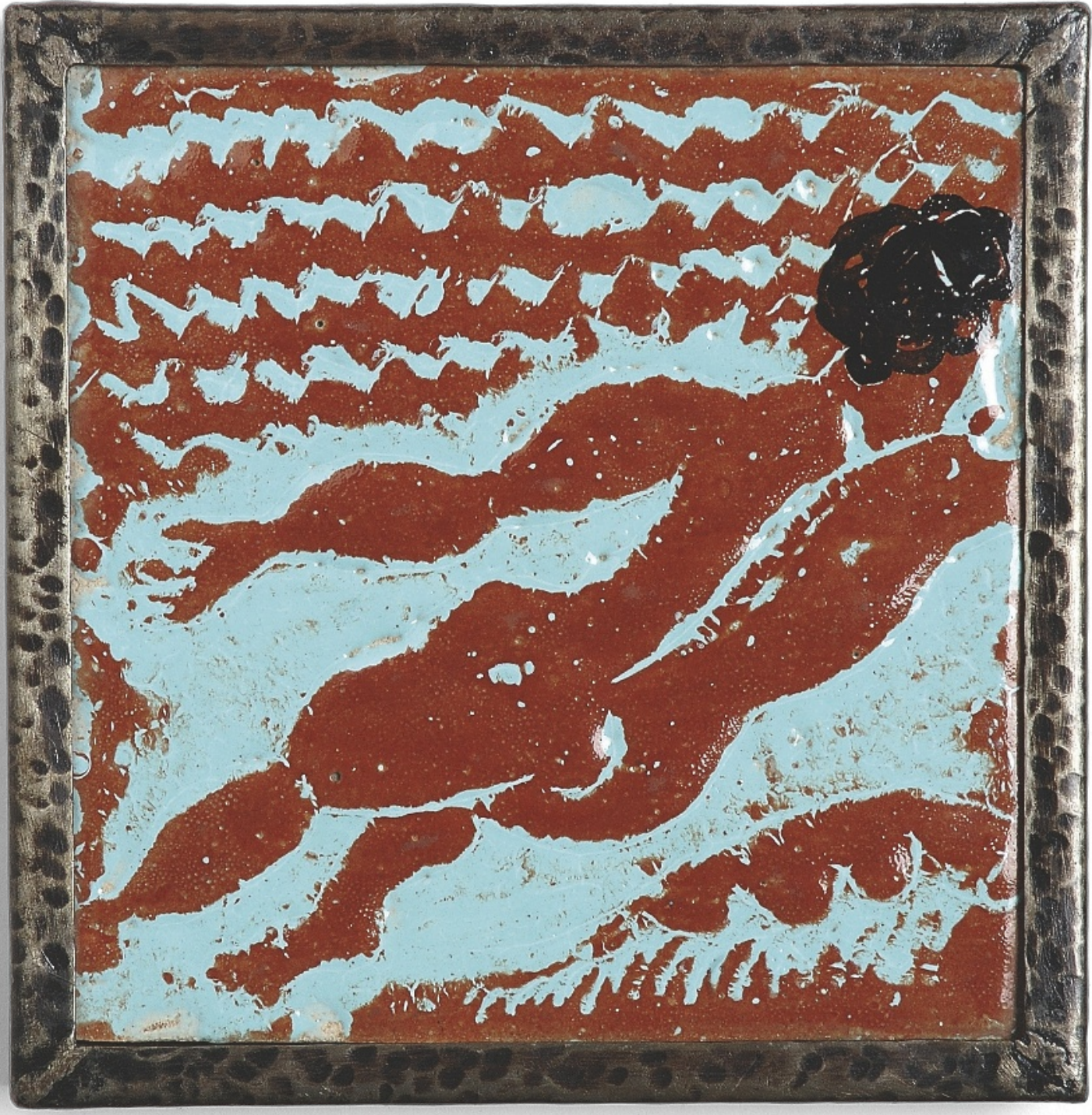


de l'industrie orientale où le même principe de décoration de surface se manifeste sous une forme moins justifiée, je pense à la porcelaine chinoise craquelée, qui doit son origine à la difficulté de trouver un rapport entre la couverture de la porcelaine et la masse de cette dernière permettant à la première de disparaître au même rythme que la seconde lors de la cuisson à feu fort.

Ces exemples instructifs nous montrent également que, dans les arts, le style résulte pour une part d'une adaptation adroite aux inévitables défauts et imperfections des matériaux et des moyens employés en vue de l'obtention d'une fin, et que tout le secret consiste souvent à faire de nécessité vertu au lieu de la contrarier.

Pour les chaussures européennes telles que nous les connaissons, le produit brillant le plus conforme au style demeure encore le cirage de bottes, cette laque extrêmement fine et facile à appliquer. La mégisserie (dans laquelle l'alun remplace les agents végétaux de tannage), inventée, dit-on, en Hongrie au X $\|^{e}$ siècle, produit le cuir blanc souple des gants. Le chamois est apparenté à ce dernier: il est affiné par simple foulage et autres procédés brutaux, à l'aide d'argile et de graisse animale. Ce cuir chamois est brut des deux côtés, parce que le grain est enlevé. Parmi les variétés particulières, on peut citer le cuir de Hongrie, fameux de longue date, le cuir fin d'Erlangen, qui est brillant, le cuir français et surtout aussi le cuir danois. Certains d'entre eux supportent le lavage, d'autres non; aucun n'est étanche et tous pompent l'eau comme une éponge. À ces matériaux sont associés le style des culottes de cuir et le style des gants glacés, qui ont leurs propres lois mais que nous n'examinerons pas davantage en détail ici.

Plus importants pour la finalité qui est la nôtre, les cuirs de cheval tannés en rouge, que leur taille importante et leur grain naturel puissant et régulier sur le côté fleur, leur texture tout aussi agréable, semblable à du velours, sur le côté chair, et, enfin, leur couleur chamois prédisposent particulièrement à une utilisation comme revêtement mural et en application sur des meubles. Lorsqu'on les emploie, il faut faire ressortir le plus possible ces propriétés du cuir de cheval, ne pas les dissimuler, et prendre ici pour modèle le style de tannage canadien dont il a été question plus haut, c'està-dire observer son principe. Ceci s'applique aussi particulièrement aux coutures et aux jonctions entre les parties, qu'il ne faut pas dissimuler mais au contraire accuser franchement. 
1. Sur ce point, voir mon texte Wissenschaft, Industrie und Kunst, etc. Braunschweig, Vieweg, 1852 [Science, industrie et art, trad. de l'allemand par Émile Reiber, Estelle Thibault (éd.), Lausanne, Infolio, 2012]; voir aussi R. A. Dyce, «Report on Foreign Schools of Design " (1839), in Catalogue of the Articles of Ornamental Art in the Museum of the Department Appendix (B), Londres, MarlboroughHouse. [Note de Semper]

2. Voir G. Klemm, Allgemeine Kulturgeschichte der Menschheit [Histoire culturelle universelle de l'humanité, t. IV, Leipzig, Teubner, 1845: 261 sq.] - section sur les habitants des îles des mers du Sud et passim. [Note de Semper]

3. La notion de greffe est ici tirée du vocabulaire de l'horticulture; le même verbe impfen possède aujourd'hui le sens d'inoculation et de «vaccination». [NdT]

4. "Leurs cavaliers, au nombre de quinze mille, étaient magnifiquement parés; leurs casques se terminaient en gueules béantes et en mufles de bêtes sauvages: surmontés de hauts panaches semblables à des ailes, ils ajoutaient encore à la hauteur de leur taille. " (Plutarque, "Vie de Marius", 27, in Les Vies des hommes illustres, trad. Ricard, Paris, Furne, 1840.) [NdT]

5. Voir G. Klemm, Allgemeine Kulturwissenschaft [Science universelle de la culture], 2 t., Leipzig, Brockhaus, 1854, passim. [Note de Semper]
6. L'histoire de Shakuntala, aimée puis abandonnée par le roi Dushmanta relatée dans le Mahabharata ou encore dans La Reconnaissance de Shakuntala de Kalidasa (Ive ou ve s. ap. J.-C.), connut de multiples adaptations en Europe au XIXe siècle. [NdT]

7. À supposer que le récit qui les concerne soit authentique et ne se rapporte pas plutôt au Tabernacle de David. [Note de Semper]

8. Ramayana I, p. 605. [Note de Semper]

9. Le Periplous était le récit de voyage d'un géographe grec de l'Antiquité. [NdT]

10. C'étaient en particulier les tribus résidant le plus loin des côtes occidentales qui se distinguaient dans la pelleterie (Tacite, Germania, 17): " lls choisissent les animaux qui ont les fourrures les plus fines et ils comparent les peaux qu'ils ont arrachées à des petits échantillons réunis en catalogues (maculis) d'autres peaux animales (ou, selon une autre version, de peaux d'animaux marins venues de l'océan du Nord et de la mer inconnue)." Sur ce point, voir supra l'article sur la couture. [Note de Semper]

11. Catulle, éd. d'Isaac Voss, Londres, 1694, p. 190. [Note de Semper]

12. "Serum pelles" (Plin. XXXIV 14). [Note de Semper]
13. Sur les peaux chez les Anciens, voir les intéressantes remarques de Böttiger dans ses Griechische Vasengemälde [Peintures de vases grecs], Magdebourg, Keil, 1800, $3^{e}$ cahier, p. 187 , où l'on peut trouver la bibliographie relative à cette question. [Note de Semper]

14. Cf. Justin III, 29; Ammien Marcellin XXXI, 6, 2. Sur les peaux en Allemagne au Moyen Âge, voir Karl Weinhold, Die deutschen Frauen im Mittelalter [Les Femmes allemandes au Moyen Âge], Vienne, Gerold, 1851, p. 426. [Note de Semper] 


\section{extrait 3}

\section{Quatrième chapitre.}

L'art textile.

Considérations

techniques et

historiques.

Sections 30 à 31.

Notes page 218

\section{§ 30. Le caoutchouc, factotum de l'industrie}

Un matériau naturel important a entraîné, mais seulement à une époque toute récente, une sorte de révolution dans la totalité du vaste domaine de l'industrie, en raison de sa remarquable souplesse, qui lui permet d'être utilisé et de se prêter à toutes les finalités. Je veux parler du Gummi elasticum ou caoutchouc, comme on l'appelle en Inde. Son domaine stylistique est le plus étendu qu'on puisse imaginer, car sa sphère d'action presque illimitée est l'imitation. Ce matériau est pour ainsi dire le singe des matériaux utilitaires. Il est extrait du suc laiteux de plantes tropicales, le Ficus elastica en Inde orientale, d'autres variétés de figuiers à Java, le Siphonia elastica au Brésil et en Amérique centrale, l'Urceolaria elastica dans l'archipel indien, une plante grimpante géante. Les propriétés remarquables du caoutchouc ont été pour la première fois découvertes en Europe par Condamine qui, en 1735, a publié un mémoire sur la question, sans succès à l'époque. Ce n'est que depuis quinze ans environ que ce matériau a commencé à éveiller l'attention des industriels, après avoir été dans un premier temps seulement utilisé pour des jouets et pour le nettoyage du papier. Ses propriétés chimiques ont alors été étudiées; elles ne sont pas moins importantes que ses propriétés mécaniques; les plus significatives sont son indissolubilité et sa stabilité chimique. Aucun acide ne l'affecte, à l'exception des sels de nitrate concentrés; il est seulement soluble dans le naphte et dans certaines huiles essentielles comme l'huile de lavande, l'huile de sassafra, etc. II peut également se dissoudre dans les huiles non volatiles, par exemple l'huile de lin, mais cette association lui faire perdre ses propriétés de séchage. À cela s'ajoutent les propriétés mécaniques de ce matériau, à savoir son élasticité, sa ténacité, son extensibilité, son imperméabilité à l'eau et aux différents gaz, sa légèreté, sa souplesse, sa capacité de durcissement, son caractère lisse, etc. II ne peut pas non plus dépasser son degré naturel de densité; bien qu'il cède à une forte pression, il retrouve toujours sa densité normale; à l'inverse, il est facilement extensible et, dans ce cas, il tend davantage à se solidifier. Enfin, on peut le faire entrer dans des alliages et le teindre.

De ces propriétés spécifiques du caoutchouc découlent ses usages et le style qui doit être observé dans ces derniers. On l'emploie en l'occurrence de trois manières:

1) sous la forme d'une masse solide utilisée en plaques épaisses ou fines ou en formes compactes;

2) sous celle d'un ruban souple pour des bandeaux et tissus;

3) sous celle d'un vernis qui, en séchant, forme en surface une couche solide, dont les propriétés peuvent être variées indéfiniment.

Nous ne nous intéresserons ici, dans un premier temps, qu'aux usages du caoutchouc comme revêtement semblable à du cuir, parce que le deuxième usage ressort du domaine de la filature et du tissage dont il ne sera question

\section{ci-contre}

fig. 12

Détail de caryatide, cadre en ébonite Napoléon III, $x \mid x^{e} s$. Avec l'aimable autorisation de Antiques de Laval. que plus loin, tandis que le troisième est étroitement apparenté à l'industrie de la laque à laquelle nous consacrerons la section qui suit celle-ci.

Le caoutchouc tel qu'il est importé à l'état brut contient quantité d'impuretés qui ont souvent été introduites à des fins malhonnêtes. Pour nettoyer la masse, on a imaginé plusieurs méthodes, parmi lesquelles le 


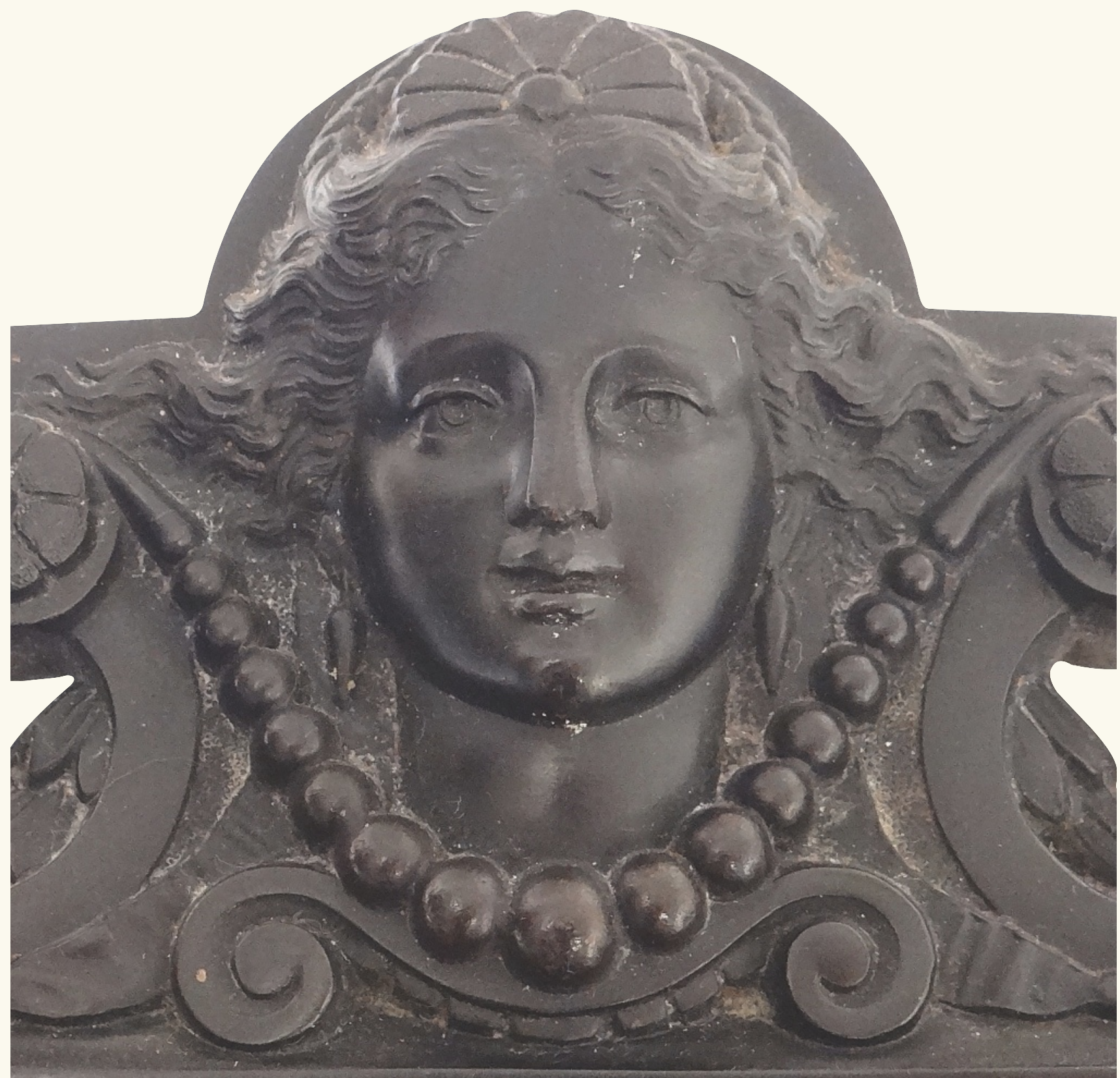




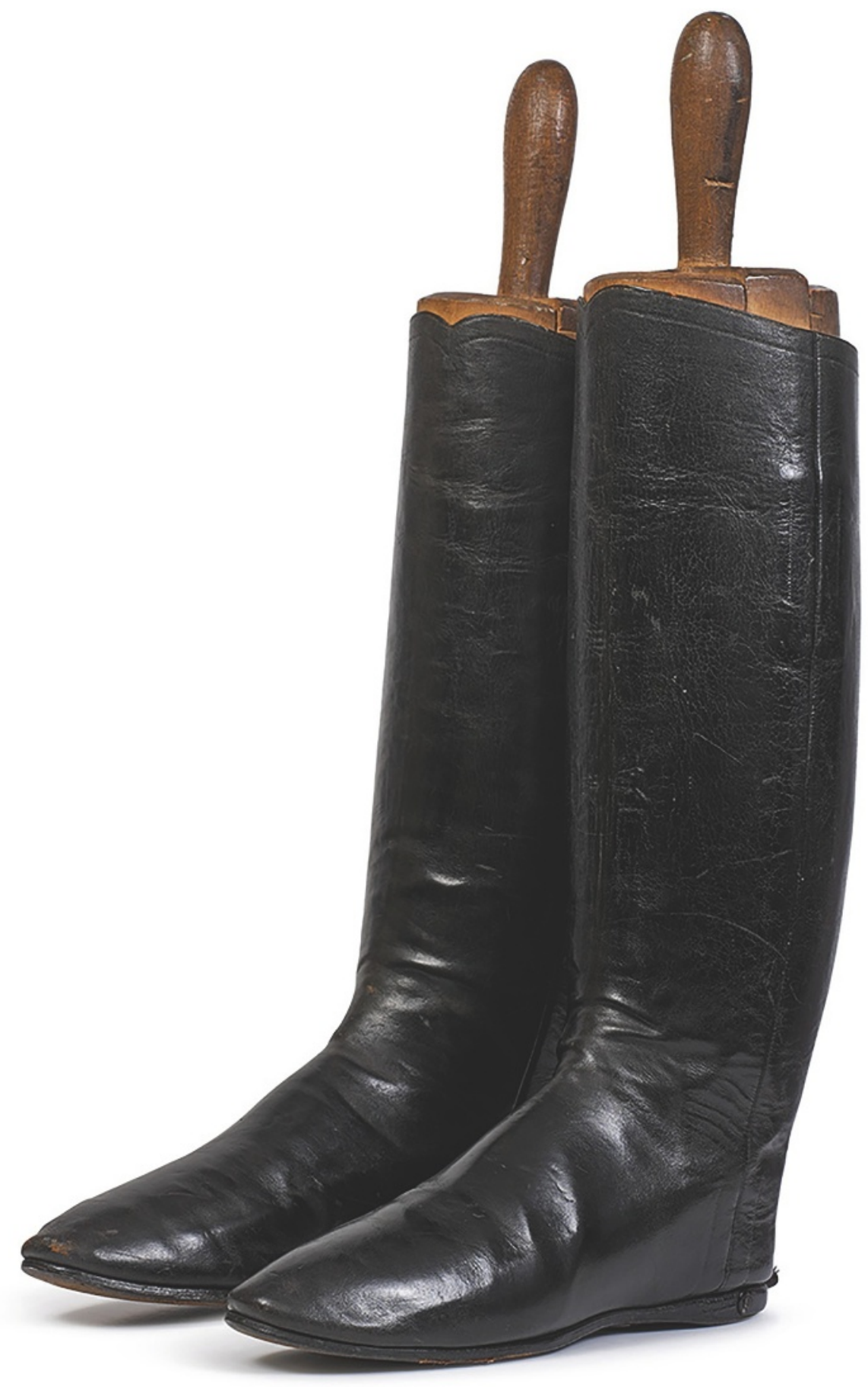


procédé de M. Sievier, ancien directeur de la Joint Stock Coutchouc Company à Tottenham, est réputé le plus fonctionnel. On malaxe et mastique le caoutchouc brut coupé en petits morceaux dans un moulin, d'où il ressort sous la forme d'une masse compacte. Le travail intérieur des morceaux provoque une telle chaleur qu'il faut constamment verser de l'eau sur cette masse, ce qui en même temps la nettoie. La boule ovoïde rougeâtre qui est le résultat de cette première manipulation est ensuite une nouvelle fois malaxée à sec, en ajoutant un peu de chaux vive. La chaleur ainsi produite expulse hors de la masse les parties liquides et rend celle-ci épaisse et noire. Une troisième et une quatrième opération sont réalisées conformément à un principe analogue de mastication, mais en utilisant cette fois une pression très puissante; la masse qui en ressort est enfin assez homogène pour pouvoir être pressée dans des moules de fer parallélépipédiques et dans des formes cylindriques. Les gâteaux ainsi formés, le plus souvent quadrangulaires, font environ 18 pieds de long, 9 pieds de large et 5 pouces d'épaisseur; on les découpe en tranches de l'épaisseur désirée au moyen de machines à découper réglables. Avec ces tranches, on fabrique des tuyaux pour des utilisations chimiques et autres, en soudant les deux bordures en biais, et on les emploie par ailleurs aux usages les plus variés. Cependant, les propriétés naturelles du caoutchouc subissent un préjudice important lorsqu'on le soumet à ces manipulations (par exemple, ce qu'on appelle le «caoutchouc purifié ", le produit de cette préparation, ne peut presque plus être utilisé pour gommer un dessin, car il se ramollit rapidement et devient également friable), sans perdre pour autant ses inconvénients, le fait qu'il se rigidifie sous l'effet du froid et qu'il devienne facilement collant sous l'effet de la chaleur.

Le grand mérite d'avoir supprimé ces deux défauts revient à l'Américain Goodyear qui a volé à l'Anglais Hancock son invention du procédé dit de vulcanisation. Celui-ci rend ce matériau presque insensible à l'influence de la chaleur et du froid. On sature le caoutchouc avec du soufre et on l'expose ensuite à une température de $120^{\circ}$ Réaumur, l'épreuve du volcan pour ainsi dire. Ce n'est qu'avec cette invention que le caoutchouc a acquis toute l'importance qui est la sienne pour l'industrie; c'est à présent un matériau presque inaltérable et qui en même temps se prête absolument à tous les usages, un factotum de l'industrie. Un tout nouveau procédé du même ingénieux Américain a permis de lui donner aussi la dureté de la pierre, la seule qualité qui lui manquait encore; on peut ainsi l'utiliser à bon escient à la place de l'ébène, de la corne et de la lave pour fabriquer des boutons, manches de couteau, peignes, composants de machines, caisses et toutes sortes des meubles, à l'aide de procédures de ce genre, étrangères aux matériaux imités mais qui facilitent considérablement la fabrication des articles et en réduisent le coût. Une propriété du matériau ainsi préparé qui mérite encore d'être particulièrement soulignée est qu'il se prête à être martelé, ce qui le rend encore plus analogue aux métaux; de plus, il peut être poli et possède la particularité de pouvoir adopter toutes les couleurs possibles. Sous ce dernier aspect, une limitation de très bon aloi est imposée par le ton naturel profond qui est celui de la masse: cette tonalité s'associe de façon tout à fait plaisante avec les différents matériaux de couleur employés, incorporés sous la forme de granulés ou de poudre dans la masse un peu translucide, et elle tempère ainsi quelque peu les graves entorses à l'harmonie des couleurs (dont notre industrie occidentale moderne n'a pas conscience et

\section{ci-contre}

fig. 13

Bottes du duc de

Wellington fabriquées par Hoby, deux pièces de cuir de veau noires et semelles en caoutchouc, vers 1817-1852. Photo English Heritage. Photography Relic Imaging Ltd. 
qu'elle ne comprend pas). (Sur ce point, voir § 13.) II faut encore souligner ici la propriété qu'a le caoutchouc préparé de fixer facilement la galvanoplastie et toute autre dorure.

J'emprunte à l'intéressant article du Dr Bucher sur les produits de caoutchouc à la dernière Exposition universelle de Paris, dont je me suis déjà en partie inspiré dans ce qui précède ${ }^{\mathbf{1}}$, la liste d'objets suivante, afin de montrer l'étendue des domaines couverts dès maintenant par cet étonnant matériau, et le degré d'intérêt qu'il ne peut manquer d'éveiller constamment chez les techniciens et même chez les industriels de l'art: on a pu voir à Paris des chaussures à fins clapets qui étaient imperméables à l'eau mais permettaient l'évaporation de la transpiration des pieds à l'intérieur; des vêtements de toute nature; des tapisseries imperméables, dont un modèle crépi de sable de couleur, présenté par Gagin à Clignancourt, prévu pour le revêtement extérieur des murs; des cartes géographiques; des tentes; des pontons; des bateaux de sauvetage; des bouées; des costumes de plongeur; des anneaux pour la suspension des voitures, à la place des ressorts; des cadres de tableaux; des meubles bruts ou plaqués; des selles; des reliures de livres; des petits robinets pour tonneaux, etc. ; des boutons; des arrosoirs; des crosses d'armes; des fourreaux d'épée; des cartouchières; des bobines et d'autres pièces de machines; des peignes de toilette et des peignes de tisserand; des buscs; des tiges pour corsets, parasols et parapluies; des bâtons de marche; des montures de lunettes d'une extraordinaire finesse, souplesse et tenue; des poignées de couteaux et d'outils de toutes sortes; des règles pour boîtes à compas avec indications millimétriques; des hautsreliefs avec et sans dorure; des ornements, des petites boîtes et de la quincaillerie de toute sorte. Même le velours rouge tendu devant les placards et les lacets et la passementerie dorée qui l'ornent sont en gomme! Une utilisation extraordinaire est encore le placage de plaques de caoutchouc sur les bateaux: à la différence des plaques de cuivre, elles ne sont pas sujettes à oxydation et leur élasticité leur permet de bien résister aux insectes et pholades. Des navires pourvus de plaques de ce genre ont quitté l'an dernier des ports américains et français pour de grands voyages. On utilisait déjà par le passé du caoutchouc vulcanisé pour ferrer les chevaux et pour les roues de vélo (qui ne résistent de fait pas très bien en pratique). La nouvelle invention de Goodyear rendra peut-être le caoutchouc plus approprié à cet usage.

Avec un tel matériau, le styliste est dépassé!

\section{§ 31. Le style actuellement dominant dans les produits de caoutchouc}

Parmi tous les matériaux, si l'on songe à toutes ses propriétés et qu'on les fond en une seule, c'est le métal qui présente le plus de ressemblance avec celui qui nous occupe, étant donné la multiplicité des possibilités techniques qu'ils offrent tous les deux. Par suite, il pourrait être pertinent de déplacer ces interrogations sur le style du caoutchouc dans la section consacrée aux métaux. Mais on ne peut complètement faire abstraction du caoutchouc dans la présente section, si l'on songe à la question du revêtement et du traitement des surfaces en général, où ce matériau commence à jouer un rôle très important. Dans ce domaine, il est intéressant de laisser 
dans un premier temps parler l'expérience, qui ne laisse pas d'être instructive, même si l'histoire de l'industrie du caoutchouc n'en est encore qu'à ses débuts. Des points de comparaison sont fournis par les deux Expositions de 1851 et 1855. Les produits de caoutchouc et de gutta-percha ont été très abondamment représentés dans l'une comme dans l'autre, en particulier dans les sections américaines et anglaises, et elles nous renseignent de façon certaine sur l'état de la nouvelle industrie au début et à la fin de cette période de quatre ans. Lors de l'Exposition de 1851 à Hyde Park, cette technique était dominée par le principe consistant à exploiter à l'extrême l'aptitude du caoutchouc à adopter toutes les formes, y compris les plus compliquées; l'insouciance native du caoutchouc devait s'affirmer dans toutes les extravagances possibles et cultivait l'art des pirouettes; les meilleurs articles et études qui avaient alors été consacrés à cette Exposition universelle s'en étaient émus à juste titre. Est-ce l'influence des voix qui se firent alors entendre ou le bon sens des Américains qui a su trouver lui-même sa voie? Toujours est-il que ces derniers, depuis, ont appris à maîtriser le sens du ressort juvénile du caoutchouc ${ }^{2}$; ils ont cessé de se laisser entraîner par la grande plasticité du matériau à choisir des formes et ornements artificiels et inappropriés et ont peut-être même fait preuve, lors de la dernière exposition, d'un excès opposé de conformisme stylistique, en faisant prédominer, même pour les coffrets à bijoux et les autres objets précieux de ce genre fabriqués en caoutchouc, les surfaces lisses, vides de toute ornementation plastique, recouvertes d'une garniture argentée et dorée délibérément sobre; ne recevant ainsi sa parure ornementale que d'un ajout étranger, le matériau lui-même ne se faisait remarquer que par l'extraordinaire uniformité de sa masse, par la douceur de sa couleur noire, par le poli irréprochable de ses surfaces lisses, enfin par sa solidité et son inaltérabilité, manifestées à l'extérieur et pour ainsi dire symbolisées par la simplicité de ses formes.

Le progrès, ici, est incontestable, mais on voit en même temps que les nouvelles propriétés que l'esprit inventif de Goodyear est finalement parvenu à tirer de ce matériau, à savoir sa texture ferme semblable à de la corne, ont influencé ce renversement dans le traitement esthétique du matériau. On s'est focalisé sur la qualité dont la découverte était la dernière en date et celle-ci est devenue prédominante dans tout le domaine technique où ce matériau se prêtait pourtant aux usages les plus divers.

À ma connaissance, beaucoup d'objets utilisant le caoutchouc sous sa forme durcie sont pressés ou coulés dans des moules. Mais aucune procédure formelle n'est suffisamment parfaite pour pouvoir éviter entièrement certains défauts de forme, raccords et autres imperfections du produit; d'un autre côté, l'usage des moules autorise une grande richesse d'ornements sans coûts supplémentaires, à l'exception des frais engagés initialement pour se procurer le moule, et cette richesse d'ornementation des surfaces peut être mise à profit pour dissimuler ou masquer les défauts formels que l'on remarque si facilement sur une surface entièrement plane. Une surface assortie d'applications, un peu sur le principe des beaux vases Henri II moulés produits sur la base de considérations techniques tout à fait analogues (voir la partie sur la céramique, rubrique «Faïence»), n'est donc en aucun cas contraire au style pour une bonne part de ces objets, et il s'ensuit que, dans certains cas, on est fondé à considérer que la simplicité 
affectée dans le traitement du matériau dont il a été question plus haut est une aberration en matière de goût, qui va trop loin dans une direction opposée à la direction initiale.

Ainsi, je ne suis absolument pas favorable aux chaussures de caoutchouc américaines dont la surface est maintenue trop lisse: ce choix revient à ne pas conforter la propriété la plus fondamentale du caoutchouc, celle qui est ici la plus importante avec son imperméabilité, mais au contraire à en perturber l'effet, voire à l'annuler tout à fait en réalité. Une certaine rugosité de la peau artificielle de caoutchouc est absolument nécessaire pour couvrir des organismes vivants en mouvement. Elle tempérerait aussi un peu la lourdeur du pied armé d'une chaussure de caoutchouc, qui le fait ressembler à une jambe de bois et rend actuellement si déplaisant le port de celle-ci.

L'imitation du velours de soie en gomme me semble plus condamnable encore. II faudrait ici tirer parti de l'adaptabilité de la matière pour former des reliefs par pressage et au moyen d'autres procédés, afin de donner vie à la surface qui, en soi, est morte, et ne possède pas de grain naturel ni d'autre décor naturel, pour ainsi dire. Etant donné que, en dehors du pressage, la soudure des parties contribue aussi grandement, dans l'industrie du caoutchouc, à lui faire remplir sa fonction de représentation, les deux procédures devraient être utilisées conjointement dans la décoration des surfaces, et déterminer le style des revêtements de gomme de ce type; en revanche, il faut s'abstenir d'imiter les produits textiles comme le velours, car ceux-ci sont issus de procédures tout à fait différentes de celles qui ont été énumérées.

J'ai déjà souligné plus haut le charme tout à fait particulier qui est attaché au caoutchouc teinté; sur ce point, ce matériau est semblable à la paille, à la cire, au bois et au cuir colorés et aux autres matériaux teintés qui possèdent une teinte naturelle. Celle-ci sert de lien commun entre les couleurs et unifie leurs dissonances; là encore, il ne faut pas laisser inutilisé cet avantage offert à un haut degré par notre matériau, davantage que par tout autre; la soudure permet d'obtenir un système de polychromie charmant pour la décoration des surfaces, auxquelles les reliefs pressés donnent vie (Comparer ce qui précède avec le chapitre «Hyalotechnique» dans la partie sur la céramique).

\section{§ 32. Le caoutchouc est utilisable pour la couverture des maisons}

La nature a cherché à couvrir ses formations organiques de deux manières et ces deux systèmes de couverture offrent à l'homme un modèle pour la confection de ses couvertures artificielles. La protection naturelle des organismes consiste soit dans des systèmes de peau qui forment une surface continue, impénétrable à l'eau et opposant une certaine résistance à d'autres influences extérieures, comme c'est le cas pour les plantes, pour beaucoup d'habitants du monde aquatique, par exemple les dauphins, les baleines, les anguilles, etc., ainsi que pour beaucoup d'animaux terrestres et pour l'homme, soit dans un système d'écailles que l'on rencontre dans beaucoup de formations végétales et chez la plupart des poissons (qui en sont 


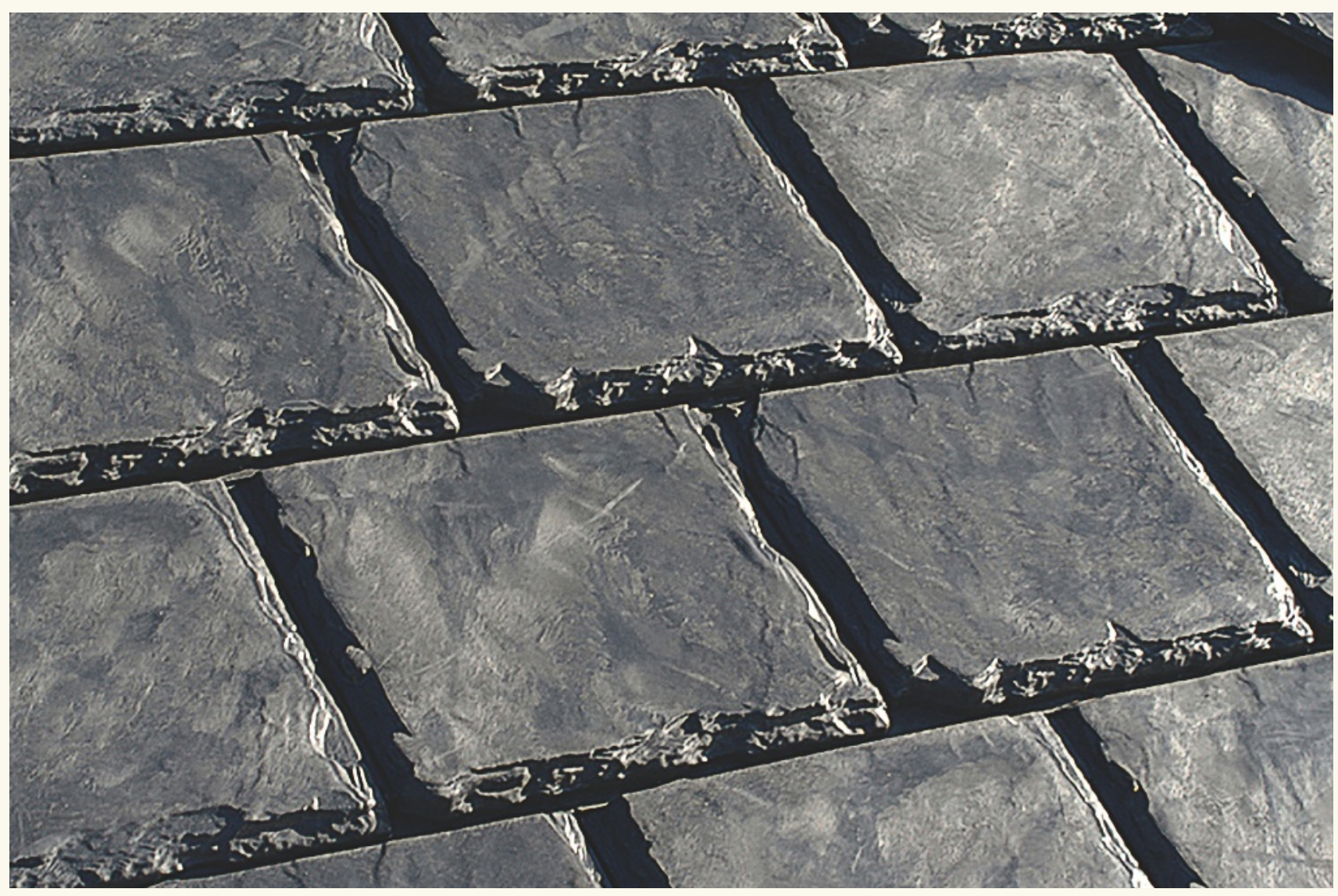

fig. 14

Détail d'un toit en tuiles

en caoutchouc, modèle

Blackstone Euroslate

d'Euroshield $®$ Roofing -

Rubber Roofing. 
les représentants les plus manifestes), qui est aussi à la base des plumes d'oiseau et auquel il faut également ramener, en dernière instance, le pelage des animaux à poils.

Jusqu'ici, nous n'avons pas trouvé de matériau offrant la densité et la souplesse nécessaires pour la couverture extérieure et les toits de nos maisons, si nous nous en tenons au principe cité au début. L'enduit de mortier possède il est vrai beaucoup de propriétés qui le rendent utilisable à cette fin mais, sous nos climats, il n'est pas entièrement suffisant, du moins pour la couverture des toits, si l'on respecte le principe de la continuité des surfaces. (Nous reviendrons sur ce point dans ce qui va suivre.) Jusqu'à présent, la couverture d'asphalte n'a pas non plus répondu aux attentes qu'on avait placées en elle de ce point de vue. Avec le caoutchouc et les ersatz moins chers qui restent encore à inventer, nombreux sont ceux qui annoncent là encore une révolution dans la technique de construction des maisons et par suite dans le style de l'architecture, pour autant que celle-ci demeure dépendante de la matière, même si ce n'est plus la matière mais seulement l'histoire qui donne leur raison d'être au système d'imbrication de nos toits et à ceux-ci eux-mêmes. Je doute cependant que le système de la continuité des surfaces dans les toitures extérieures ne se substitue jamais entièrement au système immémorial des écailles, étant donné que celui-ci, sans parler du privilège qui revient à la tradition artistique, possède aussi des avantages matériels incontestables par rapport à l'autre, au nombre desquels il faut surtout compter la facilité avec laquelle les toitures en écaille peuvent être réparées. Dès lors que la toiture en écaille se compose d'emblée de pièces différentes, elle n'a pas besoin d'être entièrement restaurée lors de sa réfection, comme il est nécessaire de le faire lorsque la couverture est continue.

1. Cf. (Lothar Bucher, "Die Pariser Ausstellung " [L'Exposition de Paris]), Nationalzeitung,

15 septembre 1855 . [Note de Semper]

2. Semper fait ici un jeu de mots en référence à un synonyme de Kautschuk, "Federharz", dont il sépare les deux parties (Feder signifie la plume ou le ressort, Harz la résine). [Ndt] 
§56. Teintures, impressions, etc.

La teinture et la coloration des peaux font partie de l'étonnant groupe d'inventions qui ne sont pas nées de la nécessité mais du pur plaisir et qui ont compté parmi les plus anciennes, parce qu'elles ont pour ainsi dire été inspirées à l'homme par l'instinct de joie. Le plaisir de la couleur se développe avant le plaisir de la forme; même l'insecte d'organisation rudimentaire se réjouit de la lumière du soleil; les fleurs éclatantes des champs aiment la flamme et les enfants la lumière.

Les colorants les plus simples, c'est-à-dire ceux que l'on trouve le plus facilement, sont les sucs de plantes; là encore, l'homme à l'état naturel n'observait nulle part des couleurs ajoutées en surface, la couleur était pour lui inséparable de la forme, qu'elle imprégnait. La coloration est plus naturelle et plus facile, et donc plus originelle que l'apposition de couches de peinture. Cette thèse a pour corrélat une dimension très importante de la théorie du style sur laquelle j'aurai à revenir souvent en exposant ma conception de la polychromie dans les arts plastiques des Anciens.

À la pratique de la coloration était parfois associée celle de la teinture, car l'aspiration à pérenniser le plaisir est aussi ancienne que le plaisir.

Nos chimistes sont capables d'expliquer de façon pertinente ou du moins de démontrer expérimentalement que certains sels et bases alcalines réagissent aux substances colorantes en modifiant la couleur de ces dernières, tout en favorisant l'imprégnation des supports par ces couleurs et la véracité de celles-ci. Les avancées les plus récentes de la coloration ont pu grandement tirer parti de ces progrès de la science. Cependant, on peut se demander si, dans ce domaine même, j'entends dans le domaine purement technique de la coloration, la plus haute Antiquité, l'Ancien Empire égyptien et la Chaldée archaïque ne connaissaient pas infiniment mieux les secrets des nuances et de la tenue des colorants que nos manufactures les plus renommées et nos meilleurs préparateurs en bacs chauffés à la vapeur. On peut se demander également si tous les secrets de la nature que nous avons percés à jour et mis en œuvre à cette fin n'étaient pas déjà connus d'eux et s'ils n'étaient pas parfaitement capables d'en faire usage, quand bien même ils proposaient les explications les plus insolites (de notre point de vue) pour les effets qu'ils savaient maîtriser. Pline rapporte sans équivoque possible que les Égyptiens connaissaient l'art de préparer les tissus par des applications de différents colorants qui formaient des motifs invisibles: des motifs multicolores faisaient leur apparition lorsque les tissus étaient extraits des bacs de couleur où ils n'étaient plongés qu'un instant: "Mirumque cum sit unus in cortina colos, ex illo alius atque alius fit in veste, accipientis medicamenti qualitate mutatus, nec postea ablui potest: Ita cortina non dubie confusura colores si pictos acciperet ${ }^{1}$. 》

Nos artistes de la couleur n'ont pas encore élaboré une telle invention: une combinaison d'impression et de coloration avec les couleurs les plus différentes et en même temps les plus intimement apparentées par la nature.

Mais ce ne sont pas ces raffinements de la pratique consistant à décorer de couleurs vêtements et tissus qui doivent, à mon sens, susciter notre extrait 4

Quatrième chapitre.
L'art textile.
Considérations
techniques et
historiques.
Section 56.
Notes page 229




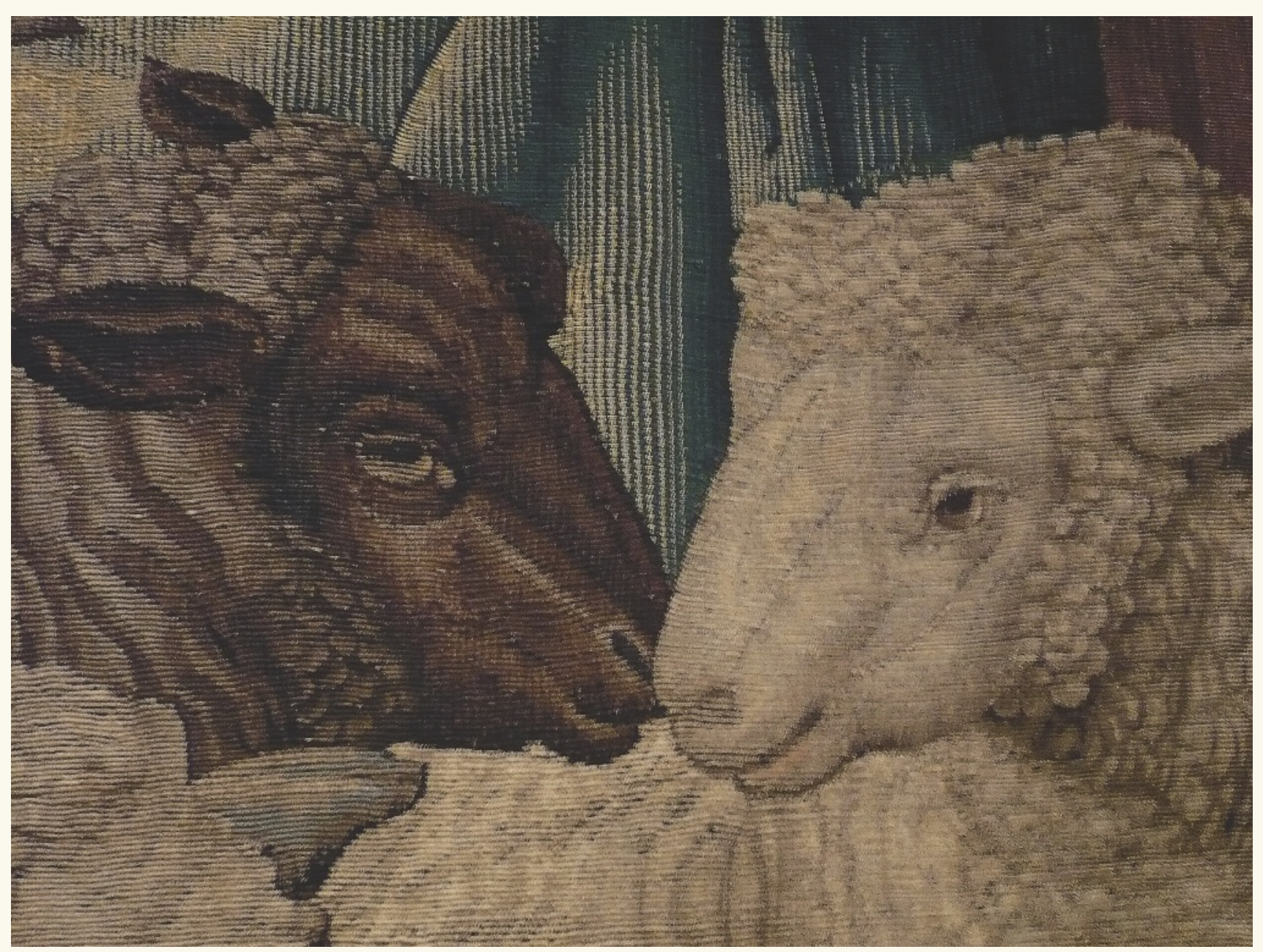

fig. 15

Détail de Histoire de Judith,

tapisserie de Tournai, $x v^{\ominus} \mathrm{s}$.

Musée du Cinquantenaire

Bruxelles. Photo Isabelle

Kalinowski. 
plus grande admiration pour la maîtrise des Anciens; elle se manifestait bien davantage dans l'application claire de quelques principes stylistiques simples sur lesquels ils fondaient une musique de couleurs parfaitement homogène à la musique de leurs formes et dont les accords résonnaient avec cette dernière et la complétaient de la manière la plus admirable.

Notre art moderne de la couleur atteint des sommets dans la préparation des fils colorés de laine, lin, coton ou soie; il permet aux tisserands ou autres fabricants de choisir et d'utiliser à leur guise les fils ainsi préparés; ce faisant, il cherche à obtenir autant que possible les couleurs abstraites dans leur pureté absolue et à les présenter dans toutes leurs nuances d'intensité et toutes les tonalités intermédiaires. L'absolutisme de ce système ignore tous les infléchissements susceptibles d'être apportés par le tissu, et davantage encore par la destination de la marchandise; tout au plus reconnaît-on qu'un type de tissu, par exemple le coton ou le lin, se prête moins qu'un autre, par exemple la laine et la soie, au rendu de telle ou telle couleur; on a dès lors recours à toutes les finesses et astuces de la chimie pour obtenir, en dépit de ces difficultés de restitution, un rouge écarlate ou un orange presque aussi pur et aussi rayonnant sur du coton ou du lin que sur de la laine ou de la soie. En un mot, le style qui dépend du matériau brut et de la destination de l'objet n'est aucunement pris en compte, alors que les variations de style dans les procédures utilisées sont illimitées et infinies, compte tenu de l'abondance exubérante de moyens et de matériaux offerte par la chimie et la mécanique: partant, ce style n'en est pas un.

Nous avons beau redoubler d'efforts et astreindre à cette fin tout notre savoir et notre volonté, nous sommes incapables d'obtenir certaines couleurs que les femmes d'Inde, de Chine et du Kurdistan savent fabriquer avec les moyens les plus rudimentaires et en l'absence de toute connaissance en matière de chimie; la profondeur, la splendeur et les tonalités naturelles indéfinissables de ces couleurs nous ravissent et nous laissent perplexes. La raison en est qu'il s'agit là de tonalités vraiment naturelles qui ne s'accordent pas avec nos échelles de couleur abstraites; elles ne sont pas seulement produites par le colorant mais aussi par le matériau brut qui a été coloré, par le sens naturel du style et l'ingénuité de celles qui les ont fabriquées.

Ces couleurs naturelles aux harmoniques profondes que seul l'Orient, avec ses traditions antiques, produit encore aujourd'hui, toujours associées à une tonalité commune de l'air et qui ne sont jamais de pures abstractions de couleur et n'aspirent en aucun cas à l'être, font écho à ce que nous pouvons imaginer de l'ars tingendi des Anciens. Un souffle naturel unissait l'ensemble du système des couleurs des Anciens qui, indéfinissable autrement, ne peut être décrit qu'à l'aide de comparaisons naturelles; il s'évanouit dès l'instant où on fait trop violence à la nature et cherche à le remplacer par le biais de la chimie. Peut-être y parviendra-t-on un jour, mais pour l'instant, la science n'a pu suffisamment pénétrer les ateliers de la nature pour trouver des substituts à ses produits.

Les Anciens teignaient leurs fils avant de les tisser et de les travailler; lorsque tel n'était pas le cas, le produit fini, par exemple le chiton ou le peplos prêt à être porté, était plongé dans le bac de couleur. 


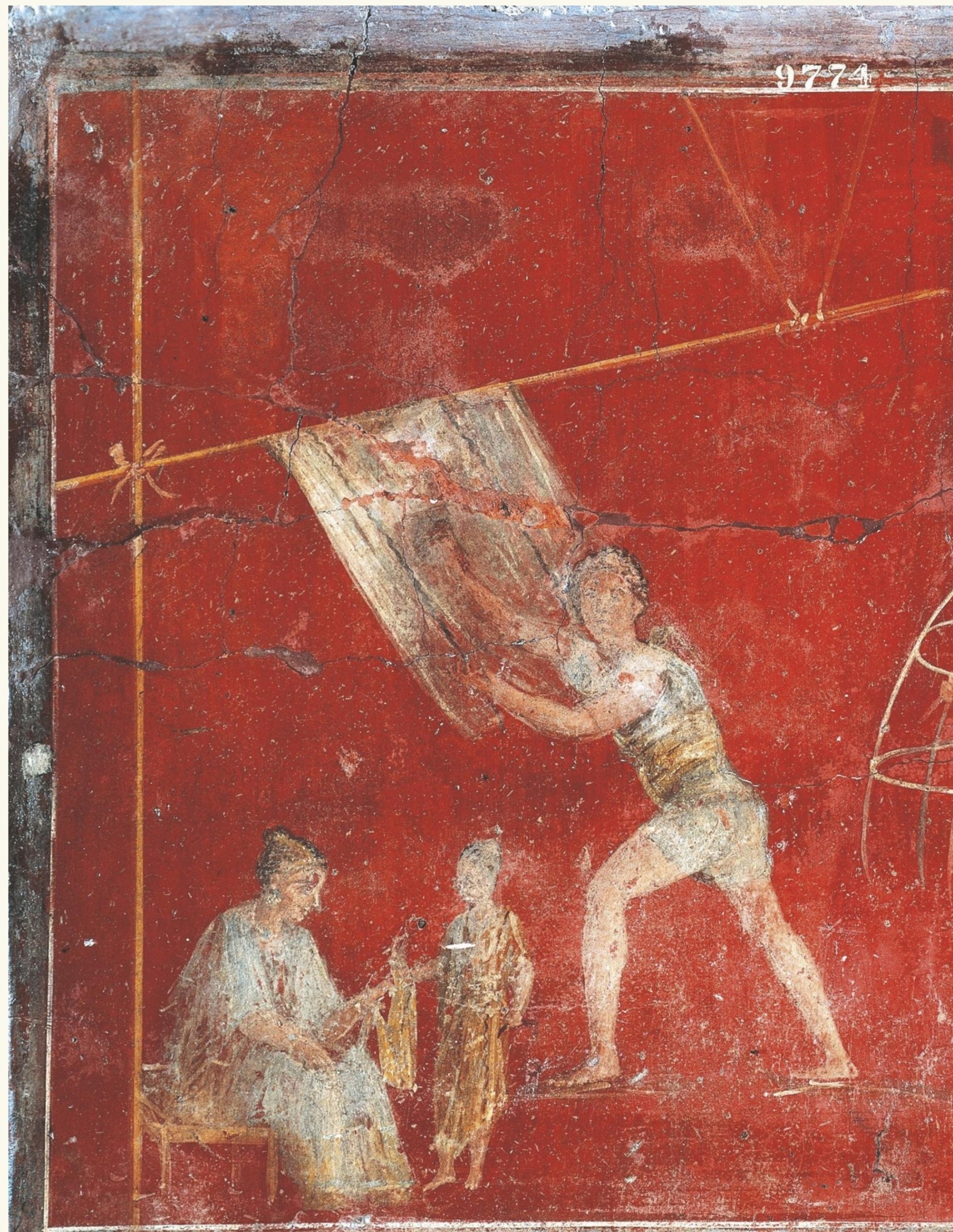


fig. 16

Pompéi, fresque de l'atelier de foulons de Veranius Hypsaeus (Veranio Ipseo): détail de la cage d'osier à soufrer pour blanchir le tissu et apprêtage de la laine, frottée avec de la terre de couleur ou de la craie pour fixer la teinture, ${ }^{\text {er }} \mathrm{s}$. Naples, Museo Archeologico Nazionale. Akg-images / De Agostini Picture Lib. / L. Pedicini. 
Chez les Égyptiens, il était même d'usage de colorer la laine vivante directement sur les moutons par une application de pourpre précieuse; on ne sait pas exactement s'ils n'utilisaient que des colorants externes ou si la nourriture donnée aux bêtes servait aussi à colorer la laine. Dans tous les cas, ils teignaient la laine brute et non blanchie et celle-ci devait donner à la teinture une «teinte» (hue) particulière, un aspect naturel inimitable: on considérait que la tonalité des pigments les plus précieux et les plus purs devait être coupée par le biais de ce procédé naturel extrêmement raffiné. II en allait de même avec le coton et la soie; même le blanc était regardé comme une coloration spécifique et n'était sans doute jamais poussé à l'extrême mais conservait toujours, comme le noir, une nuance de couleur dans un sens ou dans l'autre. Le blanc était pour eux, parmi toutes les couleurs, l'extrême inaccessible sur l'échelle de la dilution, le noir représentait le pôle opposé de l'épaississement et de la concentration. Toutes les tonalités se fondaient dans le blanc comme dans le noir, mais on ne voulait pas aller aussi loin. Voilà pourquoi le blanc fait partie des couleurs pourpres, comme le noir.

Pline énumère plusieurs espèces de moutons connues pour la couleur naturelle de leur laine; la laine noire des moutons d'Espagne, la laine blanche des moutons des Alpes, d'Érythrée et de Bétique, la laine jaune des moutons de Canosa, celle des moutons de Tarente, dans les tons de jaune. On utilisait ces variétés pour des vêtements d'apparat. Seule la laine noire n'était pas teintée.

Même les matières colorantes avaient leurs particularités, on ne cherchait pas à en extraire le colorant pur; on les utilisait avec leur arrière-goût, le "goût de pierre à fusil2" que la nature leur avait donné. Notons que les matières colorantes étaient extrêmement simples, même si, comme on l'a montré plus haut par un exemple, les effets chimiques des acides, des sels et des alcalins n'étaient pas inconnus et qu'on y avait parfois recours.

Deux grandes nuances ou tonalités de couleurs dominaient l'ensemble de la gamme chromatique antique, depuis les temps les plus anciens de la préhistoire. L'une de ces deux grandes tonalités de couleur avait sans doute pour base les iodures métalliques; ce colorant superbe se retrouvait dans les différents organismes marins avec les nuances les plus variées mais les plus naturelles, et pouvait parfois être travaillé pour donner les couleurs les plus opposées, le rouge, le jaune et le bleu, qui sont cependant tous liés entre eux par un seul et même air de famille merveilleusement doux et en même temps profond et austère. Qu'on se promène dans un cabinet réunissant une collection de conchyles et qu'on compare les centaines de tonalités de rouge écarlate, du violet au bleu, du bleu au jaune d'herbe de mer en passant par le vert marin, du jaune au blanc en passant par toutes les nuances, un blanc que l'on peut aussi rejoindre à partir du bleu et du rouge, qui conserve toujours sa «teinte" (hue) de blanc de mer et célèbre sa gloire dans la perle, qui réunit en elle et reflète les trois couleurs fondamentales et toutes les teintes intermédiaires: Iorsqu'on s'est convaincu de la merveilleuse harmonie qui règne entre les couleurs de tous ces produits de la mer, ou qu'on la reconnaît, plus splendide encore, dans la magnificence éternellement changeante des couleurs des fonds marins qui ont donné naissance à tous ces produits, on réalise soudain clairement 
ce que les Anciens entendaient par «couleurs pourpres» et on comprend que le noir, le violet, le rouge, le bleu-vert et le jaune et même le blanc, dans certains cas et dans certaines tonalités, en faisaient partie. Pour la préparation de ces couleurs, les Anciens utilisaient principalement trois substances $^{3}$ : les plantes marines de différentes variétés et deux espèces de coquillages marins; I'un, le buccinum Gr. keryx, était ramassé sur les falaises et les rochers; l'autre, purpura ou pelagia, était capturé dans l'eau de mer avec des appâts. On trouvait l'un et l'autre en grande quantité dans toute la Méditerranée et même dans l'océan Atlantique, ou encore dans le golfe Persique. Selon les lieux de provenance, la qualité de la couleur était plus ou moins grande et les couleurs mêmes variaient. Les coquillages de l'océan Atlantique donnaient la pourpre la plus noire, ceux des côtes italiques et siciliennes donnaient une pourpre violette, les coquillages phéniciens et ceux des mers du Sud une pourpre rouge écarlate.

On dit que les Phéniciens ont été les inventeurs de ce type de teinture; ce sont eux qui ont diffusé le goût et la prédilection pour la pourpre en Europe, en Afrique et en Asie. Ils ne sont aucunement restés les uniques détenteurs de cette industrie, mais, à la faveur des circonstances, ils se sont vus en mesure de le porter à un haut degré de perfection et de conserver leur premier rang. Le tissu le plus approprié pour la coloration pourpre était la laine, mais on parvenait également à teinter de pourpre le lin, le coton et la soie. On commençait par préparer la laine avec le jus du buccinum avant de la plonger dans celui du purpura, qui donnait la pourpre améthyste, très appréciée; ou bien on procédait en ordre inversé et on obtenait alors la splendide couleur du sang épais, qui faisait la gloire et la fierté des teinturiers de Tyr! Les tissus ainsi teintés étaient appelés purpurae dibaphae. À ces deux variétés de pourpre royale et sacrée et au faux buccinum (qui n'était employé pur qu'à des fins de falsification) s'opposait l'espèce générale du conchyle, qui englobait toutes les tonalités plus claires, tirant sur le bleu ou jaunes. Le processus de coloration était relativement simple, d'après ce qu'on peut en déduire du principal passage de Pline consacré à cette question, qui a été cité plus haut ${ }^{4}$. Cependant, il exigeait quantité de coups de main, notamment pour déterminer jusqu'à quel degré de cuisson une couleur pouvait être portée.

Pour obtenir les couleurs du conchyle tirant sur le jaune, le bleu et le vert, on employait en association avec le jus de pourpre les différentes variétés d'herbe marine et d'autres produits de la mer, ainsi que l'atteste l'allusion de Pline dans la citation ci-dessus.

La seconde grande variété de teinture, par opposition avec la teinture de pourpre, est la teinture végétale (colores herbaceae), qu'il vaut peut-être mieux appeler teinture terrestre d'après une autre appellation de Pline, dans la mesure où des animaux, par exemple les chenilles kermès, sont aussi utilisés dans la préparation des couleurs et où l'antithèse avec le genre précédent de teinture avec des produits de la mer est mieux perceptible. Ces couleurs terrestres conservaient elles aussi leur tonalité naturelle et on se gardait de distiller une substance colorée abstraite à partir des produits naturels et de leur faire perdre ainsi toute leur individualité. 
ci-contre

fig. 17

Paul Poiret, Atelier Martine,

Les Eucalyptus, 1914.

Impression au cylindre,

$106 \times 79 \mathrm{~cm}$. Paris,

Bibliothèque Forney. Photo

(C) Bibliothèque Forney

Roger-Viollet.
On a aussi tenté de mélanger et de marier les deux types de teinture; par exemple, on préparait de la pourpre de Tyr avec du coccus, et on en tirait une couleur appelée hysginum. ${ }^{5}$ Mais Pline blâme ce raffinement excessif.

Ainsi, les tissus artificiellement colorés étaient rattachés entre eux et avec la nature par un double lien, dans la mesure où celle-ci apposait sa marque spécifique dans le tissu et dans les couleurs. Par ce moyen, les disharmonies pouvaient facilement être évitées, tandis que les effets les plus splendides d'équilibre comme de contraste entre les couleurs étaient facilités et préparés. Ce principe classique de la teinture se reflète clairement dans les désignations des nuances de couleur les plus appréciées pour les vêtements, tapis et autres textiles. Les désignations abstraites de couleur, comme rouge, noir, jaune, vert, etc., sont rares; la couleur a toujours pour modèle un phénomène naturel particulier. De ce point de vue, la description que nous donne Ovide du Longchamp romain sur les rives du Tibre est particulièrement significative ${ }^{6}$ : «Le plus beau printemps, sous le doux ciel de la Lusitanie, ne pouvait revêtir les campagnes de couleurs plus variées et plus belles qu'il ne pare aujourd'hui les champs des bords du Tibre, lorsque le printemps invite nos belles à la promenade. Les noms nous manquent pour distinguer toutes ces couleurs. La myrte de Paphos ou les feuilles plus sombres du chêne, l'amandier, les graminées doivent donner leur couleur et leur nom à la laine. La rose blanche doit se voir supplantée. On peut voir ressortir ici la couleur de l'air quand il n'est troublé par aucun nuage, et le regard glisse ensuite de cette couleur à celle de l'eau. C'est là que surgit, certain de tout renvoyer dans l'ombre, semblable à la déesse du matin couvert de rosée, le rouge plus léger, avec à sa suite la couleur de la toison d'or et celle, profondément saturée, de l'améthyste. La ronde des nymphes dans leurs atours innombrables n'a pas une telle variété de reflets: toutes les déesses de la mer, des sources, des forêts et des montagnes se sont réunies, et toutes les couleurs auxquelles elles président ainsi qu'à la nature ${ }^{7}$. "

II faudrait encore ajouter bien des remarques sur les teintures de l'Orient actuel qui, de façon générale, ne se sont pas trop éloignées de la tradition antique; par opposition à celles-ci, il y aurait également beaucoup, beaucoup à dire sur l'harmonie des couleurs européennes modernes dans les arts techniques et leur principes, à supposer qu'on puisse parler ici de principes; mais, pour les raisons déjà évoquées, je laisse à de plus compétents que moi le soin de s'en charger et je me contente de remarquer encore que l'influence de la teinture sur la polychromie dans les arts plastiques et les monuments des Anciens ne sera pas ignorée dans ce qui va suivre ${ }^{8}$.

On trouvera des remarques très utiles sur la parure ornementale et colorée des différentes étoffes et les errements du goût qui la régissent dans le «Rapport supplémentaire» de Redgrave où il est question de "garment fabrics ${ }^{9} »$ [étoffes vestimentaires]. 


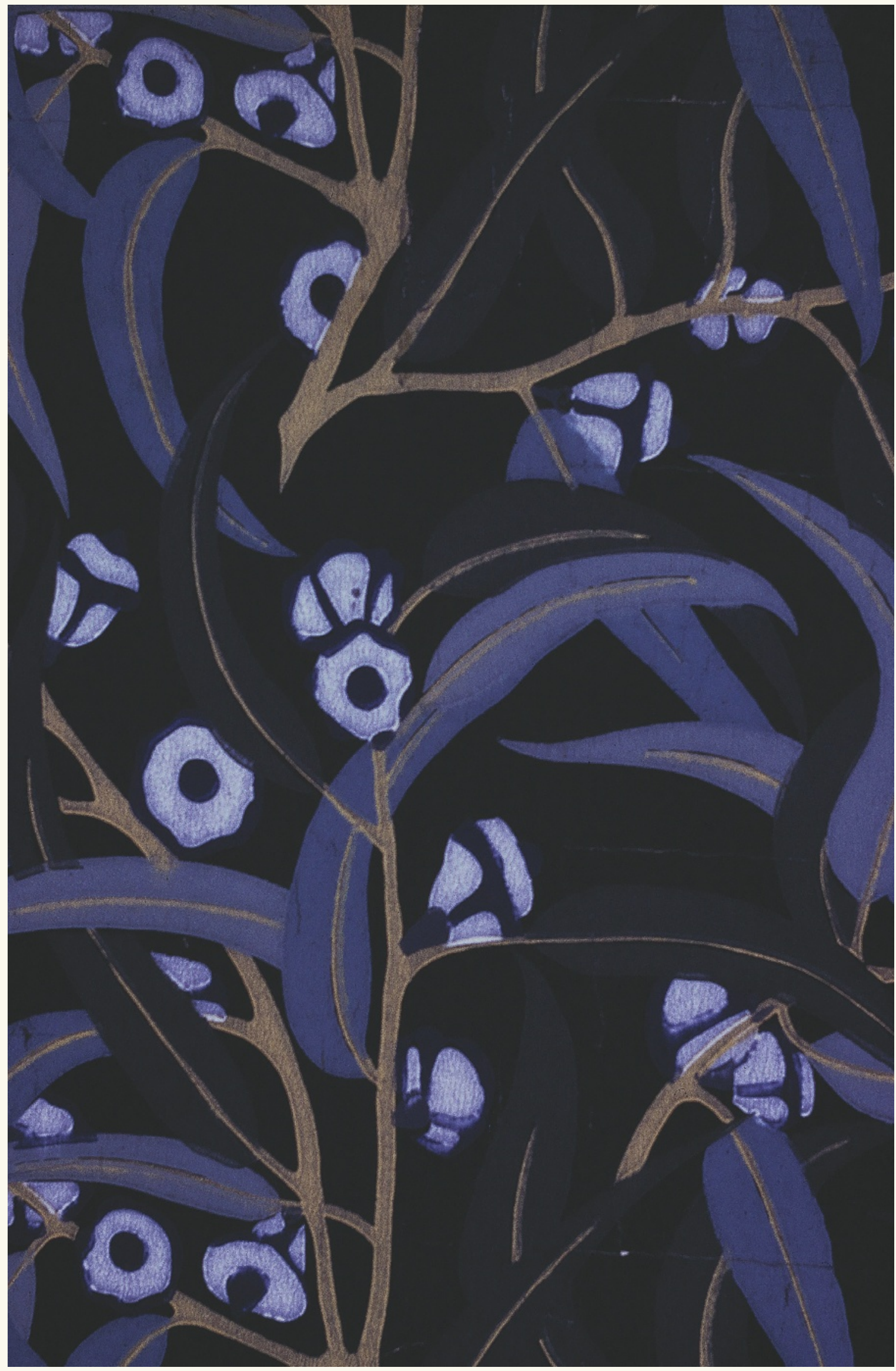




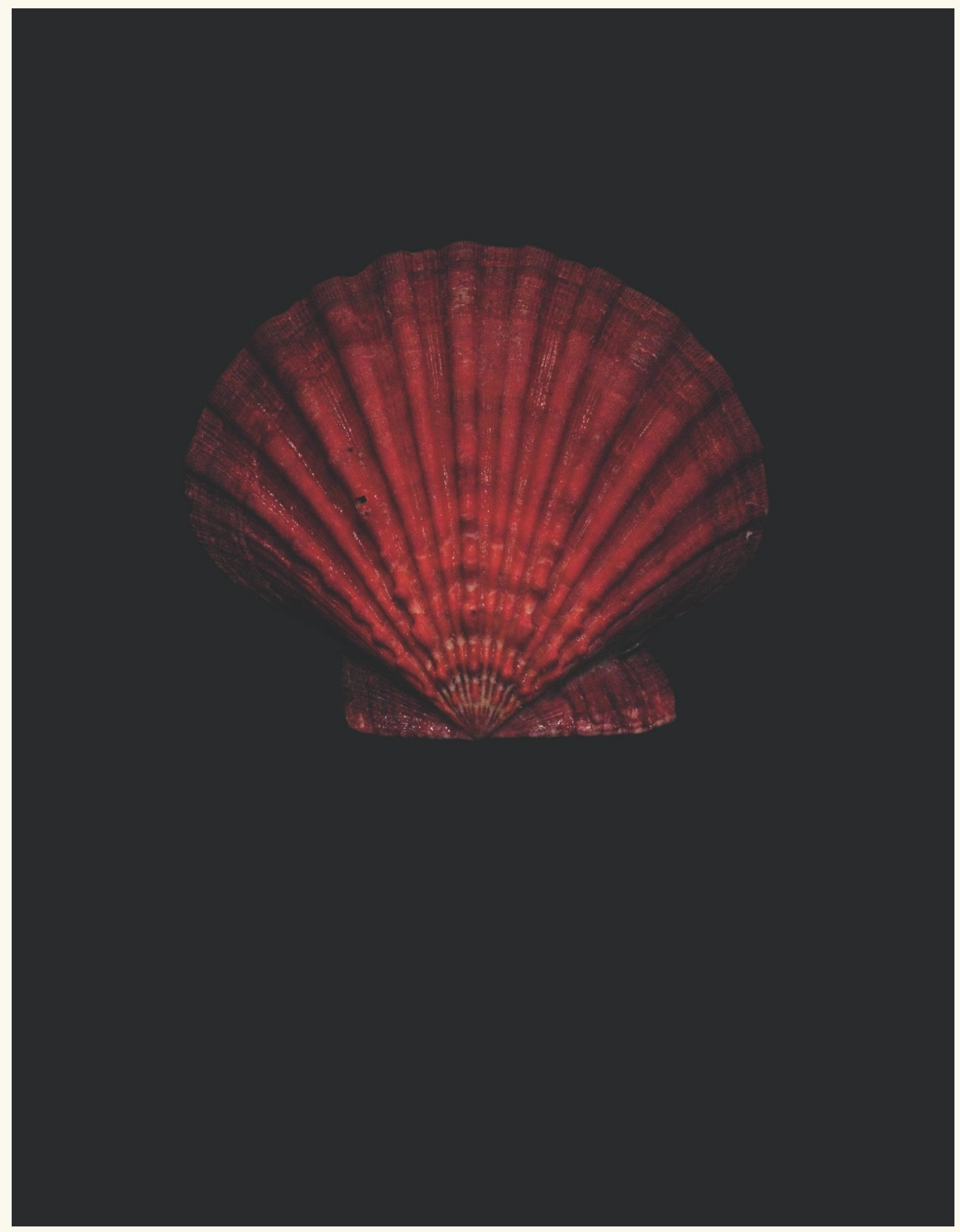


1. Pline, Histoire naturelle XXXV, 42

[Note de Semper]

Nous citons ici, pour plus de clarté, la traduction française du passage complet par Émile Littré : «En Égypte on teint les étoffes par un procédé fort singulier. Blanches d'abord, on les foule, puis on les enduit non de couleurs, mais de mordants, qui ainsi appliqués n'apparaissent pas sur les étoffes; alors on plonge celles-ci dans une chaudière de teinture bouillante, et on les retire un instant après entièrement teintes: ce qu'il y a de merveilleux, c'est que, n'y ayant qu'une seule couleur dans la chaudière, l'étoffe qui en sort est de différentes couleurs, suivant la nature des mordants; et les couleurs ne peuvent plus être enlevées par le lavage. Ainsi la chaudière, qui sans aucun doute aurait fait une seule couleur de plusieurs si on y eût plongé des étoffes déjà peintes, en fait plusieurs d'une seule. " (Histoire naturelle de Pline, avec la traduction en français par M. E. Littré, t. II, Paris, Firmin Didot, 1877 : 486.) [NdT]

2. En français dans le texte. [NdT]
3. Pline, Histoire naturelle IX, 36: «Sed unde conchyliis pretia? quis virus gravis in fuco, color austreus in glauco, et irascenti similis mari? " [Wilhelm Adolf] Schmidt, [Die griechischen Papyrusurkunden der königlichen Bibliothek zu Berlin, Berlin, 1842] formule l'hypothèse que Pline faisait ici allusion à la puanteur de ces couleurs: on laisse au lecteur le soin de décider de la pertinence de cette lecture. [Note de Semper]

Nous citons ici une traduction en français de 1830 , en reprenant le début du paragraphe pour une meilleure compréhension de ce passage: «Devant cette couleur précieuse [la couleur pourpre] les faisceaux et les haches romaines écartent la foule. Elle est la majesté de l'enfance; elle distingue le sénateur du chevalier ; au pied des autels, elle fléchit les dieux; nos vêtements empruntent d'elle leur éclat;

elle se mêle à l'or dans la robe triomphale. Excusons donc la folle passion qu'elle inspire. Mais d'où les couleurs conchyliennes tirent-elles leur prix? À la teinture, leur odeur est infecte: elles contristent la vue par leur aspect verdâtre et leur couleur de mer irritée. " (Histoire naturelle de Pline, trad. nouvelle par M. Ajasson de Grandsagne, t. VII, Paris, Panckoucke, 1830.) [NdT]

4. Sur la pourpre dans l'Antiquité, voir [Pasquale] Amati, De Restitutione purpurarum, Cesena, Blasini, 1784, $3^{\ominus}$ éd. qui comprend en annexe les essais de [G. P.] Capellius, De antiqua et nupera purpura, [Venise, 1775] et de Don Michaele Rosa, Dissertazione delle porpore e delle materie vestiarie presso gli antichi, 1786; [Arnold Hermann Ludwig] Heeren, Ideen [über Politik, den Verkehr und den Hande der vornehmsten Völker der Alten Welt, Göttingen, 1793], $1^{\text {re }}$ partie, $2^{\mathrm{e}}$ section p. 88; A. Th. Hartmann, Die Hebräerin am Putztisch und als Braut, [Amsterdam, Ziegler, 1809-1810], $1^{\text {re }}$ partie, p. 367 ; W. A. Schmidt, op. cit.

Pour ce qui est des leçons et de la compréhension du texte de la notice de Pline sur les variétés de couleur pourpre et leur préparation, malheureusement corrompu, je ne suis pas d'accord sur tous les points avec M. Schmidt. Mais ces questions n'entretiennent pas de lien direct avec le principe esthétique que j'ai présenté dans le texte, dont l'exposé m'importe seul ici : c'est la raison pour laquelle je ne les aborderai pas ici mais reviendrai sur ce point dans les remarques conclusives de cette section. [Note de Semper]

5. Le rouge turc ou quelque chose d'approchant.

[Note de Semper]

6. Semper cite ici non

Ovide mais un manuel de vulgarisation du pédagogue protestant berlinois Johann Heinrich Ludwig Meierotto (1742-

1800), qui avait composé un livre de lectures latines à destination de ses élèves, Über Sitten und Lebensart der Römer in verschiedenen Zeiten der Republik [Des mœurs et du mode de vie des Romains à différentes époques de la République], 2 t., Berlin, Mylius, 1776. L'ouvrage proposait une paraphrase en langue allemande de textes latins dont la référence était donnée en marge ou en note: pour animer son propos, il lui donnait dans le passage cité par Semper la forme d'un dialogue entre deux Romains, Plinius et Regulus. II est significatif que Semper présente ici comme un texte d'Ovide ce qui est plutôt une variation très libre à partir de passages de L'Art d'aimer (III, 165 et III, 199), tout en prenant soin de

préciser exactement

sa source. Le livre de Meierotto rappelait avec beaucoup d'insistance

l'opposition entre la "simplicité" des premiers temps de la République et la décadence du goût survenue par la suite, sous le signe du "luxe»: la troisième partie du volume cité par Semper s'intitulait « Histoire du luxe " et le dialogue entre Plinius et Regulus était sous-titré "Considérations sur le luxe des personnes privées sous les empereurs du ${ }^{\text {er }}$ siècle".

Il est utile de citer ici le début du texte où est justement évoquée la pourpre: "Je dois également avouer que tout en trouvant splendide une telle parure [il était question précédemment d'une parure de perles et de pierres précieuses], tout comme la pourpre, je ne les trouve pas belles. À elles seules, les règles du bon goût me

l'interdisent en effet. En revanche, Pline! tu devrais voir les vêtements de nos femmes. Le plus beau printemps, etc. " [NdT]

7. J.H.L. Meierotto, op. cit., t. II, p. 213; [Joannes Georgius] Graev[ius] Thes[aurus] a[ntiquitatum] $R$ [omanarum], Volumen Tertium, Venise, Javarina, 1732, p. 1310 sq. ; Ovide, De Arte am[andi], III, p. 169. [Note de Semper]

8. On trouvera dans les articles concernés des journaux polytechniques les plus connus un inventaire et parfois des extraits de la très riche littérature relative aux teintures et à tout ce qui s'y rapporte; elle se cantonne cependant toujours aux questions techniques. Voir aussi [Michel Eugène] Chevreul, Farbenharmonie in ihrer Anwendung... deutsch von einem Techniker Stuttgart, 1840. Un très bon essai sur la teinture figure dans Sheridan Muspratt, Theoretische, praktische und analytische Chemie in Anwendung

auf Künste und Gewerbe. Frei bearbeitet von F. Stohmann, t. I, Braunschweig, Schwetschke \& Sohn, 1856. [Note de Semper]

Semper citait la traduction allemande du livre de Michel Eugène Chevreul, De la loi du contraste simultané des couleurs et de l'assortiment des objets colorés considérés d'après cette loi dans ses rapports avec la peinture, les tapisseries des Gobelins, les tapisseries de Beauvais pour meubles, les tapis, la mosaïque, les vitraux colorés, l'impression des étoffes, l'imprimerie, l'enluminure, la décoration des édifices, l'habillement et l'horticulture, Paris,

Pitois-Levrault, 1839. Michel Eugène Chevreul (1786-1889), directeur de la manufacture des Gobelins, montrait dans ce mémoire de 750 pages que la difficulté d'obtenir des couleurs stables provenait du fait 


\section{extrait 5}

Quatrième chapitre. L'art textile. Considérations techniques et historiques. Section 59.

Notes page 241
Le principe du revêtement a exercé en tout temps et chez tous les peuples une grande influence sur le style de l'architecture et des autres arts

\section{§59. Généralités}

Dans la troisième grande section, nous avons déjà évoqué à plusieurs reprises le fait que la plupart des symboles décoratifs dans l'architecture trouvaient leur origine dans les arts textiles et en étaient dérivés; ces considérations ont préparé celles qui vont suivre à présent, quant à l'influence profonde et universelle de ces arts et des éléments couvrants et liants qui en font originellement partie sur le style et l'identité formelle des arts et de l'architecture en particulier. On pourrait s'étonner de ne pas rencontrer, dans toute la littérature sur les arts, une seule tentative sérieuse pour traiter cette question aux conséquences si décisives, puisqu'elle fournit la clé de beaucoup d'énigmes de la théorie de l'art et la quintessence de la plupart des oppositions et des contrastes que nous rencontrons dans le domaine de l'histoire de l'art en ce qui concerne la forme et le style.

II est vrai qu'il a fallu attendre pour cela les plus récentes découvertes et recherches qui étaient un préalable nécessaire à la résolution générale de cette question. Je veux parler de l'approche toute nouvelle inaugurée par Quatremère de Quincy et qui s'est imposée depuis au terme d'une controverse presque ininterrompue qui a opposé des années durant des savants et des artistes: la thèse de la polychromie de l'architecture et de la sculpture antiques, d'après laquelle ces dernières n'étaient pas exposées à nu, dans la couleur du matériau utilisé, mais recouvertes d'une couche de peinture. Je pense aussi aux importantes fouilles et découvertes menées dans les régions désertifiées où florissaient jadis les royaumes immémoriaux des Assyriens, des Mèdes et des Babyloniens; aux représentations et descriptions plus précises de monuments artistiques connus auparavant et aux importantes découvertes de monuments nouveaux dans les régions de la Perse, de l'Asie Mineure, de l'Égypte, de la Cyrénaïque et de l'Afrique. Enfin, je mentionnerai les recherches non moins importantes menées au cours des vingt dernières années dans le domaine de l'art médiéval, aussi bien chrétien qu'islamique.

Le résultat le plus significatif de ces conquêtes toutes récentes dans le champ de l'histoire de l'art est l'effondrement d'une théorie savante obsolète qui était infiniment préjudiciable à la compréhension du monde des formes antiques, celle qui considérait que l'art grec avait poussé à l'origine sur le sol de la Grèce comme une plante indigène, alors qu'il n'est que l'efflorescence magnifique, la finalité dernière, le produit ultime d'un principe de formation ${ }^{1}$ extrêmement ancien dont, pour ainsi dire, les racines plongent et sont profondément ancrées dans le sol de tous les pays où se sont constitués depuis des temps très anciens des organismes sociaux.

La coupure et la séparation qui ont ainsi été opérées entre l'Antiquité classique et le tableau d'ensemble grandiose représenté par le monde antique dans sa totalité, au sein duquel elle ne se détache pour ainsi dire que comme le groupe principal dont l'arrière-plan est indispensable, parce que lui seul la porte et l'explique dans son sens véritable, ont été 


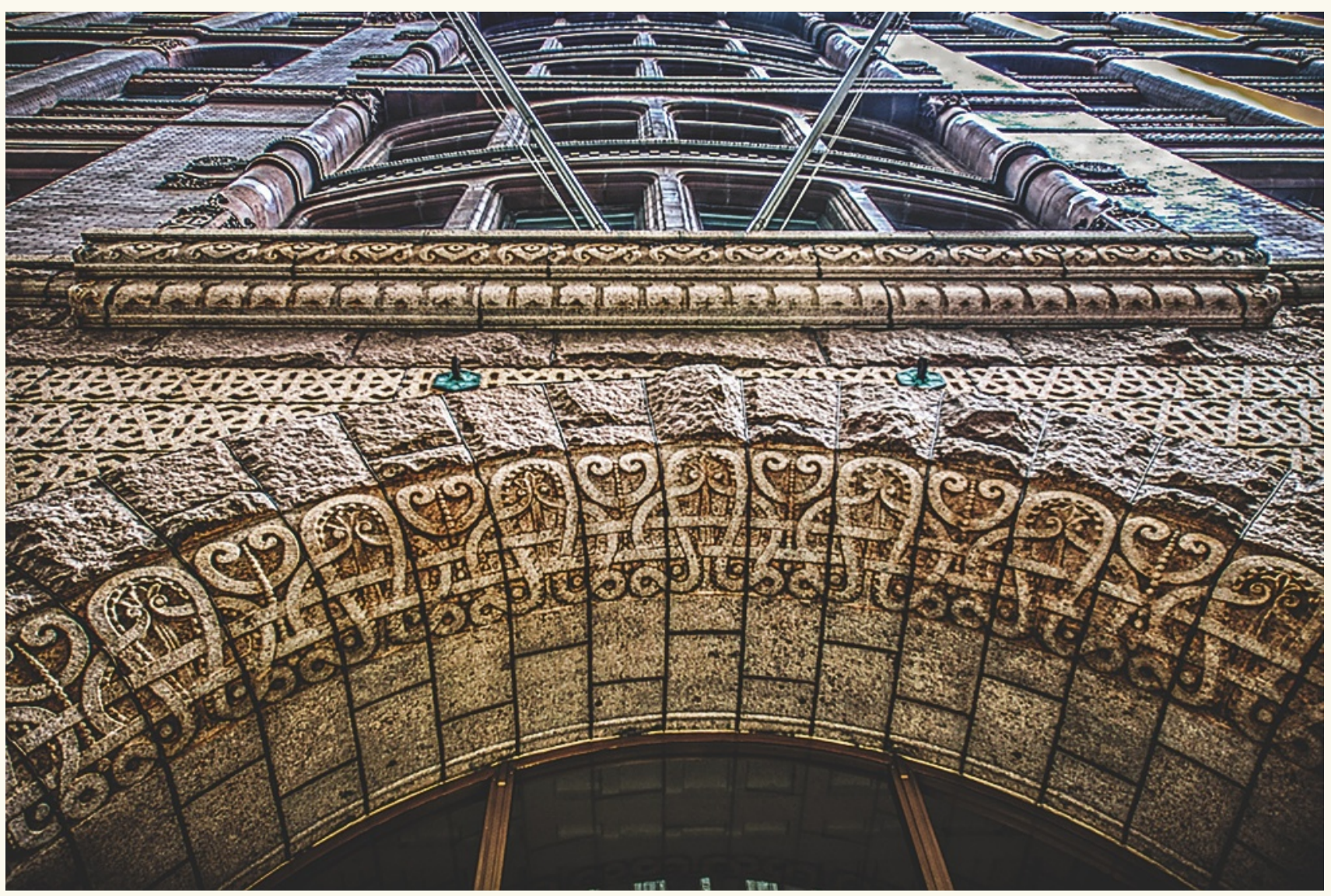

fig. 19

Daniel Burnham, John

Wellborn Root, Rookery Building, Chicago, 1887-

1888, détail du portail

d'entrée de John Wellborn

Root, architecte très

influencé par les théories

de Gottfried Semper.

Photo (c) Ken Ilio. 
très dommageables à une juste compréhension de l'art classique, et on a complètement perdu de vue les rapports de ce tableau fragmentaire avec les parties qui formaient son environnement et l'ont préparé, ses parerga. C'est ce qui explique que beaucoup d'admirateurs du classicisme, chez qui le sens de la grandeur et de la multiplicité dans le beau n'est pas naturel et inné et chez qui l'enthousiasme pour la beauté n'est qu'une pose étudiée, en soient venus, par préjugé et par défaut d'indépendance du goût, à professer un mépris souverain pour l'art dit barbare, oubliant l'admiration que les Grecs eux-mêmes, Hérodote, Xénophon, Ktésias, Polybe, Diodore et Strabon en tête, vouaient à la grandeur et à l'harmonie de ces œuvres barbares. L'unanimité des auteurs grecs de la meilleure époque au sujet des monuments de l'Asie et de l'Égypte aurait dû les éclairer sur la valeur de ces derniers et, en l'absence d'un jugement personnel, ils auraient dû en toute logique prendre ce verdict des Grecs comme critère d'évaluation de ces œuvres. Mais on a l'esprit plus grec que les Grecs mêmes, on surévalue la barbarie des Barbares en pensant qu'ils s'apparentent à une variété de cannibales, alors que le terme de barbarie désigne seulement une opposition qui n'existait pas à l'origine entre l'identité grecque et non grecque et ne fit son apparition que lorsque l'épanouissement de la culture des peuples antiques dans leur ensemble, préparé de longue date, se déploya sur le sol de la Grèce. La langue d'Homère ne connaît pas encore ce terme parce que la notion à laquelle il correspond n'existait pas encore; ce n'est que beaucoup plus tard que la relation entre l'identité grecque et barbare revêtit la forme d'un conflit. L'art grec lui aussi est barbare dans ses composantes et nous devons étudier les éléments barbares à partir desquels il s'est épanoui pour préparer l'étude de l'art grec; il nous faut conjurer Hélène de revenir d'entre les «Mères », en chair et en os, bien vivante et vraie.

Un autre contraste n'est pas moins significatif pour nous: celui du Moyen Âge et de l'Antiquité. Le Moyen Âge qui commence à peine à être mieux connu, avec le romantisme de son architecture et de son art en général, nous ramène par l'intermédiaire des Romains au principe de formation ${ }^{2}$ immémorial; dans le même temps, cependant, il combat celui-ci de la façon la plus résolue; sous ces deux aspects, il est nécessaire à une juste compréhension et évaluation de l'Antiquité. Simultanément, il ne peut être expliqué à partir de lui-même que de manière insuffisante et seule cette comparaison avec l'Antiquité permet de le saisir pleinement.

Le génie créateur des Grecs était appelé à remplir une mission plus noble, un objectif plus élevé que l'invention de types et de motifs artistiques nouveaux; ceux-ci étaient un héritage ancien et demeurèrent sacrés pour eux. Leur mission fut différente, elle consista en l'occurrence à reprendre ces types et ces motifs déjà achevés et fixés d'un point de vue matériel en appréhendant leur expression et leur idée immédiates, telluriques pour ainsi dire, dans un sens supérieur, dans une symbolique de la forme qui a permis que les oppositions et les principes exclusifs les uns des autres et antagonistes chez les Barbares soient réunis et œuvrent ensemble de la manière la plus libre à produire la plus belle et la plus riche des harmonies. Comment saisir ce sens supérieur, comment comprendre la forme grecque, secondaire et composée, sans connaissance préalable de ces composantes traditionnelles, qui obéissent en un sens à des lois de la nature, dans leur signification 
tellurique originelle? Celle-ci doit être préalablement posée avant que nous puissions nous tourner vers la signification supérieure mais dérivée qui lui a été attribuée par les Grecs.

Parmi ces éléments formels de l'art grec issus de traditions anciennes, aucun ne possède une importance aussi profonde que le principe $d u$ revêtement et de l'incrustation, qui domine tout l'art pré-hellénique et n'a pas connu, tant s'en faut, un affaiblissement ni une disparition dans le style grec, mais y a seulement été spiritualisé à un degré élevé et s'y perpétue dans un sens qui relève davantage de la symbolique de la construction que de la technique de la construction; il y est placé au seul service de la beauté et de la forme.

L'explication plus détaillée de cette opposition ne pourra être donnée que dans le cours de cette section qui porte justement sur l'important principe du revêtement et de l'incrustation comme élément des arts plastiques.

II s'en est fallu de peu que l'œuvre du plus grand historien de l'art français et connaisseur de l'Antiquité, le Jupiter olympien de Quatremère de Quincy ${ }^{3}$, ne résolve une question hautement importante pour la compréhension de l'art antique dans sa totalité; il lui apporte une solution partielle, qui n'est pas encore assez générale et ne touche pas encore assez aux principes: elle porte en l'occurrence sur le contenu particulier auquel il s'intéresse, à savoir la sculpture grecque.

Si le célèbre auteur de cet ouvrage avait démontré le lien intime entre la prédilection pour les statues colossales polychromes et chryséléphantines à l'époque de la floraison de la Grèce et le très ancien principe universel de l'incrustation, répandu aussi en Grèce, qui n'était pas seulement en vigueur dans la sculpture mais aussi dans l'architecture (et qui ne déterminait pas seulement la décoration, en l'occurrence, mais aussi l'essence la plus intime de cet art), s'il avait montré que, parmi d'autres matériaux employés pour les incrustations, bois, métal, terre cuite, pierre, stuc, etc., l'ivoire coloré était lui aussi en usage pour la même finalité depuis les temps les plus reculés, et que, de surcroît, c'est de l'application de cet usage à la sculpture en grand format qu'étaient issues les statues chryséléphantines, il serait parvenu à des résultats encore plus importants et d'une portée plus générale que ceux que contient déjà son remarquable traité: il y suit en fait le procédé exactement inverse en démontrant que c'est le projet de sculpter des statues colossales en ivoire ou dans des matériaux analogues qui ne peuvent pas être obtenus en grandes quantités qui conduisit nécessairement à la technique dont la description et le renouveau lui apparaissaient comme la finalité principale de son travail ${ }^{4}$.

Même si, ne serait-ce que de ce point de vue, cet ouvrage n'est pas satisfaisant pour les intérêts qui sont les nôtres, il est cependant de la plus haute importance pour nous, notamment en raison de son orientation pratique, en vertu de laquelle, pour ainsi dire, la forme ne nous est pas imposée d'emblée comme un objet fini, d'après l'école de l'idéalité esthétique; la compréhension de la forme artistique et de la haute idée qui vit en elle s'ouvre à nous, l'une et l'autre sont traitées comme inséparables double page suivante

fig. 20

Le Carson, Pirie, Scott and Company Building à Chicago, détail des terracotta, arch. Louis Sullivan, 1899-1903/04. Photo (C) Steve Minor. 


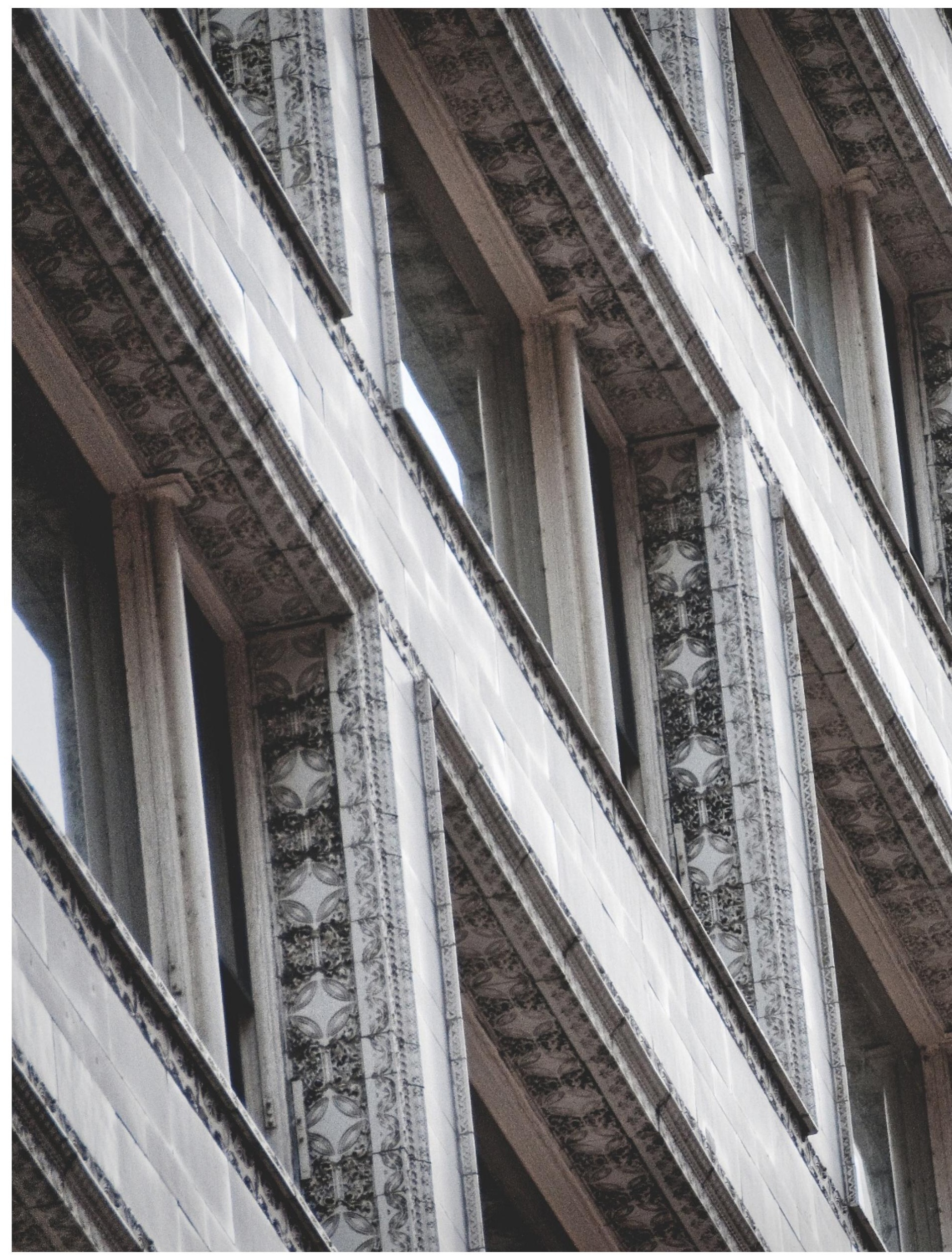




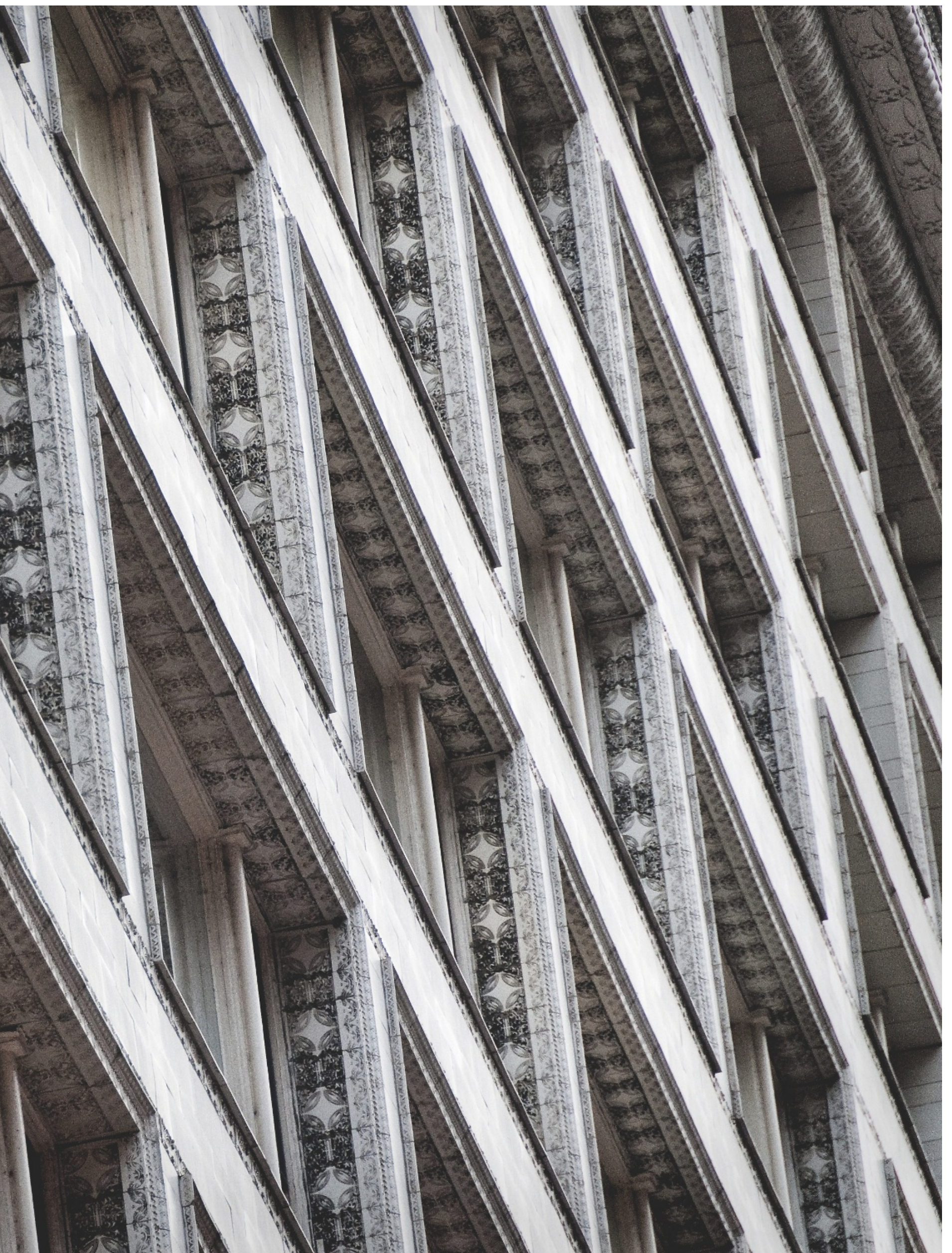


du matériau et de l'exécution technique, et l'auteur montre que l'esprit grec s'est justement révélé dans la maîtrise la plus libre de l'un et de l'autre, ainsi que de la tradition ancienne devenue sacrée.

À peu près au même moment que le Jupiter olympien ou peu de temps auparavant est paru le grand ouvrage sur l'Égypte qui a été le résultat des travaux des savants et artistes qui ont accompagné l'expédition de Bonaparte dans ce pays. Ce livre contient beaucoup de représentations de monuments polychromes et incrustés et, en ce qui concerne l'objet qui nous occupe, les passages qui s'y réfèrent dans le texte accompagnant les illustrations sont encore plus instructifs que ces dernières, bien souvent peu fiables et non fidèles du point de vue du style. De façon générale, cependant, cet ouvrage est resté sans effet sur la conception générale de la technique artistique antique, parce qu'on se refusait à admettre, du fait des préjugés alors dominants, l'existence d'un lien entre l'Égypte et l'art grec. Les publications importantes qui ont été éditées par la suite au sujet des monuments de cet énigmatique et très ancien pays ont connu le même sort; elles sont demeurées presque entièrement inutilisées pour la question qui nous intéresse. On s'était habitué à considérer ce pays comme une Chine de l'Antiquité, coupée de tout lien avec le reste du monde cultivé de l'Antiquité, et c'était doublement un tort, car l'Égypte aussi bien que la Chine représentent des maillons très importants dans la chaîne générale des phénomènes qui touchent à l'histoire culturelle et plus particulièrement à l'histoire de l'art.

Après cela, on aurait pu supposer que le bel ouvrage sur Pompéi dont les premiers volumes furent publiés un peu plus tard par Mazois et qui, après la mort prématurée de ce dernier, fut achevé par $\mathrm{Gau}^{5}$, contribuerait d'autant plus à fonder une nouvelle conception de l'art classique dans la totalité de ses manifestations, mais là encore, ce ne fut guère le cas; en effet, même si les peintures murales et d'autres expressions spécifiques de l'art de l'Antiquité se dévoilent ici à nous de façon complète, ainsi que les liens qui les unissent, et même si les relations entre l'art grec ancien et les monuments qui ont ressurgi dans les cités provinciales de la Grande Grèce sont incontestables, on se refuse à y voir davantage que l'expression d'une technique spécifique des Romains datant d'une époque où ceux-ci avaient déjà emprunté une orientation capricieuse, qui n'avait guère plus à voir avec l'art classique antique que les peintures murales et les autres spécificités des monuments de l'Égypte.

Les unes étaient censées remonter à l'enfance, les autres exprimer la décadence d'un art pour ainsi dire retombé en enfance; on n'était en droit de tirer des unes et des autres, pensait-on, aucune conclusion sur ce qu'avait été, en réalité, l'art grec véritable.

Quelque temps après, vers 1830 , Hittorff publia pour la première fois la facture polychrome d'un monument authentiquement grec, provoquant de forts émois dans le monde des antiquaires et déclenchant une remarquable bataille de plumes à laquelle prirent part des artistes et des savants. Ce texte est d'une grande importance pour le thème qui nous occupe: à plusieurs reprises, en effet, il fut à deux doigts de traiter précisément la question qui nous intéresse, même s'il ne le fit pour ainsi dire que par hasard. 


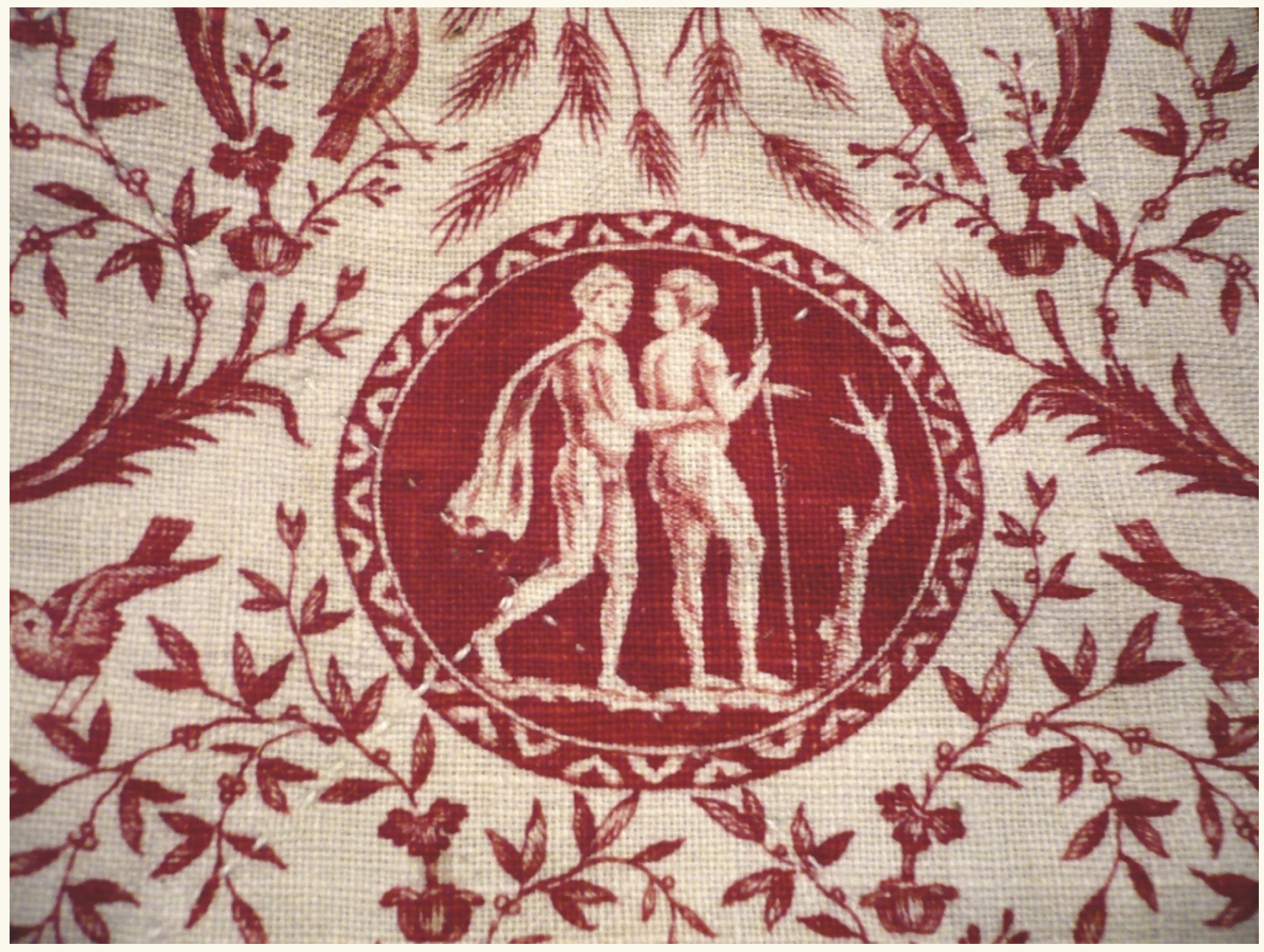

L'histoire de ces débats auxquels a pris part l'auteur du présent livre a été relatée dans tous les détails dans le dernier ouvrage de Hittorff, L'Architecture polychrome ${ }^{6}$; nous y renvoyons et, dans ce qui va suivre, nous aurons maintes fois l'occasion de nous référer à ce volume.

II est cependant impossible de ne pas mentionner ici l'épisode majeur de cette guerre de plumes, à savoir la controverse déclenchée par K.A. Böttiger ${ }^{7}$ qui, en se fondant principalement sur certains passages de Pline, a affirmé que les Grecs de la plus belle époque n'ont peint que sur des panneaux de bois, que la peinture murale proprement dite ne jouissait pas chez eux d'une grande considération et qu'elle n'était pas souvent utilisée dans la décoration des monuments; la peinture murale, selon lui, devait être considérée comme l'une des causes et en même temps comme un symptôme de la décadence de la peinture; ce n'était qu'à l'époque impériale, à Rome, que la peinture murale s'était mise à occuper la place qui lui était attribuée à tort pour la Grèce antique de la meilleure période.

Le partisan le plus acharné de ce point de vue, Raoul-Rochette, qui, ne reculant devant l'emploi d'aucune arme, est monté au créneau pour le défendre avec beaucoup de vivacité dans un certain nombre d'articles fig. 21

Toile de Jouy de la manufacture d'Oberkampf, détail : vignette inspirée d'une peinture murale de Pompéi, vers 1820. Collection particulière, Paris. Photo Isabelle Kalinowski. 
assez courts et de façon beaucoup plus détaillée dans un livre érudit mais de mauvais goût, les Peintures antiques inédites ${ }^{8}$, est combattu par M. Letronne, dont le principal texte relatif à cette question est les Lettres d'un antiquaire à un artiste ${ }^{9}$.

Avec une égale érudition, qui ne le conduit cependant jamais à énoncer des sottises comme c'est souvent le cas pour son adversaire, et davantage d'esprit, Letronne défend le point de vue opposé, en affirmant que la plus grande partie des peintures les plus célèbres qui ornaient les murs des monuments de l'architecture grecque et, plus précisément, les œuvres de l'école de peinture grecque stricto sensu, juste avant et pendant l'époque de Périclès, étaient de véritables peintures murales et non des tableaux ${ }^{\mathbf{1 0}}$. Si les deux protagonistes du débat avaient considéré l'objet qui les opposait du point de vue général de l'histoire de l'art de l'Antiquité et accepté de reconnaître dans le type de décoration des murs par la peinture chez les Grecs et les Romains un principe extrêmement ancien de l'architecture de tous les peuples du monde antique, qui, dans le cadre du classicisme, connut seulement une transformation spécifique, en lien avec l'architecture, et une spiritualisation, sans renier pour autant de quelque façon que ce soit son origine pour ainsi dire pré-architecturale, ils auraient pu, à partir de là, chercher à accorder les passages des Anciens qui traitent de la peinture, les traces d'anciennes peintures murales grecques et les vestiges de l'art romain avec ce que nous enseigne l'histoire des premiers commencements de l'art, et ils auraient pu se tendre la main pour se réconcilier en terrain neutre, devant les œuvres monumentales de Polygnote et de Mikon, de Panénos et d'Onatas, de Timagoras et d'Agatharchos, qui n'étaient pas des peintures de chevalet mais des peintures murales, tout en appartenant en un sens supérieur et de par leur style à la peinture de chevalet. En effet, ces œuvres correspondent à l'époque où le principe du revêtement, de tradition immémoriale, ne fut plus conservé dans l'architecture des Grecs sur un mode matériel mais seulement sur un mode symbolique et spiritualisé, alors qu'aux époques plus anciennes et aux époques plus tardives, et surtout à partir d'Alexandre, le même principe s'affirma sur un mode réaliste plus barbare et entra même en conflit, à Rome, avec un nouveau principe architectural mettant en avant la construction de pierre comme élément définissant la forme. Au lieu de quoi chacun demeura campé sur ses positions; Raoul-Rochette ne vit partout que des tableaux peints sur bois suspendus aux murs d'une façon ou d'une autre; pour lui, les plus grands tableaux de l'école historique n'étaient pas autre chose; il hésitait même à concéder que, dans certains cas et à titre exceptionnel, ils fussent artificiellement encastrés dans les murs; il aurait mieux fait de montrer que, dans leur caractère, dans leur mode de répartition spatiale sur la surface des murs, sinon par leur nature effective, même les peintures murales proprement dites étaient des tableaux de chevalet, ou plus justement des revêtements muraux peints.

II n'est qu'un seul passage de son livre ${ }^{\mathbf{1 1}}$ où il suggère que le lien entre le principe du placage chez les Grecs et les anciennes traditions artistiques de l'Orient ne lui avait pas échappé; mais je doute qu'il ait reconnu la signification décisive de ce facteur, qu'il ne désigne que comme un «point curieux d'archéologie12 ». II renvoie à cette occasion à son Histoire générale de 
l'art des Anciens qui, à ma connaissance, n'est jamais parue. Cependant, Letronne lui non plus n'a pas bien compris ce qu'il fallait faire, moins bien encore peut-être que son adversaire; en effet, au lieu de ne voir que des exceptions dans les occurrences très fréquentes d'authentiques tableaux de chevalet en lien avec la décoration murale, qu'ils soient peints sur du bois, de la pierre, de la terre cuite, de l'ardoise, du verre, de l'ivoire ou du métal, il aurait dû saisir cette occasion pour souligner avec la dernière insistance le lien entre ce phénomène courant pour les périodes ancienne et tardive de l'art grec et la nature du principe de décoration murale chez les Anciens, ainsi que l'essence véritable de l'art classique. II aurait dû dans un premier temps établir un rapprochement entre cette méthode très répandue d'incrustation de tableaux dans les murs et le fait plus frappant encore que toutes les sculptures ornant les monuments des Anciens (sans faire partie des ornements proprement dits) sont fondamentalement et le plus souvent aussi effectivement des plaques encastrées; fort de ce constat, il aurait pu poursuivre son raisonnement.

Cette tradition d'incrustation est de fait répandue dans l'ensemble de l'art grec et régit surtout la nature propre de l'architecture, dans laquelle elle ne se limite aucunement à une ornementation à tendance décorative (tendenziös-dekorativ) des surfaces par la sculpture et la peinture mais détermine de façon essentielle la forme artistique dans son ensemble; l'une et l'autre, cependant, la forme artistique et la décoration, sont si intimement unies dans l'architecture grecque par cette influence du principe de revêtement des surfaces qu'il est impossible de les considérer séparément au sein de cet art. Là encore, celui-ci s'oppose à l'architecture barbare dans laquelle les mêmes éléments, à savoir la structure et la décoration ${ }^{\mathbf{1 3}}$, se présentent, selon le degré d'évolution atteint, de façon plus ou moins inorganique, mécanique pour ainsi dire, et en manifestant le plus explicitement possible leur matérialité.

L'exposé le plus complet de ce théorème important de la théorie du style, dans lequel je vois davantage qu'un «point curieux d'archéologie», doit être réservé pour la section consacrée à l'effet conjugué de tous les arts dans l'architecture, mais compte tenu de la validité universelle de ce principe pour tous les arts et pas seulement pour l'architecture, une partie importante des considérations auxquelles il nous conduit doivent nécessairement être d'ores et déjà présentées ici, où elles ont en outre naturellement leur place, en toute logique, étant donné le procédé technique sur lesquelles se fonde le théorème en question, en l'occurrence celui du revêtement.

Ce qui me fait particulièrement mettre en doute que Raoul-Rochette ait pu songer dès 1836, l'année où il annonçait le livre Histoire générale de l'art des Anciens, à une résolution générale des points qui sont en cause ici, c'est le fait que les découvertes importantes des monuments assyriens et babyloniens par [Paul Émile] Botta et [Austen Henry] Layard ${ }^{\mathbf{1 4}}$ ne sont intervenues qu'après cette date, en nous autorisant pour la première fois à observer les phénomènes en question dans leur contexte historicoculturel, sans chaînon manquant, et à reconstituer la loi qui s'exprime en eux. De la même façon, il a fallu également les améliorations apportées par les plus récents relevés des monuments de la Perse, la connaissance plus précise de la région classique de l'Asie Mineure, saturée des traces 


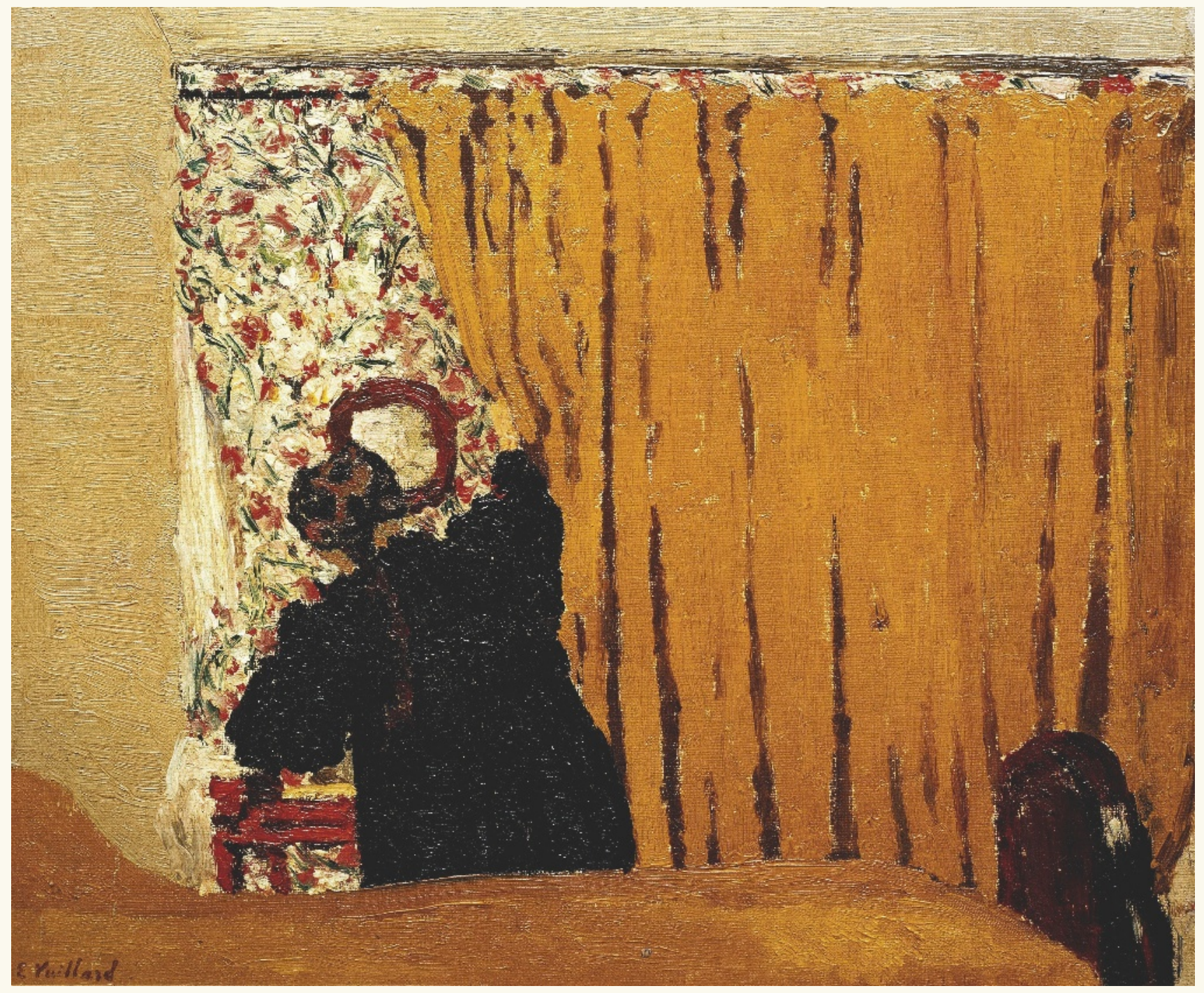

fig. 22

Édouard Vuillard, Le rideau

jaune, vers 1893 , huile sur toile, $34,7 \times 38,7 \mathrm{~cm}$ Washington, National

Gallery of Art, Ailsa

Mellon Bruce Collection

1970.17.95. Akg-images /

Album / Joseph Martin. 
les plus remarquables d'une très ancienne civilisation, ainsi que l'ensemble des plus récentes découvertes parfois surprenantes que nous ont livrées I'Italie, la Cyrénaïque et même l'Égypte, qui n'avait jamais été explorée entièrement. Cette question à mon sens extrêmement importante m'occupe depuis longtemps, comme l'attestent les remarques que j'ai rédigées sur le sujet dans des opuscules publiés pour une part en allemand, pour une part en anglais ${ }^{15}$.

\section{Semper emploie ici le terme de Bildungsprinzip, qui renvoie aux lois de la morphologie végétale. Sur le rapport entre Semper et la "métamorphose des plantes " goethéenne, voir supra l'article de Muriel van Vliet, p. 152. [NdT] \\ 2. Le terme employé est une nouvelle fois Bildungsprinzip (voir note précédente). [NdT] \\ 3. Quatremère de Quincy, Le Jupiter olympien ou l'Art de la sculpture antique considéré dans un nouveau point de vue, Paris, 1815. [Note de Semper]}

4. Quatremère de Quincy, "Avant-propos ", in ibid., p. Xsqq. et passim. [Note de Semper]

5. François Mazois, Les Ruines de Pompéi, continué par François Christian Gau, 4 t., Paris, Firmin Didot, 1824-1838. [NdT]

\section{Restitution du} temple d'Empédocle à Selinonte ou l'Architecture polychrome chez les Grecs par J. T. Hittorff, Paris, 1851. [Note de Semper]

7. Karl August Böttiger, Ideen zur Archäologie der Malerei, Dresde, 1811. [Note de Semper]

8. Peintures antiques inédites, etc., faisant suite aux monumens inédits par M. Raoul-Rochette, Paris, Imprimerie royale, 1836. [Note de Semper]

9. Lettres d'un antiquaire à un artiste sur l'emploi de la peinture murale, etc., par M. Letronne, Paris, 1836. [Note de Semper]

10. Semper emploie ici le terme ancien Schildereien (Schild signifie le bouclier et, depuis le $x v^{e}$ siècle, l'un des sens de schildern était «peindre»). [NdT]
11. Peintures antiques inédites, etc., op. cit. p. 346, note 4. [Note de Semper]

Dans ce passage, RaoulRochette écrit: "Nous trouvons dans l'histoire de l'art des Romains, tout imparfaite que nous la possédions, une foule de traits qui établissent la réalité de cet usage emprunté à la Grèce, d'encastrer dans un mur des peintures de style historique, exécutées sur bois. Le corps entier des lois romaines en offrirait beaucoup d'indices à qui voudrait le parcourir à cette intention. Mais, pour nous en tenir aux témoignages fournis par l'histoire de l'art, nous lisons dans Pline qu'Hortensius avait fait construire, dans sa villa de Tusculum, un appartement pour y placer le tableau des Argonautes, peinture célèbre de Cydias; et nous savons que plus tard ce même tableau, acquis par Agrippa, fut inséré dans un pan de mur de son portique de Neptune.
(...) Un trait du même genre, qui se rapporte aussi à Agrippa, se place naturellement ici; c'est la décoration de ses Septa, édifice dont le revêtement intérieur était formé de plaques de marbres précieux alternant avec des tableaux encastrés. " La note mentionnée par Semper est la suivante: "Dion Cassius LIII, 23. Les mots plaxi lithinais répondent à ceux de crustae (Pline XXXV, 1; cf. Isidore, Origines XIX, 12) et d'abaci, Vitruve VII, 3 , employés par les auteurs latins, et dont on connaît parfaitement la valeur. Ce mode de revêtement et de placage, qui s'exécutait, soit en marbre, soit en bois peint, était une pratique dérivée de la haute Antiquité asiatique; et c'est un point curieux d'archéologie que j'aurai lieu d'établir, avec tous ses détails et avec toutes ses preuves, dans mon Histoire générale de l'art des Anciens, où l'on verra le rapport intime qui existait entre cette pratique orientale et l'usage de la peinture sur bois, chez les Grecs. » . [NdT]

12. En français dans le texte. [NdT]

13. Les termes allemands sont ici Struktur et Dekoration. [NdT]
14. The Monuments of Niniveh, from Drawings Made on the Spot by Austin Henry Layard Esq., Londres, 1849; A Second Series of the Monuments of Niniveh, etc. from Drawings Made During a Second Expedition to Assyria, 71 Plates, folio oblong, Londres, 1853; Discoveries on the Ruins of Niniveh and Babylon, etc. with Maps, Plans and Illustrations, in $8^{\circ}$, Londres, 1853 ; Niniveh and Its Remains, with an Account of a Visit to the Chaldaean Christians of Curdistan, etc., $5^{\mathrm{e}}$ éd., 2 vol., in $8^{\circ}$, Londres, 1850; A Popular Account of Discoveries at Niniveh with Numerous Woodcuts, in $8^{\circ}$, Londres, 1850 ; J. Fergusson, The Palaces of Niniveh and Persepolis Restored; an Essay on Ancient Assyrian and Persian Architecture.

[Note de Semper]

15. Die vier Elemente der Baukunst, Braunschweig, 1851; "On the Origin of Polychromy in Architecture ", ajouté en annexe à: An Apology for the Colouring of the Greek Court by Owen Jones, Crystal Palace Library, 1854 ; On the Study of Polychromy and its Revival in the Museum of Classical Antiquities, $\mathrm{n}^{\circ} 3$, juillet 1851, Londres, John W. Parker and Son. [Note de Semper] 


\section{extrait 6}

\section{Quatrième chapitre.}

L'art textile.

Considérations

techniques et

historiques.

Section 60.

Notes page 247

\section{$\S 60$. Le tout premier principe formel de l'architecture, fondé sur la notion d'espace, est indépendant de la construction. Comment on masque la réalité dans les arts}

L'art de revêtir la nudité du corps (si on laisse de côté les peintures corporelles dont il a été question plus haut) est peut-être une invention plus récente que l'usage de surfaces couvrantes pour des campements et pour clore des espaces.

II existe des tribus sauvages qui semblent être dans l'état le plus originel et qui ne connaissent aucun type de vêtement, mais auxquelles l'usage de peaux de bêtes et même une industrie plus ou moins développée du filage, du tressage et du tissage n'est pas inconnue: elles l'emploient pour installer leurs campements et en assurer la sécurité.

Même si des influences climatiques et d'autres facteurs suffisent à expliquer ce phénomène de l'histoire culturelle et s'il ne s'ensuit pas nécessairement qu'il s'agisse là d'un cours normal de la civilisation qui serait partout en vigueur, il n'en demeure pas moins certain que les débuts de la construction coïncident avec les débuts de l'art textile.

Le mur est l'élément de construction qui expose formellement et rend extérieurement perceptible à la vue, de façon pour ainsi dire absolue et sans faire appel à des notions secondaires, l'existence d'un espace clos en tant que tel.

Nous pouvons reconnaître dans l'enclos, la clôture tressée à partir d'un ensemble de pieux et de branches, la plus ancienne cloison de séparation produite par la main de l'homme, la clôture verticale de l'espace la plus originelle qui ait été inventée par celui-ci, dont la réalisation fait appel à une technique que la nature place pour ainsi dire entre les mains de l'homme.

Du tressage des branches à celui des fibres végétales à des fins d'habitation analogues, la transition est facile et naturelle.

De là, on en est venu à l'invention du tissage, d'abord avec des tiges de graminées ou des fibres végétales naturelles, puis avec des fils fabriqués à partir de matières végétales ou animales. Les différences de couleur naturelle des tiges n'ont pas tardé à entraîner leur usage dans un ordre alterné: c'est ainsi que le motif a fait son apparition. Bientôt, on ne s'est plus contenté de ces auxiliaires naturels de l'art et on est allé plus loin en ayant recours à des préparations artificielles du tissu: on a inventé la teinture et le tissage en couleurs $^{1}$ des tapis colorés pour en faire des revêtements muraux, des tapis de sol et des tentures de plafond.

Quel qu'ait pu être le cours de l'évolution progressive de ces inventions, que les choses se soient passées ainsi ou autrement nous importe peu ici; il n'en demeure pas moins certain que l'utilisation de tissages grossiers, à commencer par celui de l'enclos, conçu comme un moyen de séparer le "home", la vie à l'intérieur, de la vie à l'extérieur, et comme une figuration formelle de l'idée d'espace, a précédé à n'en pas douter la construction si rudimentaire soit-elle du mur de pierre ou de tout autre matériau. 


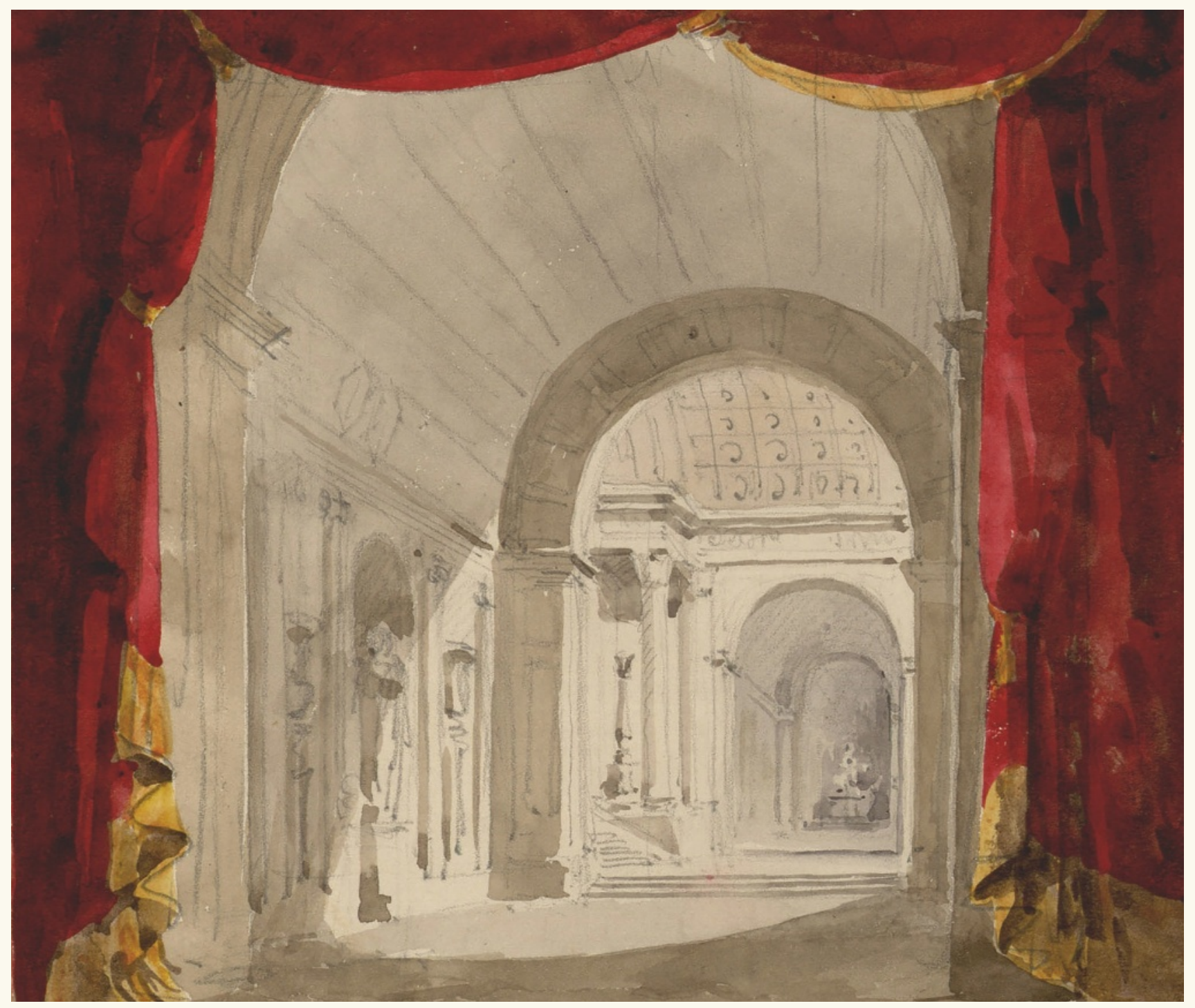

fig. 23

Jacques

Ignace Hittorff, Carnet

de dessin $n^{\circ} 5$, Fête de la

Restauration, $\mathrm{xIX} \mathrm{S}^{\mathrm{S}}$. Paris,

École Nationale Supérieure

des Beaux-Arts. Photo

(c) Beaux-Arts de Paris,

Dist. RMN-Grand Palais /

image INHA. 
Les armatures qui servent à tenir, à fixer et à porter ces clôtures de l'espace sont nécessaires mais n'entretiennent aucun rapport direct avec l'espace et la division de ce dernier. Elles sont étrangères à l'idée architectonique originelle et ne constituent pas a priori des éléments qui déterminent les formes.

II en va de même des murs construits à partir de briques crues, de pierres ou de n'importe quel autre matériau de construction, dont aucun n'entretient, de par leur nature et leur destination, le moindre rapport avec la notion d'espace, mais qui ont été mis en place à des fins de renforcement et de défense, qui garantissent la pérennité de la clôture ou sont censés servir de murs d'appui et de murs porteurs pour la fermeture de l'espace en partie supérieure, pour les greniers et les autres charges - dont la finalité, en un mot, est étrangère à l'idée originelle, à savoir la clôture de l'espace.

Au demeurant, il est extrêmement important d'observer que, partout où ces motivations secondaires sont absentes, les matériaux tissés remplissent presque en tous lieux et plus particulièrement dans les pays méridionaux et chauds leur destination originelle ancienne de séparation ostensible de l'espace, et que même dans les cas où les murs solides deviennent nécessaires, ceux-ci ne sont malgré tout rien d'autre que l'armature intérieure et non visible des véritables et légitimes représentants de l'idée d'espace, à savoir les cloisons textiles tissées et cousues de façon plus ou moins artificielle.

On retrouve ici un cas remarquable où le langage des phonèmes vient en aide à l'histoire des origines des arts et donne accès aux symboles du langage des formes dans ses premières manifestations, en confirmant l'authenticité de l'interprétation qui en est donnée. Dans toutes les langues germaniques, le mot Wand [le mur, la cloison, la paroi] (qui possède la même racine que Gewand [tissu] et la même signification fondamentale ${ }^{2}$ ) rappelle directement l'origine ancienne et le type de la clôture visible de l'espace.

De la même façon, Decke [le plafond, mais aussi la couverture], Bekleidung [le revêtement], Schranke [la limite], Zaun [la clôture] (qui est proche de Saum [la bordure, l'ourlet]) et beaucoup d'autres termes techniques ne sont pas des symboles langagiers tardivement appliqués à la construction, mais des allusions certaines à l'origine textile de ces parties des édifices.

Tout ce qui précède ne concernait que des questions pré-architecturales dont l'intérêt pratique pour l'histoire de l'art peut être mis en doute; la question qui se pose à présent est de savoir ce qu'il est advenu de notre principe de revêtement une fois que s'est accompli le mystère de la transfiguration du projet technico-constructif de l'habitation, en soi tout matériel, en une forme monumentale dont est issue l'architecture proprement dite. Ce n'est pas encore ici le lieu d'étudier plus avant les modalités de l'apparition d'une architecture monumentale, une question de la plus haute importance; mais il sera peut-être utile, pour rendre plus facilement compréhensibles certains phénomènes de l'histoire des monuments les plus anciens sur lesquels je vais revenir à l'instant, de signaler ici en passant que c'est la volonté de commémorer pour l'éternité un acte solennel, une relligio, un événement de l'histoire universelle, une action importante engageant un État, qui fournit l'occasion extérieure d'entreprendre la construction de monuments; 
rien n'interdit de penser et il est même établi de manière incontestable que, de façon tout à fait analogue, les premiers fondateurs d'un art monumental, qui présuppose toujours l'existence antérieure d'une culture relativement élaborée et même de formes de luxe, ont eu l'idée de le créer parce qu'ils ont assisté à la célébration de semblables cérémonies. Les installations de fête, les échafaudages improvisés, avec toute la pompe et les accessoires appropriés pour l'occasion, qui donnent plus de magnificence à la cérémonie en multipliant les ornements et les équipements, les tapis suspendus, les décorations de rameaux et de fleurs, les festons et couronnes, les rubans flottants et les trophées: c'est le motif du monument permanent qui va entretenir chez les générations futures la mémoire de l'acte solennel et de l'événement qui a été célébré. Ainsi, le temple égyptien est né du motif du marché de pèlerinage improvisé qui, à une époque tardive, était certainement encore très souvent installé exactement de la même manière, en plantant des pieux et en suspendant des tentures au-dessus, partout où le bruit courait qu'un dieu local quelconque pour lequel on n'avait pas encore construit de temple en dur accomplissait des miracles particuliers, attirant les fellahs de l'Égypte ancienne qui formaient des cortèges de pèlerins d'une ampleur inattendue pour venir le célébrer (voir la deuxième partie: l'Égypte). Pour éclairer ce qui a été dit par un autre exemple, j'évoquerai les fameux tombeaux de Lycie, dont deux exemplaires sont à présent reconstitués au British Museum: ces étonnants échafaudages de bois exécutés en pierre, décorés entre les poutres de plaques en relief peintes et supportant à l'étage supérieur ou sur la corniche un monument remarquable, aux allures de sarcophage, lui aussi richement sculpté de bosses saillantes, avec un toit en ogive couronné d'une crête. Ces prétendues imitations d'un style de construction en bois qui serait propre à la Lycie ne sont rien d'autre, selon moi, que des bûchers, des pièces de bois réunies artificiellement ensemble, selon une manière également en usage chez les Romains, qui étaient tendues de riches tapis: elles étaient surmontées du catafalque (pheretron) recouvert et dissimulé sous un riche couvercle doré (kaluptès) ${ }^{3}$. Des bûchers, mais en restitution monumentale.

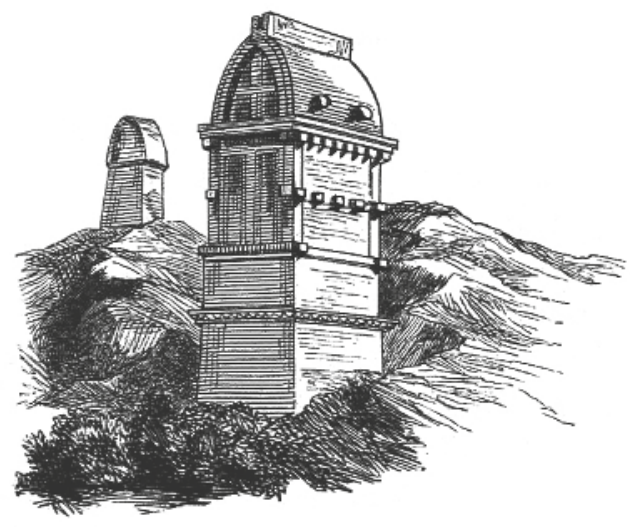

Un autre exemple frappant est la représentation monumentale et magnifiée de l'ancienne Alliance dans le Temple de Salomon, avec le motif imaginaire ou réel du tabernacle, exécuté avec une splendeur inouïe. Nous y reviendrons plus loin. fig. 24

Illustration figurant dans Der Stil, t. I, 1860, p. 230. 


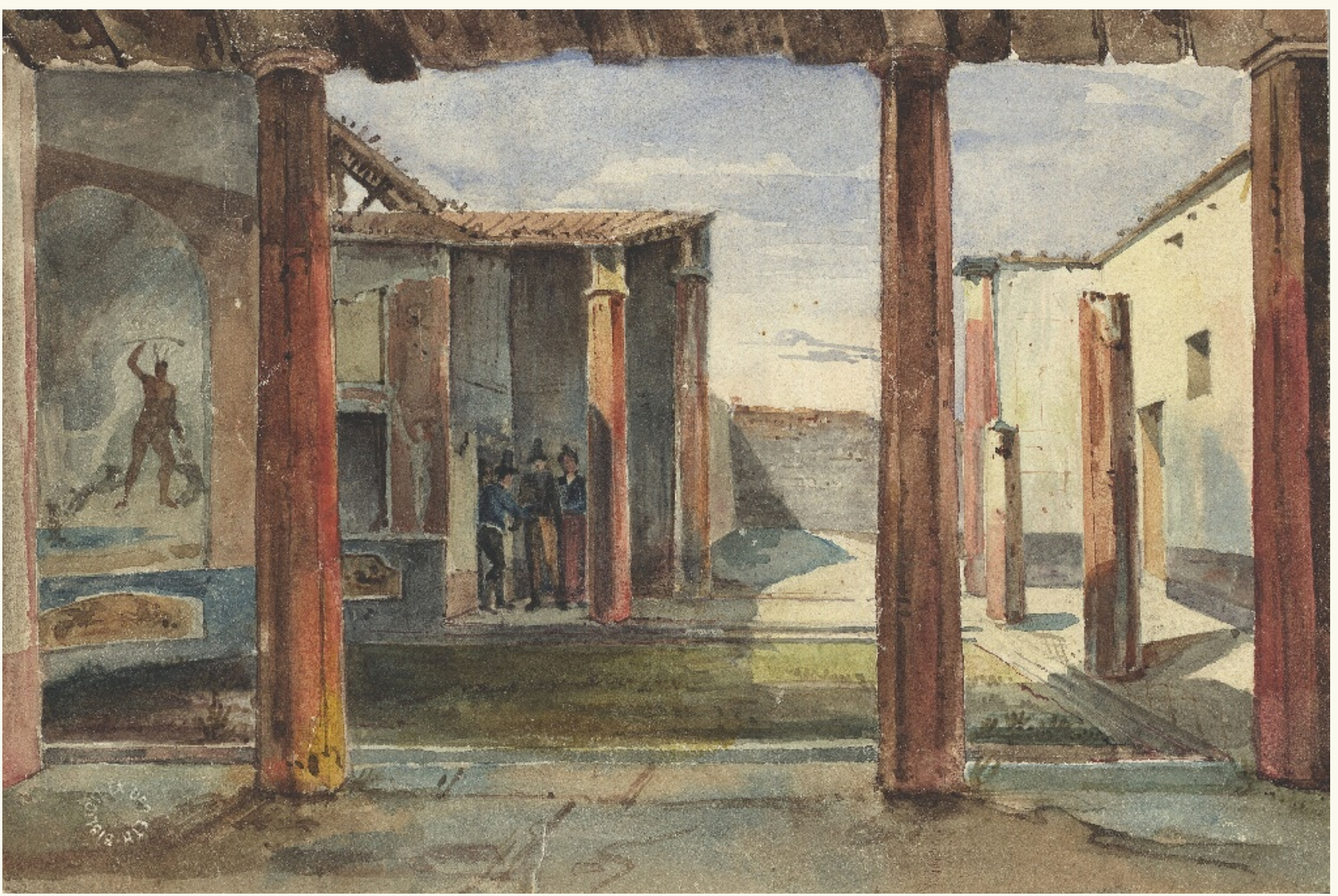

fig. 25

Gottfried Semper, Atrium,

Pompéi, 1831-1834.

gta Archiv/ETH Zurich,

Gottfried Semper. 
C'est également ainsi que, à l'époque historique encore, le style de construction si caractéristique des théâtres se constitua à partir d'une scène de planches qui était cependant richement décorée et habillée ${ }^{4}$.

En présentant ces exemples, mon intention était surtout de mettre l'accent sur le principe de la décoration extérieure et du revêtement de l'armature constructive, qui s'impose nécessairement dans les constructions festives improvisées; partout et en tout temps, ce principe découle de la nature de ces édifices. J'en déduis que le même principe de dissimulation des parties constructives, associé au traitement monumental des chapiteaux de toile et des tapis tendus entre les parties constructives de l'armature à l'origine du motif, doit apparaître comme tout aussi naturel lorsqu'il se manifeste dans les premiers monuments de l'architecture ${ }^{\mathbf{5}}$.

1. Semper emploie ici le terme «Wirkerei » qui désigne le tissage des tapis "selon la technique des Gobelins », c'est-à-dire en introduisant un motif de différentes couleurs. [NdT]

2. Cette hypothèse étymologique est aujourd'hui discutée, comme le rappelle Michael Gnehm (voir supra, p. 106). [NdT]

3. Diodore de Sicile XVIII, 26 , où il décrit le sarcophage d'Alexandre. Dans une tombe de Panticapea, on a retrouvé un semblable catafalque de bois portant des peintures (cf. Journal des Savants, juin 1835 , p. 338-339).

[Note de Semper]

4. Une inscription de Patara en Asie Mineure, citée par Robert Walpole (Travels in Various Countries of the East, Londres, 1820, t. I, p. 524), mentionne «tèn loguéiou kataskeutèn kai plakosin " [l'ornementation et le dallage en marbre du théâtre]. Les proscenia à riches incrustations des théâtres provisoires de Rome étaient connus de Pline et Vitruve. [Note de Semper]
5. J'entends par là que l'activité consistant à habiller et masquer est aussi ancienne que la civilisation humaine: la joie qu'elle procure est identique à celle qu'éveillent les activités qui ont conduit les hommes à être sculpteurs, peintres, architectes, poètes, musiciens, dramaturges, artistes en un mot. Toute création artistique d'un côté, tout plaisir artistique de l'autre, présupposent une certaine humeur de carnaval, pour employer une expression moderne - la fumée des bougies de carnaval est la véritable atmosphère de l'art. L'anéantissement de la réalité, de ce qui procède de la matière, est nécessaire lorsque la forme doit se manifester comme le symbole de l'autonomie de la création humaine, riche de signification. Nous devons faire oublier les moyens nécessairement employés pour produire l'impression artistique escomptée; pas question pour nous de parader en les mettant en avant et de sortir de notre rôle; voilà qui serait pitoyable. Dans toutes les recherches artistiques anciennes, les hommes à l'état de nature étaient guidés dans cette voie par leurs sens non corrompus; les véritables grands maîtres de l'art, dans tous les domaines, sont retournés eux aussi dans cette direction, à ceci près que, dans les époques de haut développement de l'art, ces derniers masquaient aussi ce qu'il y a de matériel dans le masque. C'est ce qui conduisit Phidias à concevoir les sujets des deux côtés du tympan du Parthénon; manifestement la tâche qu'il avait à remplir, c'est-à-dire la représentation du double mythe, et les divinités qui intervenaient dans celui-ci étaient la matière qu'il avait à traiter, et il la dissimula autant que possible (comme la pierre dans laquelle il les sculpta), c'est-à-dire qu'il l'affranchit de l'obligation de manifester sur un mode démonstratif, matériel et extérieur, la nature religieuse et symbolique qu'elle possédait en dehors de l'image. Voilà pourquoi ses dieux se présentent à nous et nous enthousiasment avant tout et par-dessus tout, pris individuellement et dans leur ensemble, comme l'expression d'une beauté et d'une grandeur purement humaines. "Qu'était Hécube pour lui ? " La même raison explique que le drame n'ait pu avoir une signification qu'au commencement et au plus haut sommet de l'essor de la culture d'un peuple. Les plus anciennes peintures de vases nous donnent matériellement une idée des anciens jeux de masques des Grecs - sous une forme spiritualisée, comme dans les drames de pierre de
Phidias, le jeu de masques immémorial est repris par Eschyle, Sophocle, Euripide et, dans le même temps, par Aristophane et les autres comiques: le proscenium devient le cadre d'un tableau présentant une séquence grandiose de l'histoire de l'humanité, qui n'a pas eu lieu quelque part à une certaine époque mais se produit partout, aussi longtemps que battront les cœurs des hommes. "Qu'était Hécube pour eux? " Les drames de Shakespeare respirent l'atmosphère de la mascarade; nous retrouvons l'humeur de mascarade, l'odeur des bougies, l'ambiance de carnaval (qui, à la vérité, n'est pas toujours joyeuse) dans le Don Juan de Mozart; car la musique elle aussi a besoin de ce moyen pour éliminer la réalité; pour le musicien aussi, Hécube n'est rien ou devrait n'être rien.

Cependant, il ne sert à rien de masquer si ce qui se cache derrière le masque n'est pas juste ou si le masque ne convient pas; pour que la matière, l'indispensable, soit complètement anéantie dans la forme artistique, au sens où nous l'entendons,

il faut avant tout qu'elle ait été complètement maîtrisée auparavant. Seuls la perfection de l'accomplissement technique, le traitement juste et intelligent du matériau en fonction de ses propriétés, mais surtout la prise en compte de celles-ci dans l'élaboration même des formes, peuvent faire oublier le matériau, libérer entièrement l'œuvre d'art de ce dernier et même transformer un simple tableau de la nature en grand art. Ce sont là pour une part des points où l'esthétique de l'artiste ne veut pas entendre parler de symbolisme ni d'idéalisme, ces doctrines périlleuses que [Karl Friedrich von] Rumohr - dont nos spécialistes de l'esthétique et de la science de l'art ne connaissent plus le nom avait à juste titre combattues dans ses écrits.

Démontrer que l'architecture grecque justifie ce qui a été dit, qu'elle est régie par le principe que j'ai tenté d'exposer, selon lequel l'œuvre d'art fait oublier, dans la vision, les moyens et le matériau par le biais desquels et par la médiation desquels elle se donne à voir et produit ses effets, et se suffit à elle-même en tant que forme: telle est la tâche la plus difficile de la théorie du style.

Cf. Lessing, Dramaturgie de Hambourg, 21 et passim. [Note de Semper] 


\section{extrait 7}

Quatrième chapitre. L'art textile. Considérations techniques et historiques.

Section 63

Notes page 255

\section{§ 63. La Chine}

[...]

Même s'il a été brouillé et falsifié à bien des égards par l'apport d'éléments ultérieurs et contemporains, un principe de construction extrêmement ancien a cependant été pour ainsi dire maintenu vivant jusqu'à aujourd'hui (à supposer qu'on puisse prêter métaphoriquement une vie à l'inorganique) qui nous renseigne sur l'origine matérielle de bien des spécificités de l'architecture grecque elle-même et les explique. Nous rencontrons par exemple en Chine une technique de préparation des murs encore activement en usage alors que, dans les vestiges de l'art monumental d'Asie occidentale, d'Égypte et du monde gréco-italique, elle ne s'est perpétuée que sous une forme depuis longtemps morte, fragmentaire et en outre déjà distincte de la manière primitive, transformée et mêlée à d'autres éléments pour produire quelque chose de nouveau. Les éléments de l'architecture chinoise ne sont pas liés entre eux sur un mode organique, ni même quasi chimique, mais ils sont juxtaposés de façon mécanique sans être maintenus ensemble par une idée qui dominerait le tout; ou plutôt, l'idée qui domine le tout s'exprime justement dans la séparation et l'activité autonome de ces éléments ${ }^{\mathbf{1}}$.

La surface extérieure du mur demeure ici matériellement tout à fait séparée du mur lui-même et, de fait, elle est le plus souvent mobile. Le mur lui-même, en l'occurrence en tant que construction de pierre, élément porteur et soutien vertical remplissant une fonction statique, n'apparaît que dans les terrasses et soubassements qui constituent des composantes souvent très puissantes et essentielles de l'architecture chinoise, dont font également partie les escaliers et balustrades, qui représentent des formes de transition, pour ainsi dire, entre la construction en pierre des terrasses et les aménagements du niveau supérieur supportés par celles-ci, qui sont quant à eux des produits de la tectonique et de l'art textile.

Dans ce dernier cas, le mur ne porte que sa propre charge et sert de cloison intermédiaire entre les parties construites en bois, qui ont quant à elles pour finalité technique de soutenir le toit et le plafond qui clôt horizontalement l'espace dans la partie supérieure.

Le mur lui-même n'est en toute rigueur qu'un paravent réalisé en briques, une armature de tapisserie, il ne représente guère un élément porteur ni un soutien et n'a pas à en être un: il est bien plutôt partout symbolisé avec le plus grand soin comme une cloison tendue et préservée de la chute par les côtés, un élément mobile et entièrement indépendant de la charge du toit.

L'armature elle-même assurant le maintien des éléments couvrants, horizontaux et verticaux, qui ferment l'espace, est un mélange de formes qui relèvent aussi bien de la construction de bois (tectonique) que du tressage (art textile) et, sous ce dernier rapport, rappellent à nouveau fortement les tressages néo-zélandais.

Le principe du revêtement se manifeste en outre encore d'une autre manière dans ces parties constructives de l'architecture, en l'occurrence par le biais des enveloppes qui recouvrent le noyau de bois. 
Les subdivisions intérieures de l'aménagement domestique sont amovibles, ce sont le plus souvent de véritables tapis suspendus au mur ou carrément des treillages ou des plaques de bois fixées les unes aux autres au moyen de charnières et qui peuvent être déplacées à volonté, ou enfin des cloisons fixes de séparation qui présentent cependant encore un caractère de tapis et de paravents.

Les ornements peints et sculptés sont toujours issus des mêmes éléments constructifs, très nettement distincts dans la construction d'ensemble. Imitation de tissus, boiseries laquées, tressages de bambou, piliers et ramifications noueux métamorphosés en formes fantastiques.

Tel est le caractère général de l'architecture chinoise qui se manifeste dans le mode de construction et d'exécution technique. Cependant, les aperçus qu'il offre ont une si grande importance pour notre propos qu'il semble nécessaire d'entrer davantage dans les détails, du moins pour certains traits particuliers.

Nous distinguerons ainsi plusieurs points: nous commencerons par la clôture de l'espace, puis nous évoquerons l'armature tectonique qui en est le support et, pour finir, nous examinerons ce qui est le plus loin de notre thème actuel, les fondations de la construction. J'observerai ici que les détails qui suivent sont pour la plupart tirés d'un beau manuscrit conservé dans les collections de dessins et gravures de la Bibliothèque impériale de Paris. Ce manuscrit a été composé par quelques érudits jésuites et missionnaires en Chine sous le règne de Louis XIV et il porte pour titre Essay sur l'architecture des Chinois ${ }^{2}$. Les jésuites français du xvIII ${ }^{\mathrm{e}}$ siècle pouvaient entrer librement en Chine et y jouissaient d'importants privilèges; nous leur devons des récits très précieux et circonstanciés sur ce pays qui était alors beaucoup mieux connu en Europe qu'il ne l'est de nos jours. En dehors de ce volume, la Bibliothèque de Paris recèle d'autres magnifiques recueils de dessins d'architecture à la main; ils ont le plus souvent été superbement réalisés dans les couleurs les plus vives et avec des dorures, et il s'agit aussi bien de recueils chinois anciens que d'ensembles réalisés à la demande des missionnaires par des artistes chinois. J'ai également tiré quelques autres données de l'intéressant ouvrage de sir William Chambers, le seul architecte, à ma connaissance, qui ait parcouru la Chine et l'ait décrite pour les besoins de son $\operatorname{art}^{3}$.

\section{La clôture de l'espace}

Le motif originel de clôture de l'espace, la haie, le tressage de branches, a été développé en Chine jusqu'à des sommets de raffinement et d'accomplissement. Le caractère dénaturé d'une ornementation totalement débridée se manifestait déjà sur les plus anciens monuments chinois, les fameux vases de bronze de l'époque de la deuxième dynastie (1766-1122 av. J.-C.): l'ornementation y était pour ainsi dire directement greffée sur cette souche naturelle brute, mais de telle façon que celle-ci transparaissait, en quelque sorte, par les renversements d'un caprice baroque, comme le canevas qui donnait de la tenue à ces ornements. On le voit, le treillage forme la base de l'ornementation chinoise, et il s'agit en l'occurrence ici, à l'origine, d'une base 


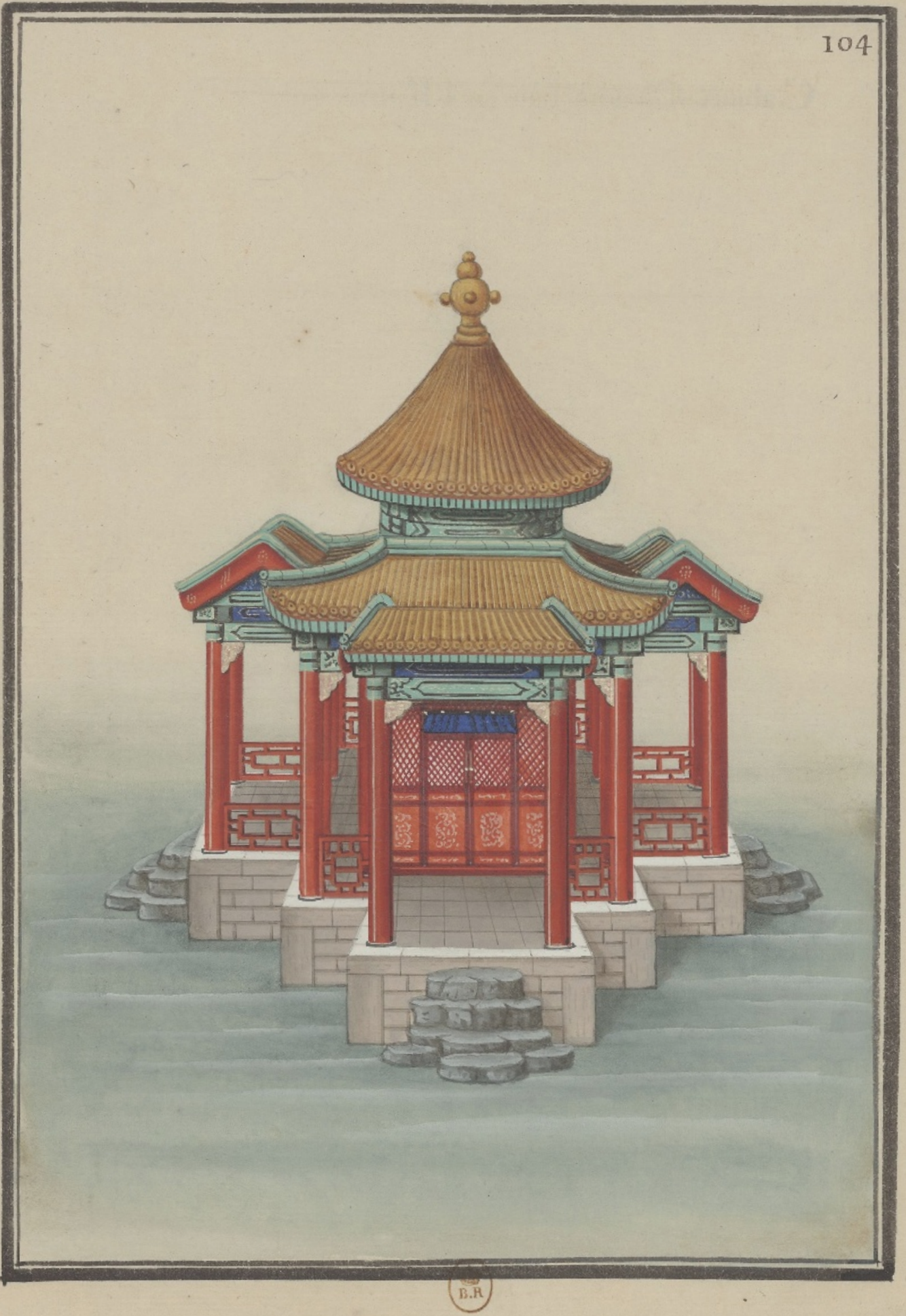


directement empruntée à la réalité; les modèles de cette forme ornementale, en effet (que nous rencontrerons à nouveau partout, mais dans des applications qui ont perdu conscience de cette origine), sont présents sous nos yeux aujourd'hui comme il y a cinq mille ans: ce sont les grilles de bambous qui ne font défaut dans aucune construction chinoise et forment un treillage qui ferme les espaces, avec une infinie variété de motifs décoratifs et un tressage tantôt plus serré, tantôt davantage ajouré; ce sont les balustrades basses qui entourent les murs des terrasses ou longent les escaliers, ou encore les lambris de faible hauteur placés entre les colonnes des pavillons et qui se prolongent le long des murs.

Le caractère de ces treillages, on l'a dit, est d'une extrême variété, mais on peut légitimement les diviser en trois classes: le treillage fin de bambou à proprement parler, qui relève davantage de l'art textile que de la tectonique; la clôture adroitement assemblée à partir de lattes plus épaisses qui tend vers l'extrême inverse et marque pour ainsi dire la transition vers la menuiserie, en répondant entièrement aux principes de cet art, même si, dans son exécution, le motif fondamental est strictement observé et si l'usage ornemental de la construction est pris en compte; entre les deux, un terme intermédiaire qui est à peu près également éloigné des deux extrêmes. Le premier treillage, le plus fin, sert avant tout au revêtement de la partie inférieure des cloisons intérieures et se compose le plus souvent dans ce cas d'un véritable tressage de bambou qui est soit laissé dans sa couleur naturelle jaune doré, soit laqué en couleurs et doré. Il remplace en outre les portes et les encadrements des fenêtres: dans ce dernier cas, il n'est pas rare que les ouvertures soient bouchées avec des coquillages transparents ou du verre de couleur qui fut utilisé en Chine, dit-on, dès le ॥ millénaire avant J.-C. pour faire des vitres de fenêtres; celles-ci peuvent également être fermées avec du papier. Dans de nombreux cas, l'espace intermédiaire libre, semblable à une frise, qui figure entre le plafond et la partie supérieure de la cloison, dont il sera encore question plus loin, est fermé sur toute sa largeur avec des lattes de bois qui forment ainsi une partie essentielle de la décoration intérieure des maisons. Dans les édifices plus monumentaux et plus solides, il n'est pas rare que ces lattes soient en métal doré, en marqueterie de bois précieux ou en albâtre.

La variété intermédiaire de finesse moyenne qui a été mentionnée en dernier est particulièrement utilisée dans les pavillons de jardin et les autres édifices de plein air pour marquer la clôture extérieure de leur périmètre. Tendue entre les colonnes et appuyée sur la balustrade qui fait le tour de la construction, elle forme un ensemble d'une très riche polychromie: à la charmante alternance de ses motifs, tirés d'un ensemble de formes géométriques de base dans lequel ils sont choisis avec grâce de façon arbitraire, ce qui brise la trop grande monotonie et rigueur de ces dernières, s'ajoutent les dorures mates, les colonnes de couleur pourpre qui soutiennent le treillage, le toit étincelant de tuiles à glaçure verte qui le surmonte, l'éclat blanc du soubassement de marbre et, pour finir, l'azur du ciel qui transparaît à travers lui et dans lequel la construction légère semble flotter ${ }^{4}$.

Cette variété n'est plus un tressage à proprement parler, c'est un assemblage de bois réalisé avec le plus grand soin, selon un système dans

\section{ci-contre}

fig. 26

Recueil. Essai sur

l'architecture chinoise,

vol. I, vue 217 (numérotée

104). Paris, Bibliothèque

nationale de France, inv. E014199. 
fig. 27

Exemple de treillage chinois, Der Stil, t. I, 1860 p. 247.

\section{ci-contre}

fig. 28

Recueil. Essai sur l'architecture chinoise, vol. I, vue 85 (numérotée 38). Paris, Bibliothèque nationale de France, inv. E014101. lequel les pièces de bois sont croisées entre elles et fixées les unes dans les autres avec des tenons et que l'on retrouve dans beaucoup de formes ornementales grecques.

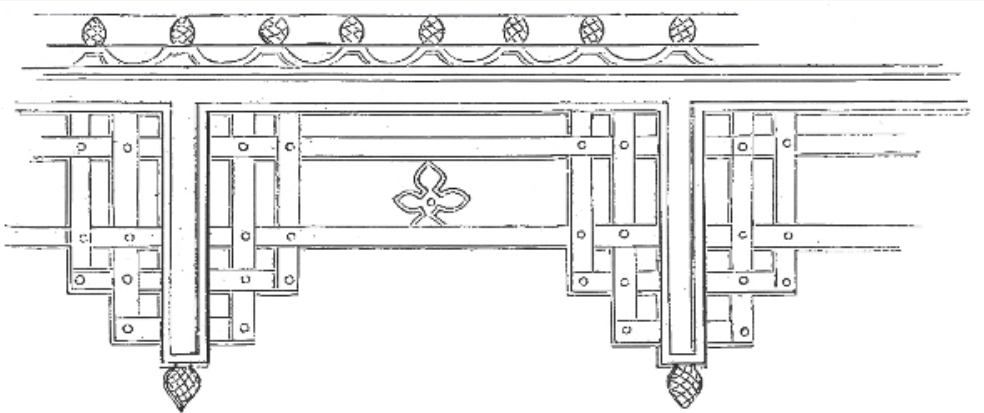

La variété la plus résistante appartient déjà entièrement à la construction de bois et, avec la balustrade, se rattache en même temps au soubassement, une association que nous retrouverons ailleurs.

La transition avec le tissu proprement dit est encore assurée ensuite par les nattes aux motifs charmants qui recouvrent le sol et qui sont utilisées comme rideau de portes et de fenêtres pour maintenir au frais l'intérieur des maisons et marquer les séparations.

Immédiatement après les nattes, il faut prendre en compte les draperies proprement dites que l'on laisse pendre librement pour délimiter les pièces intérieures ou comme rideaux de portes et de fenêtres: en Chine et dans tous les pays d'Asie, elles forment encore aujourd'hui comme dans un passé immémorial une partie essentielle de l'aménagement de l'espace.

L'excellente qualité des étoffes chinoises de soie et de fil d'or, la richesse de leurs motifs et de leurs couleurs sont célèbres depuis toujours; le mérite de l'invention du tissage de la soie revient aux Chinois à une date très ancienne.

De même que, parmi les peuples de l'Antiquité, les tapis de Babylone étaient réputés et recherchés, les étoffes chinoises et japonaises ont été au cours des siècles passés achetées à grands frais par les rois. Nos pères ont manifesté par là un goût plus sûr que nous qui faisons un usage excessif des papiers peints dus à l'inventivité des mêmes Chinois.

Plus originels du point de vue du style que ces damas et brocards tissés en couleurs, aux riches motifs, un autre produit du plus extrême intérêt pour la question qui nous occupe sont les broderies utilisées pour le revêtement des murs ou pour certains panneaux muraux dans les pièces d'apparat. Les plus anciennes statistiques chinoises et universelles, qui datent de l'époque des Hia, et dont l'authenticité et la datation dans cette période ancienne (2205 av. J.-C.) sont attestées ${ }^{5}$, énumèrent les productions de toutes les provinces de l'Empire, notamment l'or, l'argent, le cuivre, l'étain, l'acier, le fer, l'ivoire, les pierres précieuses, les perles, la nacre, les bois précieux, les laques, cinq variétés d'ocre, les fourrures, les peaux, la soie brute, le lin et le coton, les étoffes tissées dans ces matières, les productions des orfèvres et joailliers et les plumes de perdrix des montagnes et d'autres oiseaux. 


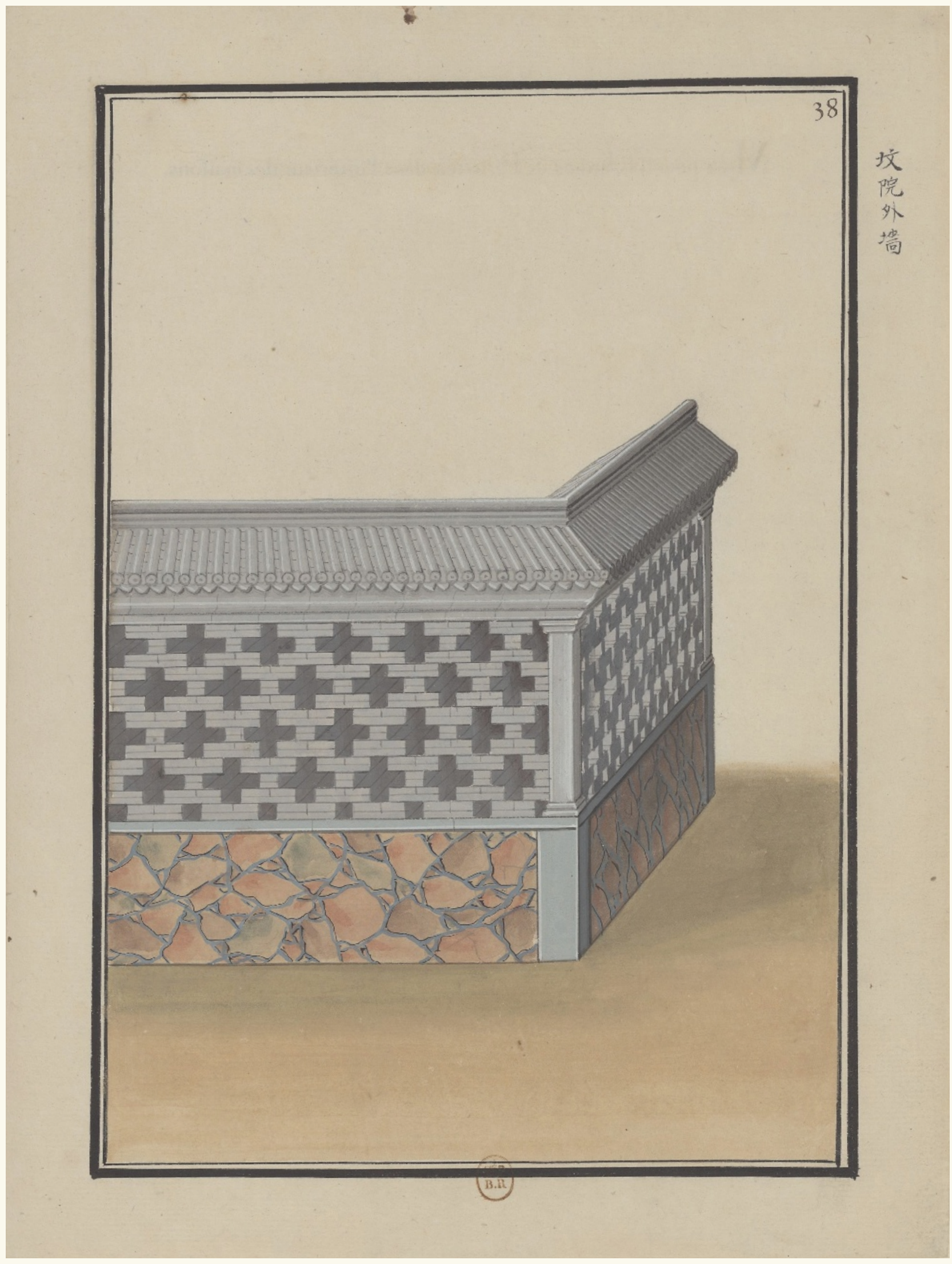


Les étoffes sont toujours mentionnées comme étant d'une seule couleur: tissus de soie rouge, noire et blanche de Ser, noire et rouge de la province de King. Le tissage à couleurs multiples n'était donc pas connu à l'époque; en revanche, la mention fréquente des plumes indique clairement l'usage qui était le leur: elles étaient employées dans des broderies. La broderie à plat, qui est restée de nos jours le travail favori des Chinoises, était donc encore à l'époque un opus plumarium au sens strict du terme. La broderie jouait le rôle qui sera plus tard celui de la peinture et elle est plus ancienne que cette dernière, si l'on entend par là davantage qu'un simple badigeon, une sorte de composition en couleurs sur une surface. C'est là un fait certain, de même que les boiseries murales et les papiers peints sont apparus plus tard que les draperies et les revêtements muraux textiles.

La plus ancienne broderie chinoise en couleurs était donc brodée à plat et exécutée à partir d'étoffes de couleur et de plumes. Or, la caractéristique de cette broderie de plumes est que le dessin forme une surépaisseur plate au-dessus de la surface du tissu, donnant naissance à une sorte de basrelief polychrome.

Non seulement ce style a été conservé en Chine lorsqu'on a remplacé, dans les broderies, les plumes par des fils teintés artificiellement, mais on l'a même développé, au point que les objets brodés ont véritablement acquis un relief et qu'un modelé relativement développé s'est ainsi constitué, avec des effets calculés de clair-obscur. On fabrique encore aujourd'hui de cette façon, à l'aiguille et dans des fils de soie de belles couleurs, des figures grandeur nature dont le style est résolument en relief, voire des frises entières et des compositions cohérentes. J'ai pu voir des témoignages de cet art en 1851 à l'Exposition de Londres, et leur style et leur traitement m'ont rappelé si fortement les fameux bas-reliefs de Ninive que, depuis, je ne parviens plus à voir dans ces derniers autre chose qu'une traduction en albâtre de tapis brodés des anciens Assyriens, en l'occurrence des broderies en relief semblables à ces tapisseries chinoises modernes du point de vue de leur date de fabrication, mais presque antédiluviennes dans leur style.

En même temps, il faut encore souligner que, dans le pays qui nous occupe, ce style qui trouve incontestablement ses racines dans la broderie a été transposé dans d'autres branches de l'industrie artistique et qu'il est de fait devenu une composante essentielle de l'ensemble des techniques artistiques de l'Asie orientale, en se manifestant sous les formes les plus variées. La peinture de laque et surtout aussi la peinture de porcelaine au Japon et en Chine, mais aussi la peinture d'émail de ces pays se fondent sur la même méthode, une sorte de peinture en relief, sur laquelle nous reviendrons davantage en détail dans la section sur la «porcelaine» de la partie consacrée à la céramique.

$[\ldots]$ 
1. Pour plus de détails, voir l'article «Chine» de la deuxième section de ce livre. [Note de Semper]

2. Le manuscrit évoqué par Semper est très vraisemblablement l'Essai sur l'architecture chinoise, en deux volumes, conservé au département des Estampes et de la photographie de la Bibliothèque nationale de France sous la cote PET FOL-OE-13 (A). II est accessible sous forme numérisée sur le portail Gallica. Les images reproduites ci-contre en sont issues; elles ne figuraient pas dans le texte de Semper. [NdT]

3. Sir William Chambers, Designs of Chinese Buildings, Furniture, Dresses [Machines and Utensils, Engraved by the Best Hands, From the Originals Drawn in China, in fol., Londres, Published for the Author, 1757]. On pourra trouver une bibliographie relative à la Chine, mais dans laquelle ne figurent pas les manuscrits mentionnés plus haut, à la fin de

l'ouvrage Chine moderne ou description historique, géographique et littéraire de ce vaste Empire, par M. G. Pauthier et M. Bazin, Paris, 1853 (formant partie de L'Univers pittoresque). [Note de Semper]
4. On peut voir dans le recueil mentionné plus haut de dessins originaux conservés à la Bibliothèque de Paris plusieurs pavillons impériaux de ce type, dans une éclatante magnificence de couleurs, qui produisent une excellente impression. [Note de Semper]

5. Voir les annales impériales (Chu-king) rassemblées par Confucius vers la fin du vi ${ }^{e}$ siècle av. J.-C. (cf. Pauthier, op. cit., p. 47).

[Note de Semper] 